Southern Methodist University

SMU Scholar

Anthropology Theses and Dissertations

Anthropology

Spring 2019

\title{
Women's Experiences With Maternity Care and Medical Discourse In Florence, Italy
}

Michaela Wallerstedt

Southern Methodist University, mwallerste@smu.edu

Follow this and additional works at: https://scholar.smu.edu/hum_sci_anthropology_etds

Part of the Social and Cultural Anthropology Commons

\section{Recommended Citation}

Wallerstedt, Michaela, "Women's Experiences With Maternity Care and Medical Discourse In Florence, Italy" (2019). Anthropology Theses and Dissertations. DOI: https://doi.org/10.25172/td/14475347 https://scholar.smu.edu/hum_sci_anthropology_etds/9

This Dissertation is brought to you for free and open access by the Anthropology at SMU Scholar. It has been accepted for inclusion in Anthropology Theses and Dissertations by an authorized administrator of SMU Scholar. For more information, please visit http://digitalrepository.smu.edu. 
Dr. Carolyn Smith-Morris

Associate Professor of Anthropology

Dr. Caroline Brettell

Ruth Collins Altshuler Professor of

Anthropology

Dr. Nia Parson

Associate Professor of Anthropology

Dr. Elizabeth Krause

Professor of Anthropology 
WOMEN'S EXPERIENCES WITH MATERNITY CARE AND MEDICAL DISCOURSE IN FLORENCE, ITALY

\author{
A Dissertation Presented to the Graduate Faculty of \\ Dedman College \\ Southern Methodist University \\ in \\ Partial Fulfillment of the Requirements \\ for the degree of \\ Doctor of Philosophy \\ with a \\ Major in Anthropology \\ by \\ Michaela Wallerstedt \\ (B.A., Stanford University) \\ (M.A., Southern Methodist University)
}

May 18, 2019 
Copyright (2019)

Michaela Wallerstedt

All Rights Reserved 


\section{ACKNOWLEDGEMENTS}

This dissertation is born from countless hours of research and writing. I would not have finished this without the help of family, friends, mentors, colleagues, and all the people who helped along the way. I am thankful for the new mothers who took time out of their busy schedules to help me with my research. I am also thankful to all the midwives and the midwifery organization that invited me to witness their work. I would not have been able to finish my research without all of these people.

I'd like to acknowledge my mentors that guided me in my education over the past 8 years. Their roles have been essential in my professional and educational growth. I could not have finished this research without the help from Dr. Carolyn Smith-Morris, Dr. Caroline Brettell, and Dr. Nia Parson at SMU and Dr. Elizabeth Krause at the University of Massachusetts, Amherst. I am very grateful to the tremendous effort Dr. Smith-Morris has taken in developing and re-developing my research proposal, as well as the enormous investment of time she put in to helping me develop the ideas in this dissertation.

I am also grateful to Dr. Diane Hardgrave who continued to support my graduate career even after her time at Southern Methodist University. Dr. Laura Iannuzzi was a tremendous pillar of support as I tried to navigate the difficulties of maternity care research in Italy. I'd also like to thank the late Dr. Victoria Lockwood for her support before her passing.

I'd also like to thank the people involved in the NSF Summer Institute for Research Design, including Dr. Russell Bernard, Dr. Jeffrey Johnson, Dr. Susan Weller, and Dr. Amber Wutich. Their specific feedback was indispensable in designing, and giving me the tools to 
redesign, my research project. I would also like to thank all of the other participants in this program. I never would have gotten through the intensity of the program without the support from all the other graduate students.

I'd also like to thank all the graduate students who helped me along the way. Dr. Adrienne Strong has been a source of support in every area of my graduate experience since our time in SIRD. I am extremely grateful that Sydney Yeager has also been there for me in all of my difficulties and tribulations. She has continued to support me since the beginning of our time in graduate school and her feedback on dissertation provided me with the much needed feedback to help me finish writing my dissertation.

Thank you to everybody who has helped me to finish this process. 
Women's Experiences with Maternity Care

and Medical Discourse in Florence, Italy

Advisor: Dr. Carolyn Smith-Morris

Doctor of Philosophy conferred May 18, 2019

Dissertating Completed April 15, 2019

This dissertation is based on ethnographic research in Florence, Italy. The primary focus of this research is based on a comparison of medical discourse from Italian State documents with women's experiences during pregnancy and childbirth in Italy. Mirroring trends throughout the developed world, Italy has maintained high rates of cesarean sections since the turn of the century. Italy's unique political and cultural history has made Tuscany one of the best regions for maternity care within a country with significant regional variability. This dissertation looks at historical and current cultural trends to understand the ways in which women experience highquality maternity care in Florence.

This dissertation interrogates women's experiences during pregnancy and childbirth through the theoretical lenses of political philosophy, agency and practice theory, and the medicalization of reproduction. This dissertation provides new avenues through which to draw connections between these three social theories. Medical discourse in the State documents demonstrates the ways in which women's subjectivities and experiences are erased in an effort create a population upon which it is (theoretically) easier to enact interventions. Discourse ignores women's agency in favor of implying that doctors and healthcare professionals are far more important actors in pregnancy and childbirth. 
But Italian women assert their own agency against medicalized birth through their reproductive socialities. By making connections with other mothers and midwives, women find support beyond medicalized models of maternity care. Local hospitals and healthcare clinics become sites that foster reproductive sociality. Women seek out care from healthcare professionals, primarily midwives, not due to their medical competence but due to their ability to create relationships with their patients. Midwives are part of what makes hospitals the ideal place for birth; a safe haven from the potential risk of birth.

This idealization of birth, however, often gives way to less than desired care, demonstrating the fractures and inconsistencies in the way midwifery-based care is perceived. These fractures and inconsistencies are also seen in how women conceive of healthcare throughout the country. Women themselves simultaneously value and devalue their own socialities. Women's discussion of the Italian healthcare system demonstrates how deep-seated ideologies of rationalist medical behaviors and stereotypes about the South. Women afford flexibility in departing from ideal modes of birth in their own decisions, but do not afford women the same flexibility in the South. Medicalized rhetoric seeps into deep seated beliefs about the South, demonstrating that women's own positive experiences are not always valued as a means to achieving quality healthcare. Through analyzing the connection medical discourse and women's reproductive sociality, I demonstrate the tenuousness with which experience is valued. 


\section{TABLE OF CONTENTS}

CHAPTER 1: BIRTH, REBIRTH, AND A LITTLE BIT OF TUSCAN SUN ...................

Cesarean Sections and the Italian State..................................................4

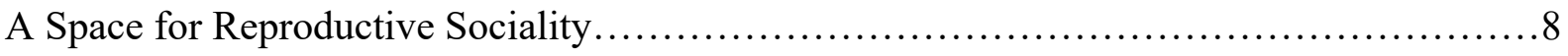

CHAPTER 2: POWER, AGENCY, AND MEDICALIZATION $\ldots \ldots \ldots \ldots \ldots \ldots \ldots \ldots \ldots \ldots \ldots \ldots$

Italian Unification and the Rise of Healthcare Disparities............................. 17

The State, The Body, and Bio-Realities........................................... 24

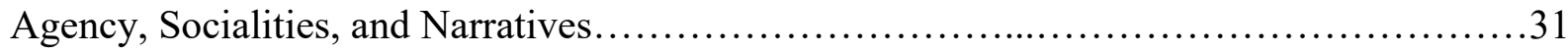

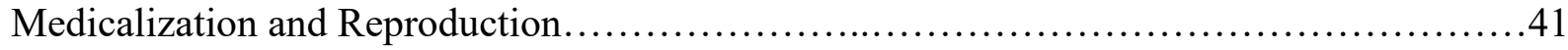

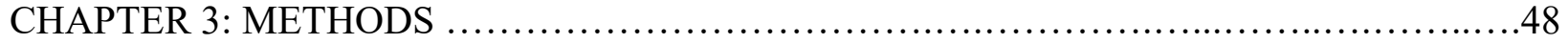

Initial Research Design \& Lesson from the Field...................................49

Final Research Design.......................................................54

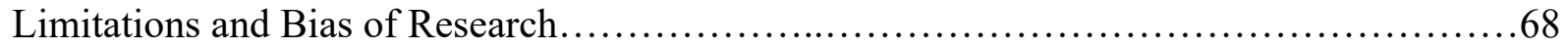

Data Analysis..................................................................

CHAPTER 4: THE UNIVERSAL REPRODUCTIVE BODY: GLOBALIZED RATIONALITIES IN MATERNITY CARE DISCOURSE .........................73

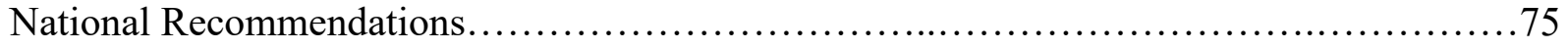

Regional Health Governance and the Regione Tocsana Website...........................94

Discussion: National vs. Regional, the Disappearing Subjective Woman................... 100

CHAPTER 5: LOCAL BODIES, SOCIAL BODIES: REPRODUCTIVE SOCIALITIES IN

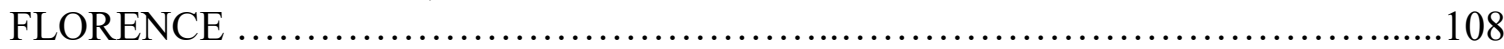

The Healthcare System and Women's Information Seeking Behaviors................. 109

The Sociality of Reproductive Bodies.......................................... 115

Discussion: Reproductive Socialities.......................................... 125

CHAPTER 6: BIRTH IN THE HOSPITAL: MEDICAL INTERVENTIONS AND WOMEN'S

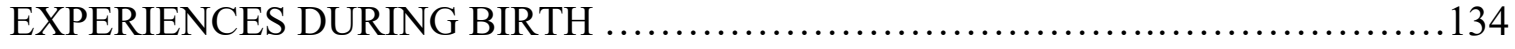


Protagonista, Fondamentale, Niente: Different Actors’ Roles in Childbirth.

Birthing Stories: Interactions and Events at the Hospital............................ 147

Discussion: Hospitals, Space, and Roles in Childbirth.............................. 156

CHAPTER 7: WHEN THINGS FALL APART: WHEN MATERNITY CARE FRACTURES 166

'They're Fascists about Natural Childbirth': When Women's Choices Clash with the Local Healthcare System............................................................. 168

After Birth................................................................ 171

Amelia: Fractured Care ...................................................... 177

Contradictions Within the Healthcare System Ideologies.............................. 179

Fractured Care and (Seemingly) Contradictory Beliefs................................ 189

CHAPTER 8: CONCLUSION: WOMEN'S REPRODUCTIVE SOCIALITIES AND GLOBAL MATERNITY CARE NARRATIVES ................................................ 198

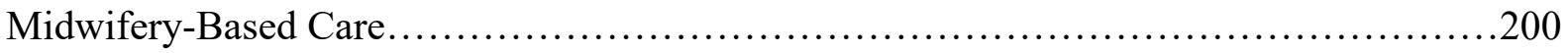

Maternity Care: State Discourse Meets Practical Application..........................206

Global Flows, National Ideologies and Maternity Care within Anthropology...............209

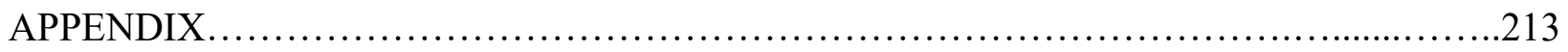

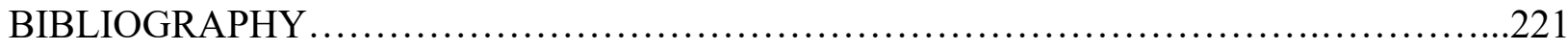




\section{LIST OF TABLES}

1.1 Italian Cesarean Section Rate 2001-2005 ..............................................

2.1 Number of Births in Each Major Hospital in Florence in 2016..........................22

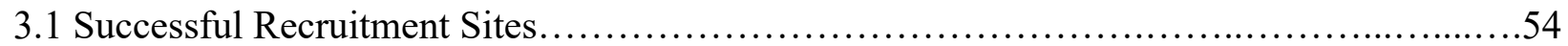

3.2 Number of Participants Interviewed in Each Time Period Before and After Birth.............57

4.1 Number and Type of Sources in Each Section of Part One of the Guidelines................82

5.1 Women's Responses to the question "What source of information was most important for your choices in pregnancy and childbirth?"....................................110

5.2 Reasons why women $(\mathrm{n}=23)$ chose midwives as most important source..................112

5.3 Reasons women $(n=8)$ gave for stating doctors as their main source of information.........113

5.4 Reasons women gave for choosing non healthcare professional sources as most

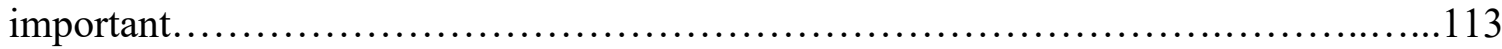

5.5 Women's reasons for why they did or did not fear childbirth.......................... 123

6.1 Percentage of Women Who Consider Each Pain Control Technique or Mode of Birth Safe.. 147

6.2 Percentage of Different Lengths of Birth Narratives................................. 151

7.1 Most common reasons Italian women consider the Tuscan healthcare system to be good...185

7.2 Reasons participants gave for women not making good decisions in the rest of Italy...... 187 


\section{CHAPTER 1 BIRTH, REBIRTH, AND A LITTLE BIT OF TUSCAN SUN}

In one of the subtle but important moments of the 2003 romantic comedy Under the Tuscan Sun, the main character Frances gets a surprise visit from her pregnant friend, Patti. Patti walks around Frances' estate wondering about her baby and what the birth will be like. Frances begins a joke by telling Patti, "the local midwife puts a knife under the bed." As Patti looks at her friend, confused, Frances says, with a smile, "to cut the pain." Frances assures Patti that she can give birth in a hospital in Florence only an hour away. After the baby is born, Frances opens the window of her hospital room to a beautiful view of the Duomo and the Florence skyline. As the window opens, the light floods in, evoking the romanticized Italian phrase for giving birth, "dare alla luce" or "give to the light." While some details in this scene are entirely unrealistic (there are no hospitals in the center of Florence that have a view at the same height as the Duomo), this story highlights one of the many ways in which birth is an ever-present theme in Italy, and Florence in particular. A romanticized view of birth in Florence provides the backdrop to my research. While not all women interviewed for my project presented such a Hollywoodtype portrait of their own births, much like Patti and Frances, relationships formed the foundation of their positive experiences during pregnancy and childbirth.

Contrasting with these idealized tropes are national statistics about Italy's birthing culture. For most of this century, Italy has had the highest or one of the highest cesarean section rates in Europe. Most recent data from the OECD has shown a slight decrease in Italy's cesarean 
section rate from the highest of 39.5 in 2006 to 35.3 in $2015^{1}$ (OECD 2017). Due to an increase in cesarean section rates in other European countries, Italy no longer has the highest cesarean section rate in Europe, but the rates are still higher than recommended. The WHO recommends that a country's cesarean section rate should be no higher than 15\% of all births (WHO 2016). Yet Italy's rates are more than double the desired percentage. While the Italian Minister of Health has stated that he believes $20 \%$ to be a more realistic goal for the country, and rates have been in decline since 2006, no region in Italy is below 20\%. How might one make sense of this contrast in ideals - between women's positive social experiences in birth, on the one hand, and the highly medicalized, hospital-based cesarean experience of so many Italian women? As my ethnography will show, one answer lies in the failure of State discourse to acknowledge women's experiences and relationships.

In a healthcare system that is free at the point of access, women in Florence are provided a myriad of services, including several medical visits, ultrasounds, and prenatal classes.

Women's social experiences during pregnancy are formed by, but extend beyond, the healthcare system. Particularly during pregnancy, socialization starts in prenatal classes provided by the healthcare system but extends into the daily lives of expectant and new mothers. During labor, relationships with healthcare professionals, particularly midwives, provide the foundation for women's positive experiences.

In this dissertation, I illustrate how social relationships influence women's perceptions of their experiences and perception of quality of care they received during pregnancy and childbirth. The impact of women's social relationships on their evaluation of care, however, often represents a contradictory view of how women conceive of maternity care in Italy. In particular, decisions surrounding cesarean section, medication during birthing, and location for

\footnotetext{
${ }^{1} 2015$ is the most recent year cesarean section rates are available from the OECD
} 
birthing often reflect contrasts and conflicts between institutionalized ideals of the State and the malleable and subjective priorities of women giving birth. For example, in an effort to decrease Italy's high cesarean section rate, the Italian Ministry of Health released a set of recommendations that promoted a very simplistic view of women's experiences and decisions related to childbirth. These recommendations failed to mention women's own evaluation of how their social relationships affected their maternity care decisions. Women's assessment of these connections goes unacknowledged even in local Tuscan documents about maternity care. Instead, State documents promote the research findings and conclusions from international populations due to the supposed objective quality of those data. Meanwhile, local women's perspectives are discounted or simply not counted at all.

My argument therefore frames State-level medical discourse about cesarean sections as a window into larger beliefs about women and reproductive bodies. While a reduction of cesarean sections is the focus of many state documents, cesarean sections are not a focus of this research. Understanding the relevance of State-level medical discourse surrounding cesarean sections and women requires a broader understanding of women's conceptions of pregnancy and birth. As such, this project answers a range of questions about childbirth in Italy such as: How do Italian women view medical interventions versus other modes of birth? How do they use social relationships to ameliorate the difficulties of pregnancy and childbirth? How do local healthcare systems allow women to reject or accept certain types of medicalization in pregnancy and childbirth? In what way do women's experiences align with larger deep-seated ideologies about culture and behavior within the country? The answers to these questions help to demonstrate how women's experiences, especially their social relationships, provide a counter-narrative to State-level medical discourse, while also mirroring rationalized views of reproduction. 


\section{Cesarean Sections and the Italian State}

Italy's historically high cesarean rate must be situated within the trajectory of medicalized birth found in many Western countries in the $20^{\text {th }}$ century. Nancy Triolo (1993) details how the medicalization of birth in Sicily mirrors larger trends within Italy and other Western countries. At the turn of the $20^{\text {th }}$ century, Italian physician education and licensure was standardized, and professionalized, while the nation's midwives - who had been providing the bulk of maternity care across the country - became increasingly marginalized. Triolo (1993) and Whitaker (2000) document an historic shift in Italy as the doctor's role during birth changed from one of emergency care to that of primary healthcare practitioner. During this shift, the role of the midwife as home birth attendant diminished as their expertise was no longer valued. While midwives, an anthropological symbol of demedicalization, currently have professional status in Italy, the medicalization of birth has been a trend that has proven slow to reverse.

Tuscany's cesarean section rate and maternity care are set within a paradoxical Italian context. As described above, Italy is shifting away from having one of the highest cesarean section rates in Europe. As illustrated in Figure 1.1, Italy has decreased the cesarean section rate to $35.3 \%$ of births (OECD 2018), although it is still higher than the $15 \%$ rate recommended by the WHO (WHO 2016). 
Figure 1.1 Italian Cesarean Section Rate 2001-2015

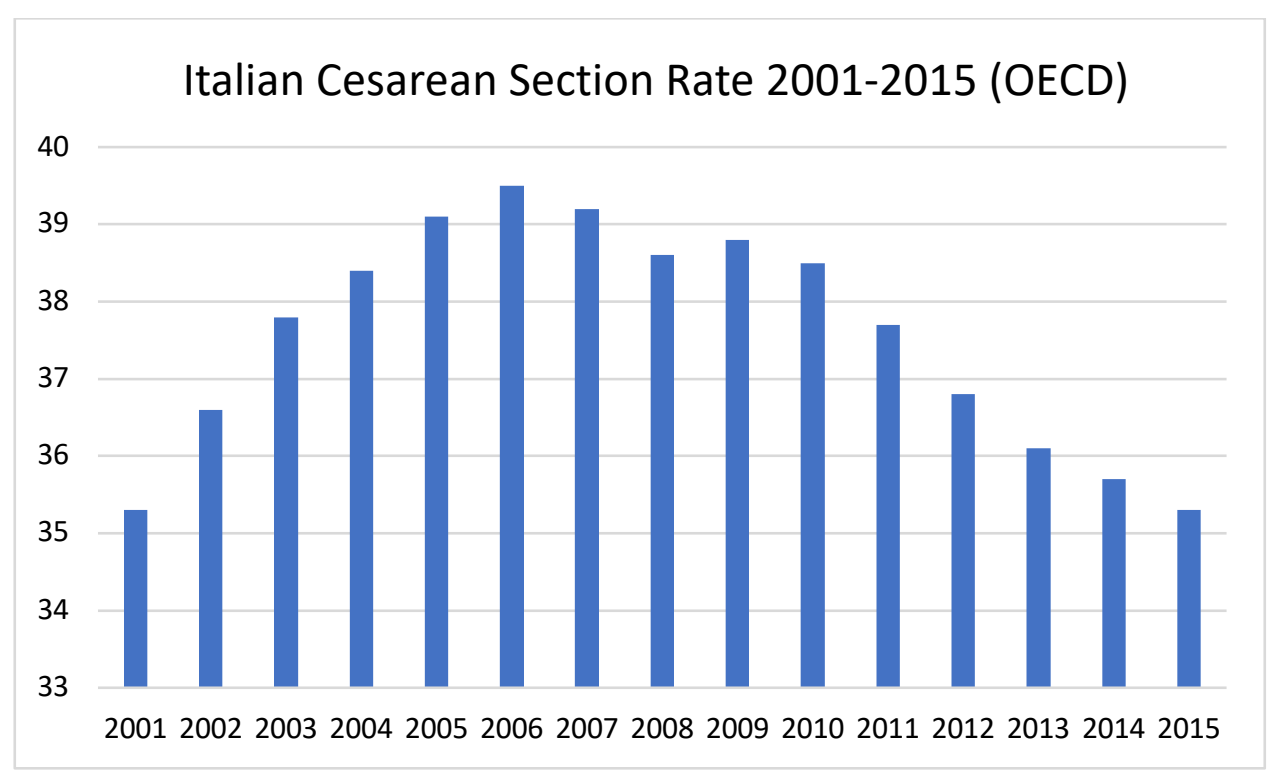

The recommendation by the $\mathrm{WHO}$ of no more than a $10-15 \%$ cesarean section rate first came in 1985 at a conference in Brazil. In 2014, the recommendations for these rates was revisited again at a meeting in Geneva, Switzerland and the findings published in 2016. The recommendations for a $10-15 \%$ cesarean section were based on "population level" data. Through a review of available research, the maternal care experts discovered that maternal mortality was improved when cesarean sections increased to $10-15 \%$, but that there was no additional improvement to maternal mortality when cesarean rates were between $15 \%$ and $30 \%$. The experts also analyzed socio-economic status and found "that a substantial part of the crude association between cesarean section rates and maternal mortality appears to be explained by socioeconomic factors" (2016:3). According to the WHO, the importance in decreasing these rates stems from the many potential risks associated with cesarean sections.

The WHO recommendations demonstrate the paradox of the Italian birth context. While the WHO's review of global maternal health data suggests that there are no improvements to maternal mortality when cesarean rates are between $10 \%$ and $30 \%$, WHO recommendations also 
say, "current data does not enable us to assess the link between maternal and newborn mortality and cesarean section rates above 30\%." Since 2000, Italy has consistently had a cesarean section rate above $30 \%$, much like several other countries around the world. The WHO's inability to analyze high cesarean section rates presents a problem for evaluating maternity care in many countries trying to decrease their rates of cesarean section. A lack of analysis of populations with cesarean sections over 30\% excludes nations, like Italy, from a more nuanced understanding of maternity care issues. Italy also has one of the lowest maternal mortality rates and infant mortality rates in the world (OECD 2017). This paradox of high cesarean sections and low maternal and infant mortality throws into sharp relief the need for more nuanced analysis of birth practices in Italy.

The Italian cesarean section paradox also demonstrates how using only national level data, as done by the WHO, obscures maternity care trends within a country. In Italy, the rate of cesarean sections varies significantly by regions. Much higher rates are often found in the South as compared to the North. Campania and Puglia, both southern regions, have a cesarean section rate of 59.1\% and 43.6\%, respectively (Basili et al. 2018). Valle d'Aosta and Tuscany, two northern regions, ${ }^{2}$ have cesarean section rates of 20.3 and 20.7, respectively (Basili et al. 2018). Infant and maternal mortality rates also fall along these geographical divisions as higher rates are generally found in the South as compared to the North (Basili et al. 2018). Maternity care trends in Italy show that the definition of "population" and the level at which data is analyzed by organizations like the WHO should not always be constrained to national level statistics.

Other research has provided a slightly more nuanced example of differences in cesarean section rates throughout Italy.In a review of regional data from 1980 to 2000, Spinelli identified

\footnotetext{
${ }^{2}$ While I recognize that Italy is often divided into North, Central, and South, in which Tuscany is considered central Italy, for this particular project I believe that a simpler division between North and South is preferable, considering the differences in economic status and ideological divisions that will be elaborated later in the dissertation
} 
five major factors that increased a woman's risk for receiving a cesarean section: increasing maternal age, birth in a private facility, not attending a prenatal course, birthing in the South, and pathologies in pregnancy. Similar to Spinelli's analysis, attempts to explain regional differences in cesarean sections has often these regional differences have often been made using large data sets, such as a survey by Donati et al. (2003) that attempted to understand women's opinions about cesarean sections throughout Italy or Cavalieri's (2013) research on regional differences in rates of hospital reimbursement for cesarean sections versus vaginal births. None of these explanations, however, discuss significant, historical, cultural, and economic processes influencing the differences between the North and South of Italy.

These differences in healthcare between the North and the South draw upon an even deeper historical context that started during the $19^{\text {th }}$ century process of Italian Unification. During the period 1815-1871, the leaders and architects of Italy's unification were recruited primarily from the northern region of Piemonte. As such, the leaders had very little experience with or knowledge of people in the southern regions, formerly the Kingdom of the Two Sicilies. The leaders relied on reports from military campaigns in which southerners were construed as barbaric, which Nelson Moe (2002) suggests had detrimental effects on the economy of the south. These economic differences were further exacerbated by the end of the "Italian Miracle" in 1975 (Terrasi 1999).

Economic differences between the North and the South are one of the factors exacerbating healthcare differences within the country. The1978 law 833/1978 established the National Healthcare System (or Servizio Sanitario Nazionale), provides healthcare for free at the point of service (Lo Scalzo 2009). In the '90s, economic strain forced the Italian government to decentralize healthcare decisions to each of the regions. After the decentralization in the ' 90 s, the government started to address the regional disparities in healthcare. Pavollini and Vicarelli 
(2012), however, suggest that regional disparities between the North and the South grew not only because of the difficulty in managing the bureaucracy of the south, but also because of the inaction of the central government to intervene in the struggling healthcare system.

One of the ways in which the government has tried to intervene has been through a series of publications aimed at reducing cesarean sections. In 2010, the Ministry of Health released the first set of the guidelines entitled Cesarean Sections: An Appropriate and Conscious Choice. The first set of guidelines were aimed at improving doctor-patient relations. In 2012, the Ministry of Health published Cesarean Sections: An Appropriate and Conscious Choice, Part Two. The second set of guidelines were aimed at improving a broader set of medical practices surrounding childbirth care and cesarean sections. The guidelines represent a general summary of research related to cesarean sections, but as I demonstrate, in the dissertation, these guidelines demonstrate a lack of specificity to any regional context that could provide sufficient recommendations to improve maternity care. Throughout this dissertation I show the ways in which unique local historical, economic, and cultural trajectories impact women's experiences with childbirth.

\section{A Space for Reproductive Sociality}

The failure of the Ministry of Health to recognize significant aspects of women's behaviors and decisions making during pregnancy and childbirth is apparent in Florentine women's experiences. Chief among these experiences are the often midwife-run prenatal classes. Midwives serve not only as a way through which information about childbirth is provided, but as a way for women to receive emotional support for their very specific needs. The social support women received in these classes also extends into women's relationship with other mothers. Women view the support they received from other mothers and midwives to be a more significant motivator for attending the classes than the information they receive. The social 
aspects of pregnancy are mirrored in Rabinow's (1993) concept of biosociality. Rabinow imagined the impact new biotechnologies, like genome sequencing, could have on human behaviors. Humans would form social groups around their newly diagnosed diseases. Biology would become the foundation upon which social relationships occurred. While Rabinow's concept of the sociality due to shared biology aligns with women's experiences during pregnancy and childbirth in Florence, the concept requires a slight reimagining. Rabinow imagines future technologies to facilitate social relationships among the sick, but pregnant women are not sick. Like Rabinow imagines of the newly diagnosed patient, pregnant women find themselves in a new biological state. Because pregnant women are not ill, I suggest that women's social behaviors must be thought of as a type of "reproductive sociality" in which women form social groups to ameliorate their changing, but not sick, lives.

Positive social relationships are not confined to pregnancy, however. During birth women also sought positive relationships with midwives not based on their medical competence but on their personal characteristics. These relationships served as a means through which the process of demedicalization of birth occurred. Early anthropologists of reproduction explored the way in which medicalized ideas about the body caused barriers to woman-centered care in childbirth (Martin 1987; Davis-Floyd 1992). The elaboration of the concept of authoritative knowledge grew out of this early desire to understand how medicalization and medical authority was exerted over women's bodies. With the expansion of the concept of authoritative knowledge in reproduction, the midwife came to be a key figure of anthropological inquiry. Anthropologists have often detailed the importance of midwives in low income communities (Sargent and Bascope 1997; Sesia 1997) and the importance of midwives as resisters to the model of medicalized birth so common in many developed countries (Szurek 1997; Davis-Floyd and Davis1997). Anthropologist represented midwives as a powerful force for demedicalizing 
childbirth and providing woman-centered care. Some anthropologists, however, suggest that this focus on midwives is nothing more than the quasi-romanticization of one of many different types of care (MacDonald 2006; Wendland 2007). My research on women's experience with maternity care provides an analysis of the successes and failures of midwife-based care through an elucidation of "care as practice" (Mol et al. 2015)

Viewing midwife-assisted birth as one of many options provides an elaboration of how medicalization and de-medicalization occur. Key to understanding the Florentine context is recognizing the role that space, especially the hospital structure, plays in women's views and acceptance of the demedicalization of childbirth. The midwife is at the center of demedicalized childbirth in Florence, but only in the hospital. Women in Florence desire natural childbirth and midwife-assisted care but are mostly unwilling to give birth at home. The hospital is seen as a space where risk is mitigated through the presence of trained doctors and technological interventions. Women do not necessarily desire to have those technological interventions during birth, but the women see them as necessary in case of any potential problems. Women's desire for a natural, midwife assisted birth is contingent upon vicinity to a hospital, suggesting that understanding the ways in which midwifery-based care demedicalizes birth requires an understanding of women's conceptions of space.

Demedicalized midwife-assisted care in the hospital, however, does not always mean high-quality care. Women's request for epidurals demonstrates how the hospital can be a site of both support and constraint. Women's experience with obstacles when requesting epidurals, demonstrates the need to understand "care as practice" or what midwives actually do. Women experienced similar issues when trying to receive help in breastfeeding while still in the hospital. While women expressed the importance midwives placed on breastfeeding in prenatal classes, women often felt that there was no actual support from midwives on this practice after birth. 
Through analyzing women's experiences with maternity care in Florence, I show that the hospital provides a space for specific ideologies to be enacted, particularly relating to natural childbirth. For women whose desires in birth aligned with these ideologies, their experiences were mostly pleasant. When women departed from these ideologies, such as when women requested epidurals, the power midwives' beliefs had in limiting women's behaviors became apparent. Women's inability to receive help with nursing after birth also demonstrates that even within certain ideological spaces, in this case the hospital, aid is not always available to partake in accepted behaviors. As Lopez (1993) demonstrates in her research on Puerto Rican women's reproductive decisions, the decisions to have a tubal ligation can allow women to escape certain types of oppression, while subjecting them to others. Construing certain decisions as agentic acts does not mean women are free to make certain choices without constraints (Lopez 1993). In Florence, the hospital is simultaneously a facilitator and a constraint to women's childbirth needs.

\section{Chapter Overview}

Through this dissertation, I will demonstrate the ways through which women's reproductive socialities are supported, transformed, and disregarded. These socialities contrast the medical discourse of State-level guidelines and recommendations aimed at improving maternity care. Through understanding the many different ways in which hospital and local healthcare systems support (and sometimes constrain) women's childbirth decisions, the dissertation demonstrates the necessity for including women's own experiences in maternity care policy.

Chapter 2 starts with a discussion of the theoretical concepts that form the foundation of my research. By interrogating research connecting the body to political aims, I focus on how anthropological research undermines the very ideas of political divisions. Medicine is easily co- 
opted by the state as a means through which to enact goals which represent a certain type of ideology or aims to control morality. This process of the state enactment of power over the body is particularly salient in the context of reproduction. But while the state represents a key cite of power to be analyzed, anthropologists have also recognized the importance in the behaviors and everyday lives of patients themselves. Through a discussion of agency, practice theory, and habitus, I discuss how the Tuscan example requires a reexamination of power and the person. I then offer a reworking of the concept of the illness narrative based on women's birth experiences. I revisit the concept of power through work on authority and the medicalization of birth. I suggest that my research creates a new avenue with which to discuss previous work on the medicalization of birth.

In Chapter 3, I discuss my methodological process for comparing of State-level medical discourse to birthing women's experiences. I also discuss several experiences in the field that challenged the implementation of my initial research design, and the adjustments I made while in the field. Many of the difficulties I experienced doing research and attempting to obtain, and keep, permission to access certain field sites, are familiar. However, I also note the importance of the particular point in time of my research, and the possibility that these methods would not have been feasible in the past and might be obsolete in the future. I also briefly discuss the limitations of doing anthropology in an urban environment and within highly bureaucratic organizations.

Chapter 4 is the first of four chapters on my research data. It begins with an analysis of government documents about birth in order to display underlying biases concerning information and research about birth in Italy. Analysis of two sets of documents, one set at the national level from the Ministry of Health, and one at the regional level from the Region of Tuscany, provides the opportunity to demonstrate different medical discourse at different levels of the government. The first set of documents focuses on changing behaviors to ameliorate the high rates cesarean 
sections throughout the country. My analysis focuses on the unrealistic portrayal of women's behaviors and emotions during pregnancy, as well as the lack of focus on actual services provided to women in local hospitals. I suggest this lack of pertinent context is due to the use of research based in populations outside of Italy. The second set of documents I analyze are from the Tuscan government and focus on different aspects of birth in Tuscany. I demonstrate that while the focus of the documents is somewhat different, that even Tuscan documents do very little to discuss women's actual experiences, focusing instead on the importance of the behaviors of medical professionals. While the Tuscan documents are more representative of local services and behaviors in Florence, women are still not considered an important part of representing maternity care. The Tuscan documents also contain many references to non-Italian sources, although not to the same extent as Ministry of Health documents.

In Chapter 5, I detail women's experiences in pregnancy. I show how the search for social relationships dominates women's reproductive experiences. A key site of facilitation of these social activities is the prenatal class where women create social bonds with other expectant mothers and midwives. These social relationships often extend beyond the classroom, when class members created chat groups through which they could reach each other at other times. Women's experiences beyond the classroom include regimens of self-care that suggest a Goldilocks type search for the ideal amount of certain behaviors. I also interrogate how women valued information about pregnancy and childbirth. In doing so, I discovered the midwife to be a key figure of information, even though Ministry of Health medical discourse never mentioned them. Even though the Ministry of Health guidelines recommended that information was an asset for women to use to overcome fear, I show the complexity with which women experienced fear about childbirth. 
Chapter 6 provides an image of women's experiences during childbirth, and a more indepth analysis of their interactions with the healthcare system. Through a discussion of person's roles during labor and delivery, the value of the midwife over the doctor is demonstrated. Women's desires to receive care from a midwife was not based necessarily on competence, but on the social and emotional connections created with midwives. Women's experiences also show the importance of the structure and how women conceive of childbirth as an inherently risky process. The hospital becomes a site to interrogate concepts of space as it relates to existing literature on medicalization. The hospital as space creates a means through which notions of medicalization in the anthropology of reproduction can be deconstructed. The hospital also becomes a space through which ideas about birth are realized and natural childbirth, albeit in a hospital, is seen as preferable. While natural childbirth is seen as preferable to having an epidural or cesarean section, a natural homebirth is considered far more dangerous than any other mode of birth. Through the use of three key birth narratives, I show exactly how women's preferences and preoccupations with birth are actualized in their experiences.

Chapter 7 provides an important contrast to the previous two chapters, allowing me to focus on all the ways in which women's positive narratives start to fall apart. Even though women detailed their many positive experiences in pregnancy and childbirth, not all women had such positive experiences. There were certain key points, particularly when asking for an epidural and aid after birth, in which women's positive experiences with turned into a struggle to receive basic care. Women's inability to conform to local beliefs about natural childbirth throws into harsh relief the idea that midwife-based care means woman centered care. The desire for care that departs from local childbirth ideologies, however, does not mean that the women escape local ideologies of idealized forms of birth. Ideologies can be difficult to overcome, as I show that even women do not always value their own experiences. Women's version of quality care 
aligns with the highly medicalized rhetoric of the Ministry of Health documents. Reproduction again becomes a site through which ideological divisions between the north and the south of the country are upheld. The simultaneous presence of competing ideologies demonstrates how women accept certain types of knowledge while rejecting others.

Chapter 8 analyzes the themes of each chapter more completely. By detailing when and how women use or disregard their reproductive sociality, I demonstrate how women can simultaneously value and devalue their own experiences. Women's often positive, but sometimes negative, experiences in pregnancy and childbirth demonstrate the power of beliefs about (natural) birth within the local healthcare system. But even with the prevalence of midwifery-based care, medical based discourse is not so easily dismissed by women, demonstrating the difficulty in women's acceptance of their own experiences as a way to evaluate the quality of healthcare.

Through analyzing women's experiences during pregnancy and childbirth in Tuscany, my research shows the conflicting relationship women have with their own experiences. Women's experiences demonstrate the failures of healthcare recommendations, but women's valuations of their own experiences often incorporate the medicalized rhetoric of these recommendations. Women's experiences with maternity care in Tuscany, however, form the foundation of interrogations of anthropological concepts and the reimagining of others. 


\section{CHAPTER 2 POWER, AGENCY, AND MEDICALIZATION}

Italy provides the backdrop for understanding the intersection of political philosophy, agency and practice theory, and the medicalization of reproduction. The unique history of the Tuscan government, particularly relating to healthcare, has provided the foundations for high quality maternity care, particularly in contrast with other regions in the country. Like many western countries, Italy has a history of medicalization of birth starting at the turn of the $20^{\text {th }}$ century. The medicalization of care in Italy marginalized midwives as birth attendants. In Tuscany, the investment in healthcare in the $20^{\text {th }}$ century has led to a focus on delivering high quality maternity care throughout the region. Tuscany also saw a rise in the role of the midwife which expands anthropological literature on the demedicaliztion of childbirth to incorporate discussion of hospital spaces.

The hospital as a space of demedicalization also provides a more nuanced analysis of the power of the state in reproduction. The recent theory of reproductive governance (Morgan and Roberts 2012) recognizes the tools that governments and organizations use to assert their power and control over women's reproduction. Foucauldian deterministic models of power provide the foundation for this theory. These models of governance often rely on the shaping of moral behaviors relating to reproduction. The ideal reproductive subject is often construed using rationalist, individual, models of behavior. A counter argument to Foucauldian deterministic models of power often focused on the behaviors of individuals through a discussion of agency or practice theory (Bourdieu 1977; Ortner 1994). Within the Tuscan contexts, explaining alternatives to Foucault's deterministic concept of power is essential. Bourdieu's concept of 
habitus and Giddens's concept of structuration are essential in understanding the nuances the power and agency among reproductive bodies. While women's choices surrounding pregnancy and childbirth often depart from State recommendations regarding maternity care, their actions are still facilitated by the local healthcare system.

Power and agency, however do not always encompass the entirety of human experience. Rabinow's (1996) concept of biosociality provides a means through which to analyze patient experience beyond the power/agency dichotomy by situating people within a broader social context. Similarly, narratives provide a way to locate lived experience within larger social, political, and cultural processes. For women in Florence, birth narratives demonstrate both what women suggest are important in birth and how they conceptualize birth as an event. By detailing the connections between these different bodies of literature and the Tuscan context, I will show how the Tuscan example provides an essential reframing of certain concepts relating to power, agency, and health.

\section{Italian Unification and the Rise of Healthcare Disparities}

Italy has a long history of settlement dating back to before the Romans, however, Italy as a country was not defined until the Risorgimento, or Italian unification. The history of unification is significant for understanding the unique context of maternity care today in Italy, and Tuscany in particular. As many scholars have noted, unification represented the merging of many regions with vastly different histories and cultures into one cohesive newly formed state. The processes involved in the unification created a divergent political and economic trajectory for the north and the south. The effects of the merging many different regions with very different histories can still be seen today through regional differences in health and maternity care. 


\section{Italian Unification}

Before the Italian unification that occurred between 1861 and $1870^{3}$, the Italian continent was comprised of many different kingdoms and principalities. The Kingdom of the Two Sicilies, which controlled the southern regions of Italy, had a long past of encounters with travelers from places such as the Middle East, Northern Africa, and Spain. Most of central Italy was part of the Papal State which was controlled by the Pope. Northern Italy was controlled by many different leaders in the years leading up to the Risorgimento, but major areas were controlled by the Grand Duchy of Tuscany, the Kingdom of Piedmont-Sardinia, and Austria. During the years leading up to the unification and for 10 years after, these many different regions of Italy slowly came under rule of the Kingdom of Piedmont-Sardinia, with Turin as the initial capital, followed by Florence, and finally Rome. During this time, governing of the Kingdom changed to a top down model in which local officials were supplanted with officials from Piedmont, a model of governance which Nelson Moe suggests was detrimental to the south (2002). After military campaigns from the northern regions returned from their conquest of the south, they construed southerners as "backwards," "barbaric," and in need of control (Noe 2002). The implementation with the one-size fits all Piedmont model and the concern to control the "backwards" south led to economic instability and further "Orientalizing" of the south that can still be seen today (Schneider 1998; Noe 2002). These changes in governing after unification were followed by attempts at unifying the country culturally. Starting at the end of the $19^{\text {th }}$ century, a standard Italian language based on the Tuscan dialect was taught to young children in school, although each region has its own local dialect, still spoken to some extent today (Noe 2002; Whitaker 2000).

\footnotetext{
${ }^{3}$ While most scholars pinpoint a specific year of unification, that year varies. 1861 is known as the year in which the Kingdom of Italy was proclaimed, however, unification was not complete during this time and the capital was not moved to its current city until 1870 .
} 
Around the turn of the century, the government undertook efforts to understand reproductive behaviors through the use of statistics and to protect breastfeeding through labor regulations, but it was not until the Fascist period that Italy saw a strong connection between the state and reproduction. Under Mussolini, who came to power in 1922, marriage and reproduction were considered a duty to the State (Whitaker 2000; Horn 1994). Reproduction came under the purview of the State, meant to be controlled using science and statistics to create not only more people but a better population (Horn 1994). Regimentation of reproduction extended into breastfeeding where mothers were encouraged to follow a rigid schedule which often caused anxieties in mothers that impacted their ability to nurse; these anxieties extended long after the fall of Fascism (Whitaker 2000).

After the end of Mussolini's fascist rule in 1943, the country was in disarray for many years until the "economic miracle" fostered in part by American financial support from the Marshall Plan. The "economic miracle" started in 1953 when Italy saw unprecedented economic growth, which led to investments in infrastructure and social welfare systems (Terrasi 1999). Terrasi (1999) suggests that between 1953 and 1975, the economic growth served to decrease economic disparities between the North and South, although Goddard (1994) suggests that a focus on industrial industries in the North served to limit the economic prosperity of the southern agricultural regions. After 1975, economic growth slowed and the industrial North was better able to adapt to these changes, further exacerbating disparities between the North and the South. (Goddard 1994). With no market for their goods and no remittances from workers who had migrated north during the boom, the South was relegated to economic precarity and economic inequalities throughout the country arose again (Terrasi 1999). These inequalities have had profound implications for healthcare. 
These disparities between the North and South of Italy have a long history and are often addressed in social and political analysis. Depending on the scholar, Italy is divided either into two main regions, north or south, or three, north, central, and south. When divided into two main regions, central Italy, where Tuscany is located, is grouped with the northern regions. While I acknowledge that the history of central Italy diverged slightly from the north, I have chosen to discuss Italy in terms of only north and south, with Tuscany considered economically and socially part of the North. Clear divides in healthcare also happen between north-central regions and the south, further justifying the grouping of north and central regions into a single northern bloc.

\section{Italian Healthcare}

Since 1978 Italy has provided healthcare to all its citizens. While the state government guarantees healthcare for all citizens, the regions retain significant control over the services they offer. Lo Scalzo et al. (2009: xx) provide a succinct description of the healthcare system:

Italy's health care system is a regionally based national health service (Servizio Sanitario Nazionale (SSN) that provides universal coverage free of charge at the point of service. The national level is responsible for ensuring the general objectives and fundamental principles of the national health care system. Regional governments, through the regional health departments, are responsible for ensuring the delivery of a benefits package through a network of population-based health management organizations (azienda sanitaria locale, 'local health enterprises' (ASLs) and public and private accredited hospitals.

The 1978 law 833/1978 that established the National Healthcare System [or Servizio Sanitario Nazionale (SSN)] was meant to "standardize the provision of care across the country" (Cicchetti et al. 2015: 251). All citizens were provided care from the government.

As Italy struggled economically in the late $20^{\text {th }}$ century, economic turbulence in the 1990s extended to the healthcare system. In an attempt to control healthcare costs, the government enacted what is known as the "second reform" (Cicchetti et al. 2015). Legislative 
Decree n.502/1992 gave more control over delivery of healthcare services to the regions (ibid.). The focus on efficiency changed to a focus on quality at the end of the "90s with Legislative Decree n.229/1999 (ibid.). With these healthcare reforms, attention turned not only to general healthcare in the country, but also to regional disparities:

Various indicators show that the health of the Italian population has improved over the last few decades...However, in almost all demographic and health indictors, there are marked regional differences for both men and women, reflecting the economic imbalances between the north and the south of the country (Lo Scalzo et al. 2009: xvii).

The healthcare problems created by the decentralization of care in Italy was further exacerbated by the economic division between the north and the south. Pavollini and Vicarelli (2012) suggest that these divisions were maintained because of the difficulty in managing the bureaucracy of the south, as well as the inaction of the central government to intervene in the struggling healthcare system. Inaction of the central government extended into the lack of monitoring and evaluation of the healthcare system in the South. (Pavollini and Vicarelli 2012; Nuti et al. 2012). Decentralization coupled with the inaction by the Italian government has led to clear degradation of the quality of care in the South.

These differences can be seen in maternity care as well. As mentioned in Chapter 1, Italy maintains one of the highest rates of cesarean sections in Europe and the developed world (OECD, 2017). At the same time, it claims one of the lowest maternal mortality rates (Central Intelligence Agency, 2015). These outcomes, however, vary significantly with higher rates of both found in the South than the North (Basili et al. 2018; Focus 2014). Attempts to explain these regional differences have often been made using large data sets, such as preferences for vaginal birth (Donati et al. 2003) or regional differences in payments for vaginal versus cesarean births (Cavalieri 2013). Attempts at explaining these differences, however, do little to address historical and cultural differences within Italy's different regions. 
As Szurek (1997) makes clear, history is important to an understanding the current birth realities in Tuscany. The economic prosperity of the region and a strong women's movement in the 1970s led to a campaign for reproductive rights. The gains made led to high investments in maternity care, which can still be seen today through the many free services offered by the local government. It is important to recognize, however, that the gains of this movement are situated within a localized manifestation of the feminist movement; similar political gains were not achieved in many southern regions for any number of reasons (Chiavola Birnbaum, 1986). In summary, it is not just the different economies, but also the divergent histories of the $20^{\text {th }}$ century that were instrumental in shaping the maternity care landscape of contemporary Italy.

\section{A Brief Overview of Maternity Care in Florence}

The Tuscan ${ }^{4}$ healthcare system is comprised of three main geographical areas. As of 2016, Florence, along with the cities of Prato, Pistoia, and Empoli, are overseen by Aziende Unità Sanitarie Locali (AUSL) Centro Toscana. Citizens generally receive non-emergency care through local healthcare clinics. There are six in Florence. For expectant mothers, these clinics are commonly where women will receive prenatal care, including prenatal classes. Women have the choice to receive care from a doctor or a midwife. All services through these healthcare clinics free at the point of access. Private hospitals and practices, from both doctors and midwives, offer prenatal care and services for a fee.

There are three main hospitals that serve the Florentine area: AOU Careggi (a university hospital), San Giovanni di Dio (colloquially known as “Torregalli”), and Ponte a Niccheri. Table 2.1 shows the number of births in each hospital for the year of 2016 .

\footnotetext{
${ }^{4}$ Throughout this dissertation, I move between discussing my fieldwork in Florence and discussing the larger context of healthcare in Tuscany. While my ethnography is set in Florence, the control with which the Tuscan region has over healthcare requires the inclusion of this level of data. My reference to Tuscany is meant to situate Florence in its larger regional context.
} 
Table 2.1 Number of Births in Each Major Hospital in Florence in 2016

\begin{tabular}{|l|l|}
\hline Hospital & Number of births in 2016 \\
\hline Careggi & 3524 \\
\hline San Giovanni di Dio & 1763 \\
\hline Ponte a Niccheri & 1122 \\
\hline
\end{tabular}

Source: Puglia et al. (2017)

All three hospitals are public hospitals. In addition, the natural birth center Centro Nascita della Margherita (colloquially known as La Margherita) is a midwife run birth clinic attached to the maternity wing of the AOU Careggi. Doctors are not permitted to practice in La Margherita but can be brought in for consultation during births that may need to be transported to the hospital for more medical care. Women can give birth in any hospital they choose, but La Margherita does not accept women who have medical complications or whose pregnancies are deemed highrisk. La Margherita also offers prenatal classes free to expectant mothers and Careggi offers informational sessions open to the public on a variety of topics, including natural childbirth, pain control in birth, and what to expect as new parents.

It is important to note some differences in the provision of maternity care in Italy from the context of the United States. Women have access to care from both private and public doctors or midwives. Some women choose a mixture of these options, while some choose only one practitioner from which to receive care. In the public system, however, these doctors generally do not accompany women to the hospital. Doctors and midwives in the labor ward of public hospitals work as shift workers. Unlike the U.S. where many women expect their doctors to attend to them during labor, this is not the reality in public hospitals in Florence. Midwives in Italy maintain a similar position to labor and delivery nurses in the U.S. and must hold a university degree. In Tuscany, midwives are present at the moment of birth for $98.36 \%$ of births, compared to an attendance rate of $88.69 \%$ for gynecologists (Basili et al. 2018). As I will 
demonstrate in Chapter 6, women in Florence considered midwives to be a more important birth attendant than doctors. The control of the healthcare system by the state in Italy provides the context for the elaboration of theories on power and the state in the next section.

\section{The State, The Body and Bio-Realities}

The state is an indispensable tool for medical authority. Understanding literature on the connection between the state and medical systems is particularly important in countries like Italy where most citizens receive healthcare from the government. As medical issues increasingly come under the purview of the state, anthropologists have uncovered the overt and covert mechanisms through which state control is enacted, especially related to issues of reproduction. Governments have the ability to force women from their homes in the name of safety (Kaufert and O'Neil 1990). Women can be forced to have cesarean sections without their consent (Irwin and Jordan 1988). Midwives can be forced to medicalize or lose their status (Triolo 1994; Whitaker 2000). While all of these examples point to potentially devastating outcomes for women, power by force is only one, and arguably not the most important, type of power a government can wield. As I will show, the government's role in shaping of ideology has a far deeper, and potentially more efficient, reach than other forms of government control, especially relating to reproduction.

Essential to understanding the connection between the state and reproduction is the concept of biopower. Michele Foucault's concept of biopower has laid the foundation for arguments in medical anthropology relating to power and the state. Foucault (1990) suggests that as governments changed in the $18^{\text {th }}$ century, governance moved away from control through the threat of death to the promotion of life. Starting in the $18^{\text {th }}$ century, as healing and medical treatments became increasingly institutionalized and no longer located within the social realm, 
medical knowledge becomes separated from the masses (Foucault 1972). Medical treatment was no longer just a means for treating disease, but a way for new nation-states to control growing populations through the promotion of health and the focus on preventative measures (ibid). The nation-state began to monitor things like the birth rate and lifespan in order to produce a particular type of healthy, productive, body (Foucault 1972). As Foucault discusses, the cornerstone of these societal changes was the control of knowledge. Foucault demonstrates that the connection between knowledge and governance was the product of specific historical and cultural processes. As new nation-states were formed in the $18^{\text {th }}$ century, governing shifted toward the control of knowledge and creation of new values as a means for governments to weave bodily control into the individual and everyday lives of the growing populations (Foucault 1972).

Critical to understanding how biopower seeps into medical discourse on reproduction in Italy is the concept of rationality. Rabinow and Rose (2006: 196-197) suggest that "at its most general, then, the concept of 'biopower' serves to bring into view a field comprised of more or less rationalized attempts to intervene upon the vital characteristics of human existence". An anthropological analysis of rationality within biomedicine, particularly in Western countries, is the adherence to a system of knowledge that is based on supposed objective facts of medicine, as well as the patient as individual (Kirmayer 1992; Mattingly 1998b). Kirmayer (1992) details a case in which a doctor could not accept a patient's non-medical reasons for not accepting a needed blood transfusion. The doctor replies to the patient's refusal with medical fact, asserting his medical authority and trying to persuade the patient to undergo the procedure. Kirmayer suggests: "Disagreement with medical opinion is prima facie evidence of irrationality. In this frustration, the doctor quickly resorts to scientific and professional authority to resolve, deflect, or ignore the patient's doubt." (1992: 330). Medical, scientific, fact is asserted as authority. 
This focus on an objective, knowledge-based view of the world among Western biomedical doctors leads to an individualization of disease, treatment, and healing (Mattingly 1998b). Mattingly suggests that "biomedical rationality is based on an individualist notion of cause" (1998b: 276), which she suggests, as does Good (1994), takes the person out of their social context. As I will show throughout this dissertation, medical rationality based in scientific knowledge and the individual patient does not align with dimensions of social context that birthing women in Florence want to bring to their experience.

More recently, anthropologists have sought to clearly define how biopolitics and rationalities are enacted as a means of power and control in women's everyday lives (Krause and DeZordo 2012). This focus on power and rationality provide the foundation for the theory of teproductive governance (Morgan and Roberts (2012). Morgan and Roberts (2012) explain the reproductive governance as a way to understand how different organizations (the state, church, NGOs) use various techniques, both direct, such as legislation or financial policies, and indirect, such as control of moral or ethical ideology. According to Foucault (1991), rationality is one of the tools with which governments assert their legitimacy. According Morgan and Roberts (2012), rationality moves beyond a biomedical framework to a moral framework in which rational reproductive behaviors are defined by historical, economic, and political processes of the place and time. In relation to reproductive governance, rationality is used to define appropriate behavior, often further marginalizing specific parts of the population (Marchesi 2012; DeZordo 2012; Mishtal 2012; Braff 2013). DeZordo's (2012) research in Brazil shows how the use of the concept of rationality among doctors allows them to delegitimize non-biomedical conceptualizations of the body and reproduction. For these doctors, rationality is seen as making reproductive decisions based on a bio-medical understanding of the body (DeZordo 2012). 
Rationalities aligned with biomedical knowledge created the foundation for the state control of reproduction.

Despite the prevalence of rationalist arguments in biomedicine and political rhetoric, anthropologists have actively argued against the concept of rationality. Anthropologists have often recognized Weber's contributions to the literature on rationality in the West. Weber argues that rationality is at the foundation of Western, capitalist, societies ([1930] 2002). Krause reminds us that "Weber did not glorify rationality. It was not something to be admired about the Occident but something that had to be shaken off, just as someone would have a visceral urge to shake off 'cold skeleton hands' were they gripping one's shoulders" (2012: 364). Echoing Weber's connection of rationality to the productivity of the West, Emily Martin suggests that "In all its forms, 'irrationality' is the enemy of 'rationality,' the enemy of order, stability, and civilization" (2009: 55). Through her research Martin seeks to challenge this separation between rationality and irrationality, and even questions whether rationality really exists (2012).

One problem with claims to rationality by biomedical authorities is particularly salient in the Italian context of reproduction. Assumptions about what constitutes rational decision-making are an extension of the concept of the "backward" reproducer. Anthropologists have detailed how reproductive technologies allow many women to overcome negative stereotypes, especially as they relate to "backward" behaviors (Van Hollen 2003; Kanaaneh 2002; Georges 2008). The framing of Southern Italian women's choices as rooted in backwardness, particularly those related to reproduction, has been a focus of many anthropological projects. While Banfield (1958) discussed the south of Italy as a bastion of backwards, amoral inhabitants, anthropologists have more clearly defined how this concept of the backward southerner has historically developed and is perpetuated in current trends (Schneider 1998). This perception of the South as different from the North and inherently backwards was originally a highly political division 
(Patriarca 1998, Noe 2002). Today, this division promotes discourse among northerners that makes less desired reproductive behaviors seem inherently southern and "backwards" in character (Krause 2005). As Schneider (1998) suggests, these differences often create an "Orientalism" of the south, in which the northern Italians try to distance themselves from backward southerners in order to be able to identify with the more modern, cosmopolitan Europe. These nuanced claims to rationality in reproduction are essential for understanding the context of childbirth in Italy and Florence. The guidelines published by the Ministry of Health $(2010 ; 2012)$ show exactly these rationalist ideologies about reproductive behaviors, as I discuss in Chapter 4. While the women's evaluation of their own experiences did not support the rationalized view of reproduction, further analysis will show the ways in which their beliefs still perpetuate the idea of the backward reproducer.

The ideological divisions that cast Southern Italians as different than Northern Italians provides a new avenue to analyze citizenship beyond state-level political divisions. In her work in Ukraine after Chernobyl, Adriana Petryna defines biological citizenship as "a massive demand for but selective access to a form of social welfare based on medical, scientific, and legal criteria that both acknowledge biological injury and compensate for it." (2002: 6). Petryna describes that biological claims for compensation were set in resource poor post-socialist Ukraine. Making these biological claims to the state was necessary for survival. Petryna's definition, while appropriate for the Ukrainian context, is not necessarily easily transportable to other locations. Her definition also shows a bias towards populations who are ill, which is not the case for pregnant women. Concepts in medical anthropology are, expectedly, often linked to illness, however populations such as pregnant women do not necessarily fall into these categories so easily. 
Another definition of biological citizenship comes from Rose and Novas (2005:2):

We use the term 'biological citizenship' descriptively, to encompass all those citizenship projects that have linked their conceptions of citizens to beliefs about the biological existence of human beings, as individuals, as families and lineages, as communities, as population and races, and as a species.

This very broad definition encompasses everything possibly related to the terms "biology" and "citizen." While they argue that Petryna's definition is too general, I argue that theirs is too general. Possibly stemming from the fact that they reportedly did not know of Petryna's work before writing their own, they have sought to distance themselves from any connection to her particular definition. As such, Petryna's definition of biological citizenship provides a more defined use of the term. As I demonstrate in Chapter 7, Petryna's definition of biological citizenship could expand to encompass how citizen's evaluation of their own behaviors allow them to align themselves with groups of citizens considered to be morally superior.

My research in Tuscany sheds new light on the way in which biologies can be governed. Tuscany's specific history has led to a healthcare system that consistently provides among the best maternal health outcomes in the country. The same cannot be said for many other regions where medical interventions, such as cesarean sections, are much higher. While anthropologists have focused on connecting local reproductive behaviors and ideologies to national, and even global, exchanges (Browner and Sargent, 2011), this literature largely disregards the level of the intra-national region. Parkhurst (2008) has suggested that regions are "good to think with," representing a level of political organization that is often ignored in preference for higher levels of analysis, such as the global or national. Such is the case with Italy, and I believe a regional analysis throws into relief the issues surrounding biological citizenship and the state.

What is the state and what level of state affiliation counts? As Carol Counihan (2004) reminds us, especially in Florence, localities and regional affiliations matter, sometimes more than affiliations to the state. By looking at how power and control of knowledge is localized in 
relation to pregnancy and childbirth in Tuscany, I argue that biological citizenship must be reexamined to include both a discussion of non-illness related health behaviors, as well as different levels of political affiliation. Krause's (2006) research demonstrates that Tuscan citizens used reproductive behaviors as a way to distinguish themselves from southerners. The tendency for northerners to differentiate themselves from southerners shows a preference in the North to aligning with a certain ideal Italy, to which the South does not conform. As I will show in Chapter 7, the ways in which women in Florence discuss maternity and care serves to divide them from the south, suggesting that biological citizenship in Italy is based less on a national affiliation than on regional affiliations. This reality demonstrates the need to expand analyses of biological citizenship beyond a study of just affiliation with a nation state. Rose and Novas (2005: 1) remind us that "The nation can no longer be seen as really or ideally, a cultural or religious unity, with a single bounded national economy, and economic and political migration challenge the capacity of states to delimit citizens in terms of place of birth or lineage or race." I believe that Rose and Novas's approach can be expanded beyond their intended connection with migration to broadening conceptions of which political and geographical demarcations citizens deem relevant. The Italian nation cannot be considered a singular cultural unit since the process of unification brought together several different regions with different languages, identities, and histories. The region in Italy, both as political divisions (Tuscany, Sicily etc.) and the North/South division, provide a much more promising level of geographical demarcation. As Li points out, viewing "governmental interventions as assemblages helps to break down the image of government as the preserve of a monolithic state operating as a singular source of power" (2007: 276). Li's vision of government is particularly fitting to the Italian context because of the decentralized healthcare system. Women's experiences with maternity care services in Italy 
depend less on the actions of the centralized government than on the region in which care is received.

Reproduction in Italy provides the opportunity to expand the connections between rationality, biopower, and biological citizenship. While anthropologists have extensively analyzed rationality and reproduction in relation to fertility, rationality in medical discourse surrounding maternity care provides a new avenue of analysis within the Italian context. As I will demonstrate, rationality-based medical discourse found in Italian maternity care documents does not accurately reflect women's experiences, although women themselves often discount their own experiences when evaluating the Italian healthcare system. The rationalist views women themselves hold about the differences in maternity care demonstrate the need to update the concept of biological citizenship within smaller geo-political demarcations, suggesting an overall reconsideration of how biopower is both produced and accepted among women in Italy.

\section{Agency, Socialities, and Narratives}

Foucault's deterministic view of power has been countered in concepts like habitus (Bourdieu 1977) or practice theory (Ortner 1994) in which culture and society are not seen as simply oppressive, but as a foundation for certain acts and choices. Anthropologists have come to see the body as not only a site for control, but the site of subjective experience and of an embodied self (Lock and Scheper-Hughes 1990; Biehl and Thomas-Moran 2009). As anthropologists sought to incorporate Foucauldian models of power into their own work, other social theorists, specifically from the field of sociology, became particularly important to providing nuances to understand the connection between the state, society, and agency.

Ortner (2006) suggests that starting in the 1980s there was a shift in anthropology away from Marxist ideas. For structural Marxists, "social and cultural phenomena were to be 
explained largely by being referred to systemic/structural mechanisms of one sort or the other." (Ortner 2006:466). This shift in the 1980s, however, coincided with the English translation of Pierre Bourdieu's highly influential book Outline of a Theory of Practice. Around this time, Ortner suggests there was an increase in "the calls for a more practice-oriented approach" (2006: 466). These practice-oriented approaches stressed the importance of individual actors and the actions they take. The practice-oriented approach that has surfaced in anthropology has focused on how power relations shape the actions of individual agents. Specifically, these approaches have focused on the complex interaction between structures of power and agency.

One important part of the new theory of practice was the emphasis on individual actors as the perpetrators of action. Previous scholarship in social theory and anthropology had focused on analyzing action that had happened at the level of the group instead of at the level of the individual (Ortner 2006). Instead of focusing on actions as being amalgamated into group action, action in practice-oriented approaches is situated at the individual level (Ortner 2006; Giddens 1973). Sherry Ortner defines "practice” as "anything people do" which she then qualifies by explaining that, because power is such an important theme in studying practice, "the most significant forms of practice are those with intentional or unintentional political implications" (2006: 470). This definition of practice displays the importance that power has in certain forms of practice-oriented approaches.

Giddens (1973: 55) defines agency and action as "involving a stream of actual or contemplated causal interventions of corporeal beings in the ongoing process of events-in-theworld" and also suggests action "does not refer to discrete acts combined together, but to a continuous flow of events. Agency and action are meaningful acts that stem from an agent's engagement with the world. This definition gives the agent a certain amount of autonomy to make decisions based on experience rather than suggesting that structures completely constrain 
human action. Understanding agency within the context of birth in Florence also requires understanding Gidden's term of "structure," which he suggests is made up of "rules and resources, recursively implicated in the reproduction of social systems" (1973: 64). For Giddens, structure is like the framework upon which actors situate their actions. Understanding the continuous flow of events surrounding women's birth in Florence provides the foundation for understanding how and when the "rules" about birth are reinforced and resisted by women.

Further expanding on the concept of structure, Giddens formulates a theory of structuration in which structure is both enabling and constraining. Agency is not simply a set of completely novel actions, but is, instead, mediated by the social structure. The structure, however, is not completely determining, as individual actors can both act with some amount of freedom in the structure and can also change the structure (Giddens 1984). Without the presence of the social structure, a person would not have any concept of appropriate action to take. The social structure gives agents a foundation upon which to act. This foundation, however, defines the ranges of action a person can take. This foundation can be changed, however, through the assertion of individual agency. Structure and agency are a feedback loop, continually reinforcing one another. Giddens concept of structuration is well linked to women's experiences with maternity care in the Florentine context; however, I believe a refinement is required. The history of maternity care in Tuscany has led to several different physical structures (such as government hospitals and health clinics) that provide the foundation for the unique social realities of pregnancy and childbirth. Women consider hospitals in Florence to be the optimal site of the idealized natural childbirth without pharmaceutical interventions, an idea reinforced by a healthcare system which places labor and delivery care in the hands of midwives. For women who would like pharmaceutical interventions in birth, hospitals become a site for reinforcing the idealized view of a natural, non-pharmacological childbirth. The physical 
structure of the hospital becomes a place where certain ideas about birth are reinforced, suggesting that physical structures provide the space in which Gidden's concept of structure as rules can be enacted.

Another sociologist, as well as an anthropologist, whose work has been important to the study of practice and agency has been Pierre Bourdieu. Bourdieu had a similar analysis of structure and agency to Giddens in that he saw the social structure as shaping the types of action people could take. Bourdieu's developed the concept of habitus to better understand the relationship between the agent and social structure. Habitus is the concept that cultural norms are embodied and shape every action we can enact: "Habitus tends to generate all the 'reasonable,' common-sense,' behaviours (and only these)" (2010: 447). Bourdieu maintains that societies "produce habitus that are capable of generating practices regulated without express regulation or any institutionalized call to order" (1977:17). Habitus, however, is not simply a set of rules that each person in a given society learns. These rules are completely embodied, meaning these rules not only shape how we act, but how we perceive and interact with the world. Bourdieu claims that habitus "tends to guarantee the "correctness" of practice" (2010: 446), in which "correctness" means the behaviors which are socially acceptable. Habitus, in effect, gives actors the foundation to act, but only within the confines of acceptable social activities. Just like Giddens, Bourdieu sees social structure as enabling and constraining. But for Bourdieu, inscribed social rules, i.e. habitus, enable a person to act through providing appropriate modes of action and also constrains a person's actions by defining the appropriate actions that can be taken.

Giddens and Bourdieu both formulated concepts that were extremely important to practice- based approaches in social theory. They were also particularly important to practiceoriented approaches in anthropology because of their utilization of concepts of power. While 
theories of practice and agency involve a nuanced analysis of the relationship between structure and agency, symbolic interactionists explained that social structures "set conditions for their action, but do not determine their action" (Ortner 2006: 457). Practice theorists, however, suggest that the social structure has a much more determining effect on human action, incorporating ideas of domination and Gramsci's term "hegemony." Ortner suggests "what a practice theory seeks to explain is the genesis, reproduction, and change of form and meaning of a given social/cultural whole" while keeping a critical eye on power relations between dominant and subordinate groups. Practice theory is the practice-oriented approach that has permeated anthropology (Ortner 2006). Practice theorists are interested in the interaction between the reproduction of social structures and suggest that an analysis of these structures cannot be reduced into separate parts. As I demonstrate in Chapter 7, women's agency and choice surrounding epidurals demonstrates the ways in which hospitals reproduce beliefs about the value of natural childbirth over women's choices.

In defining agency in reference to reproduction, Lopez (1993) suggests that "presenting women as active agents of their reproductive decisions does not suggest that they are exercising free will or that they are not oppressed, but that they make decisions within the limits of their constraints" (1993: 300). Lopez's assertion suggests that social situations can severely limit actions afforded to women and having control over reproductive decisions gives women a way of asserting their agency. The assertion of this agency over reproductive decisions allows women to transform how they view their futures (Lopez 1993; O’Dougherty 2008). While Lopez and O'Dougherty suggest that agency is not always an exercise of free will, childbirth in Florence demonstrates that certain populations have more access to exercise agency as free will under specific circumstances. The social situation in Florence provides some women with the 
opportunity to assert their agency, while denying other women theirs. In Florence, the hospital becomes the space of differential support for agency.

As discussions of agency form an integral part of research on government and power, it is important to have a deeper discussion of the role of state structures and institutions. Not only do institutions and structures impose or provide the foundation for certain behaviors, they often provide the physical space in which behaviors can be enacted. Would government recommendations be able to eliminate the sociality among pregnant women? If anthropological research on reproductive policies suggests anything, the answer is no. But can they create a space for the reshaping of existing behaviors? Yes. Healthcare institutions in Florence provided the physical space for the creation and reaffirmation of the social bonds between pregnant women. These structures, however, are located in a specific local history of values relating to childbirth. In these instances, powerful institutions provide the foundation for social behavior because of their appropriateness to the socio-historical context and such connections must be represented as such.

As practice theory and agency became a way of countering deterministic Foucauldian ideas of power, anthropologists also moved towards understanding how control over the body was not controlled solely by the state. Elizabeth Krause's $(2005 ; 2012)$ research on low fertility in Italy shows that government goals can often be at odds with local reproductive beliefs and economic circumstances. While the low birth rate in Italy was construed as "pathological," by government officials, aims at increasing the fertility rate were unsuccessful because they did not understand the behaviors and ideologies behind the limited reproduction of Italian women (ibid.). Women and healthcare professionals, however, have sought to circumvent state control over birth in various ways such as rejection of biomedical birth training (Sargent and Bascope 1996) or leaving medical facilities when faced with legal intervention (Irwin and Jordan 1987). 
Anthropologists have also shown how certain reproductive decisions, particularly tubal ligation or the decisions to undergo a cesarean section, demonstrate acts of agency on the part of women. (Lopez 1994; O’Dougherty 2008; Béhague 2002). Those decisions, while construed as agentic, are not always the desired choice, but the best choice available (Lopez 1994). In this line of thinking, Lock and Kaufert (1998) have argued that a focus on countering deterministic models of power with discussions of agency obscures the many non-medical circumstances that influence women's reproductive decisions. Providing wider social and economic contexts to women's reproductive decision provides the opportunity for anthropologists to move beyond discussions of power and agency or resistance.

Understanding women's reproductive decisions beyond a model of power and agency provides space to further interrogate how sociality impacts women's experiences during pregnancy and childbirth. Paul Rabinow's concept of biosociality suggests that experience of bioilogical realities is not always a dichotomy between power and agency. Rabinow's elaboration of biosociality was a reaction to changing concepts of illness (2006). His work on the Human Genome Project provided the foundation for what he called the ability of "nature [to] be modeled on culture understood as practice.” (Rabinow 1996: 99). What was formerly considered natural, like DNA, becomes constructed as something with a shared social aspect. Rabinow (1996: 102) echoes this in the following example:

It is not hard to imagine groups formed around the chromosome 17, locus 16,256, site 654376 , allele variant with a quinine substitution. Such groups will have medical specialists, laboratories, narratives, traditions, and a heavy panoply of pastoral keepers to help them experience, share, intervene, and "understand" their fate.

Genetic technologies formed the foundation of a new social structure based on the new "facts" of medicine (Rabinow 1996; Franklin 2012). At the same time, anthropological study of new reproductive technologies (NRTs) was in its infancy, but anthropologists saw the biosocial 
implications of these practices. Anthropologists began to focus on the intersection of biosociality and kinship in relation to NRTS (Franklin 2012). Much like Rabinow's (1996) suggestion that new genetic technologies would reorganize kinship around the biosociality of shared illness, NRTs provided a reimagining of the family and kinship. IVF allowed families to simultaneously disrupt the biological processes and maintain the biological materials which form the foundation of kinship in the West (Franklin 2012).

The implications of these NRTs, however, do not always provide a foundation for a shared biosociality. As Rapp's (2000) work on amniocentesis showed, the recognition of shared biologies did not always promote sociality among expectant mothers, as personal histories and personalities motivated women's sociality decisions. Differences in women's desire to create biosocial connections suggested that reproductive technologies often provide ambiguity in the social and kinship implications of reproduction. Franklin (2014) refered to this ambiguity as the paradox of NRTS

the more explicitly literal we have become in our ability to talk about the precise features of genes and the more accessible this knowledge has become through mechanisms such as the internet, the more uncertain it seems we are about the meaning of this information or what to do with it. (2014: 246).

Rapp's work shows that biosociality based on NRTs is not as simple as the reformation of social groups based on genetic information. Unlike Rabinow who thought that new genetic technologies would lead almost directly to a specific type of sociality, cultural contexts and women's personal histories have shaped the very ways in which biosociality is used or disregarded (Franklin 2012).

The cultural contexts surrounding biosociality can often lead to a level of secrecy or silence surrounding reproduction and reproductive technologies. Biosociality is not always culturally facilitated, as Robert (2008) notes that infertility in Peru was not something discuss. Peruvian women were not necessarily pressured to keep their infertility secret, they simply do 
not feel the need to discuss the topic. In contrast, Allison (2011) showed that talking about infertility in Ireland was made difficult by ideologies normalize fertility and motherhood. Infertility clinics were sometimes difficult to find, suggesting that the secrecy was promoted even within the healthcare system. Irish women were often only able to discuss topics of infertility through the anonymity of internet sites (Allison 2011). Faria (2018) notes a similar trend of secrecy in the biosociality among women seeking infertility treatments in Mozambique. Infertility was potentially a source of shame and grounds for divorce, therefore, women chose to keep their infertility or their search for fertility treatments private. Women often were required to travel for IVF treatment and during these travels or in clinic waiting rooms, women helped each other cope emotionally with and provide information about possible treatments. These connections often served as temporary networks that dissolve once women conceive (Faria 2018).

The secret sociality brought on by infertility provides a slight departure from the work of Rabinow and the work of many other anthropologists studying biosociality. Anthropologists studying the biosociality created by reproductive technologies often do so through the lens of kinship (Franklin 2014). Rabinow specifically envisioned biosociality as a new creation of family ties centered around illness (1996). Allison and Faria's work, however, showed the importance of sources outside of the family. Silence surrounding infertility required women to be highly selective in their sociality. Sociality was not necessarily provided through the family and required broader social connections. This type of biosociality provides women the support and information specific to their reproductive needs. In Chapter 5, through my theory of reproductive sociality, I elaborate more clearly how Rabinow's concept of biosociality must be reconsidered within a reproductive context. 
Just as biosociality forms the foundation of an elaboration of how illness is experienced in the context of people's social lives, narrative puts that experience in the words into larger cultural context. Narrative is a form of anthropological inquiry that provides connection between the individual's thoughts and feelings and their social context (Maynes et al. 2012; Mattingly1998a). Anthropology has a history of narrative analysis that started with life histories as a type of salvage ethnography of the culture of Native Americans under threat from settlers' westward expansion (Brettell 2006). Work on narratives and life histories grew into the use of narrative writing on the part of the anthropologists (ibid). Works like Nisa: The Life and Words of a !Kung Woman (Shostak 1981), Translated Woman: Crossing the Border with Esperanza's Story (Behar 1993), and We Have Already Cried Many ears: The Stories of Three Portuguese Migrant Women (Brettell 1995) demonstrate the different ways narrative and life histories can be employed through the guiding hand of the anthropologist. Abu Lughod famously experimented with narratives and representation in her book Writing Women's Worlds: Bedouin Stories (1993), which became a critique of anthropological writing itself. The use of these narratives gave form not only to the lives of the anthropological subjects, but to the many different connections and lived experience of the people anthropologists study.

In medical anthropology, a prominent source of analysis is the illness narrative. Narratives allow patients, particularly those with chronic illnesses to make sense of their illness (Kleinman 1988) and serve as a way to create explanation of patients' experiences receiving healthcare (Mattingly 1998a). These narratives are set within a context of newly discovered illness and patient's reimagining of their lives. There is, however, one area of healthcare where this focus on illness is less than ideal: pregnancy and childbirth. While pregnant women find themselves in the same liminal category as the newly ill, pregnant women are not ill. Despite the historical tendency in biomedicine to treat pregnant women as ill, anthropologists have devoted 
significant research to dispel such notions (Martin 1987; Davis-Floyd 1992). Analysis of pregnancy and childbirth provide a new avenue to discuss narratives related to health and the body.

This is why I elicited birth narratives. While I consider this to be a somewhat introductory elicitation of these types of narratives, the process was very enlightening and allowed me to see holes in current ways of exploring topics in medical anthropology. Narratives can provide a counter to misleading assumptions made among subordinate populations (Maynes et al. 2008) While I would not characterize my research population as subordinate compared to the subjects of most other anthropological research, I would say that the birth narratives serve as a way to counter recommendations from the Italian government. These narratives also serve as a way to counter the rationalistic rhetoric so often found in clinical research. In the context of pregnancy and childbirth, these narratives not only allow women to detail their own meaning but provides a way for that meaning to be understood within the larger birth context of Florence, Italy.

\section{Medicalization and Reproduction}

"Medical culture has a powerful system of socialization with exacts conformity as the price of participation" (Martin 1987:13)

Concepts of control and agency in research on the state are mirrored in the literature on medicalization and reproduction. Medicalization is the increasing inclusion of activities previously considered social issues enables an increasing control over the public by medical institutions (Crawford, 1980; Foucault, 1972; Conrad 1993). Horatio Fabrega (1980) notes that unlike in many small-scale societies in which all people share most medical knowledge, increased stratification led to specialization among medical professionals and led healing practices away from their formerly social focus. Following this shift, the medical field became problem-centered and healthcare took on the more individualistic doctor-patient model. 
"Problems" such as mental distress, reproductive practices, and physical beauty have increasingly shifted away from being perceived of as social problems toward being perceived as medical problems (Crawford, 1980, Foucault 1972).

This idea that certain conditions are medical "problems" extended into the domain of birth as well. In the early literature on childbirth, anthropologists often focused on the institution of the hospital. As Emily Martin (1987) details, when women moved from birthing at home to birthing in the hospital, women became increasingly seen not as humans with emotions but as mechanical bodies. These bodies, however, did not act as reliably as machines, thus requiring significant technological intervention to make the bodies conform to the ideal behavioral models. These interventions must come from somebody trained, such as a doctor. Martin notes, "The woman's body is the machine and the doctor is the mechanic or technician who 'fixes it." (1987: 54). Following a similar vein of analysis, Robbie Davis-Floyd (1992) further elaborated on the ways in which institutional constraints of the hospital unnecessarily medicalize birth. DavisFloyd (1992) suggests “American biomedicine's cures are based on science, effected by technology, and carried out in institutions founded on principles of patriarchy and the supremacy of the institution over the individual" (1992:46). Davis-Floyd continues with the creation of the woman-centered wholistic and highly medicalized technocratic models, espousing the benefits of the wholistic model above the technocratic. Both Martin and Davis-Floyd demonstrate how the process of medicalization of childbirth is inextricably tied to both the institution and the control of knowledge of the body. This analysis was an expansion of Brigitte Jordan's (1978) concept of authoritative knowledge:

that among all the cases where a [cesarean] section occurred and in which an outcome assessment could be made, there was not a single one in which the [cesarean] section, in retrospect, appeared necessary. I began to seriously think about why and how it was the case that women's knowledge didn't count, while medical knowledge carried the day (1993 [1978]: 149). 
Furthermore, Jordan realized that there were competing domains of knowledge present in certain childbirth situations. Jordan (1978: 152) concluded, "for any particular domain several knowledge systems exist, some of which, by consensus, come to carry more weight than others, either because they explain the state of the world better for the purpose at hand or because they are associated with a stronger power base".

Davis-Floyd and Sargent (1997) expand the processes through which authoritative knowledge gains authority: [the] dismissal of alternative forms of knowledge firmly cements the authoritative knowledge as the "way things (obviously) are" (1997: 56). These processes, however, require certain circumstances to come to fruition. In the northern territories of Canada, interventions in the difficult living conditions of the Inuit are discounted as a possible means through which to ameliorate high negative birth outcomes and the government requires all Inuit women to be evacuated to for highly medicalized hospital births in the south (Kaufert and O'Neil 1990). While women often try to resist by not going to the outpost clinics until as late in their pregnancy as possible, women's knowledge and experiences are discounted particularly because they are almost powerless in the face of medical authority that is aligned with government policy. The ways in which medical authority aligns with government power is also seen in Irwin and Jordan's (1987) work on court-ordered cesarean sections. Out of nine case studies of marginalized women, five were forced to have cesarean sections because a doctor deemed it necessary based on general protocol. Irwin and Jordan (1987) suggest that the respect given to medical authority from other institutions means that the power of the healthcare system and doctors is likely to grow through alignment with the government, but this is not always the case. Midwives are often portrayed in anthropological literatures as a tool for the resistance to medical authority. While the Mexican government required midwives to attend a training class on medicalized birth methods, these women chose not to use their new education when they went 
back to their home communities (Sesia 1997). Similarly, Sargent and Bascope (1996) found that Mexican midwives selectively used the biomedical procedures only when they were deemed relevant. In the face of unnecessary medical interventions, anthropologists have deemed midwives as the advocate of birthing women. As I will demonstrate, the presence of midwives within the Tuscan healthcare system does not necessarily mean they provide a resistance to biomedical or doctor's authority but must be situated within a system that promotes natural childbirth.

This early research on medicalization and childbirth contains the clear message that, midwife-assisted childbirth was the idealized counter to highly medicalized hospital births. For midwives and activists like Robbie Davis-Floyd and Michelle Cheyney, the demedicalized setting of home birth is an obvious focus of research. My research also presents the unique opportunity to interrogate the very way that gender and demedicalization of childbirth is constructed in anthropological literature. Drawing on Judith Butler's concept of gender performativity, MacDonald (2006) critiques the way feminists and anthropologists consider medicalized birth as a barrier to the true state of natural birth. MacDonald considers this move back to a true, natural, state to be just another cultural construct (ibid). Without the idea that home birth is a truer natural state, midwife-assisted natural childbirth becomes just another culturally accepted obstetrical option (ibid). Anthropological research that espouses the role of the midwife in creating women-centered healthcare often do so by promoting the home as the natural place for childbirth (Davis-Floyd 1992; Cheyney 2011). As such, these anthropologists reify both the gendered culture/nature dichotomy and the public/private dichotomy in which women are associated with the less valued natural and private spheres (Ortner 1972; Rosaldo 1974). My research shows that defining women-centered care cannot come solely from this gender ideology, but from women's own experiences. While midwives can offer woman- 
centered care, disregarding hospitals as a site for potential demedicalization of care does a disservice to women who would like a midwife-assisted birth, but in a hospital. My research mirrors what Wendland's (2007) describes as a "feminist obstetrics" in which birth is not dichotomized between the sentimentalized midwife assisted model and the highly medicalized hospital-based model. Maternity care in Italy provides the optimal site of analysis to deconstruct this dichotomy. Women preferred midwives to doctors and considered them essential to the birth process, but not at home. It is worth noting that Tuscany is a somewhat unique model set within a context in which midwives are respected within the medical system and women have the ability to access high quality midwifery-based services at no cost. Midwives are built into the very structure of the medical system, which the women preferred. Maternity care in Tuscany represents a demedicalized model that fits well into local cultural beliefs and preferences surrounding pregnancy and presents a means to break down the dichotomy between highly medicalized hospital birth and midwife assisted home birth.

In the past two decades, research on medicalization has moved beyond models of authoritative knowledge, toward more subtle analysis of power and more nuanced understandings of how medicalization has been received in different contexts. Georges's (2008: 275) work on the differential acceptance of reproductive technologies in Greece shows that, "despite a more or less common package of discursive and technoscientific features that tend to travel together, medicalization is not a simple one-directional process or a juggernaut of inevitable uniformity and standardization.” Authority can no longer be understood as residing only within medical institutions, but as an intersection between medical knowledge and local, historical, values (Georges 2008). Anthropologists have also extended this into other domains such as cesarean sections where the decision to have a cesarean section may be based on the desire to only suffer the pain of a cut and not also the pain of labor, since women expect doctors 
to perform a cesarean (Kuan 2010). Cesarean births may also be chosen because in certain economic environments, a cesarean is symbolic of high-quality care (Béhague 2002). Research on women's reproductive behaviors has moved away from a focus on the institutional constraints and local resistance towards a more nuanced examination of the connection between broader economic and political constraints impact women's navigation of medical authority, medicalization, and historically situated local ideologies about healthcare and the body.

Because of its historical context, Italy's paradoxical reproductive practices, and continued regional variation, has received substantial attention from anthropologists. One of the major areas for analysis of medicalization in Italy is reproduction. Work by Schneider and Schneider (1996) and Krause (2005) show the ideologies behind fertility in the country, whereas Whitaker (2000) and Horn (1994) detail the ideologies and lingering effects of the Fascist control over the reproductive body. Work specifically related to childbirth has focused on professionalization and the contested relationship between midwife, physicians, and an increasingly medicalizing profession. As birth became under the purview of physicians, midwives were ostracized and demonized by the increasingly medicalized profession (Triolo 1994; Whitaker 2000). To remain viable, Italian midwives fought to become medicalized, but in doing so, Triolo (1994) argues that they became relegated to second-class subordinates of doctors and the hospital structure. While Szurek's (1997) work on midwifery and childbirth in Tuscany shows a similar marginalized status of the midwives in the ' 90 s, she also shows how midwives within the medical system were essential in patient advocacy and resistance to medicalized birth. These examples show the contested processes that medicalization pushes forward. I argue that from the patient's perspective, the quasi-medicalization of midwives in Tuscany is an essential aspect of achieving a safe and desired birth. While anthropologists have often looked at the medicalization of childbirth as an easy dichotomous split between physicians and midwives, I hope to show that 
other factors, such as concepts of place and safety that are ingrained in local concepts of birth, are as important to maternity care as the medicalization of the professionals themselves.

\section{Conclusion}

The theoretical approaches discussed in this chapter are crucial in situating my research in an anthropological context. Further, as I will show, placing the realities of pregnancy and childbirth within the Italian and Tuscan context provides a way for not only understanding the differences in maternal health outcomes, but how evaluations maternity care becomes an ideological battleground. State power and control merge into women's experiences in unexpected ways. Agency is determined not by a woman's relative position of power, but by her acceptance or rejection of the beliefs of midwives in the space of the hospital. Women's evaluations of their own care and experience suggest that rationalist constructions of women's maternity care decisions are inappropriate. Women, however, also accept such rationalist discourse when discussing healthcare throughout Italy, demonstrating that medical discourse is not so easily overcome through experience. Women's simultaneous acceptance and disregard of their own experiences while espousing deep seated ideological stereotypes about the South suggests that the concept of biological citizenship must include a discussion of geo-political divisions beyond the state. A study of pregnancy and childbirth in Florence, as presented here, offers a counterpoint to some accepted theories of reproduction and power as well as an opportunity to expand them. 


\section{CHAPTER 3 \\ METHODS}

This research was based on a set of ever-changing goals and designs. Through multiple trips to my field site over several years, I have explored many areas of Italian culture, bureaucracy, response to "outsiders," and regional difference and I have emerged with a substantial data set addressing State recommendations for maternity care and women's lived experiences of childbirth. In this chapter, I offer my own narrative of fieldwork and attempt to convey the complexity of anthropological field research, as well as hurdles that were specific to Italy, to my topic, and to my experience.

My dissertation is based on three periods of fieldwork adding up to 18 months of time in Florence, Italy. The first period was from October 2015 to October 2016, the second period was from March 2017 to June 2017, and the third period was from September 2017 through November 2017. I also conducted preliminary research in Florence for two months in 2012. Since my project goals changed significantly between this preliminary research and the start of my official research, the data have not been used in this project. The interviews, however, did provide a foundation for understanding the system of maternity care in Florence, as well as the material for designing interview questions.

In this preliminary project, I interviewed 12 midwives and 10 new mothers, one pregnant woman and one doctor. The group of women was made up of both Italian women and expats. It is through this research that I realized three crucial things about my research. The first realization was that I wanted to make pregnant women and new mothers the focus of my research. While the midwives' perspectives were valuable, it was the women who provided a 
more complex picture of the realities of childbirth in Florence. The second realization I made was that I only wanted to interview Italian women. Originally, I considered interviewing women from other countries because I thought this might provide a way to compare Florentine women's experience with another group; however, it became clear that they had many different expectations of birth based on their country of origin and that this was not the type of comparison I was interested in making. The third realization I made was that cesarean sections were on the minds of healthcare professionals. I knew that cesarean sections were high in Italy, but healthcare professionals were very concerned about the much higher rates in the south. Some of their discussions even aligned with literature on rationality and reproduction that other anthropologists had documented in Italy (Krause 2012; Schneider 1998). After some information from midwives prompted a deeper examination of the issue, I decided to shift my focus toward cultural influences on cesarean sections.

\section{Initial Research Design \& Lessons from the Field}

After a reappraisal of maternity care trends in Italy, I shifted my research design from midwife-based care to a comparison of the cultural explanations for the significant difference in cesarean sections (in some instances almost 3 times higher) between the north and the south of Italy. This required the addition of another field site to the original research plan. Based on cesarean section data for the different regions of the country, I decided to add Naples as a field site.

My original design was a site-based approach (Arcury and Quandt 1999) comparing two hospitals, one in Florence and one in Naples. I had planned to interview expectant mothers in their second and third trimester, midwives, and gynecologists who would all be sampled through the hospital. I had picked a potential hospital in each city based on three factors. The first factor 
was the size. Both hospitals were large enough to provide some sort of anonymity to the healthcare professionals and patients. It also would provide me with a larger pool of potential research participants, which would allow me to reach more easily my desired number of interviews. I thought these factors would make it easier to write my dissertation and to gain approval for my research from the hospital. The second factor was the cesarean section rates. I chose the two hospitals because they were the largest hospitals in the area to have rates close to the cesarean section rates in their respective regions. These hospitals were meant to be a type of microcosm of what was happening in each region. The third factor was both of these hospitals were public university hospitals. I did not want to compare a university hospital to a hospital run by the local health agency (ASL), as the structures are slightly different. I also did not want to do research in a private hospital because they were generally smaller and primarily served the small parts of the population that had private insurance. I thought that a university hospital would be a place for me to more easily blend in since healthcare practitioners would be used to having to teach students about how the hospital operates, which was essentially my role.

After two months of preliminary research, in Naples in the summer of 2015, just before I started my fieldwork in Florence, I realized that my project might not be possible in Naples and searched for another hospital in the area that fit my criteria of number of births and high cesarean section rates. I found another hospital in a small city called Salerno, a 30-minute train ride from Naples. Unfortunately, after three months and one final two-week trip in November of 2015, I realized that my research design was impractical in the context of hospital births in Naples and Salerno. This design was flawed for many reasons that I had optimistically thought would not be an issue. First, I was far too optimistic about the idea that the doctors in the hospitals in the Naples area would be willing to allow me to do research in the maternity ward. While I did not present this as a study of cesarean sections, but rather a study of birth practices throughout Italy, 
the chief gynecologist I met with in Salerno eyed me suspiciously as I talked to a head midwife. I never even got to meet with a doctor in Naples; instead I was simply rebuffed by the secretary who repeatedly told me the doctor was "on vacation" or that "he'd call me." I believe my inability to make connections with doctors who supported my research was at the heart of my difficulties in gaining access to the most introductory aspects of the hospital even considering my research. I can only assume that they did not want a stranger evaluating a system that they knew had poor maternal health outcomes and saw me as a threat to their practice.

The other flaw in this research design was the lack of consideration of bureaucratic issues. While the hospital in Salerno seemed promising due to a connection I made with a prominent midwife, I was stymied by her inability to officially validate the research. I was not able to get a signature on official documents required by SMU's IRB. I was also concerned that the midwife would use her position to try to coerce midwives into participating in my research. Due to these ethical and bureaucratic issues, I decided that doing research in a hospital in Naples or Salerno was unrealistic and I decided to focus my research in Florence. This required a redesign of my research plan to incorporate only one hospital in Florence. Although it was still in a site-based design, I lost the comparative aspect with the south. Instead, I replaced this comparative aspect with a stronger emphasis on maternity care recommendations from the national Ministry of Health (Ministero della Salute). This adjustment to my research was not difficult, but I had not considered the possibility I would also have insurmountable bureaucratic issues in Florence since the hospital had been so accommodating during my preliminary research. One prominent doctor had also expressed interest in my project and vowed to help when I returned. While the doctor did help me to navigate the administrative aspects of the hospital, it took him several weeks to find a potential administrator to guide me in editing my research proposal before sending it to the ethics committee. Unfortunately, during this period this 
administrator went on personal leave and I was unable to reach him through email or the phone. I also tried to reach the doctor who had helped me, but he had a history of slow responses, even by phone, and he did not respond. It was at this point that I realized a site-based approach at a hospital would be impossible without one to two years of time spent in Italy trying to gain approval. $^{5}$ At the end of March 2016, I started to redesign my project to focus on sampling women from the local community. From March to May 2016, I redesigned the project to focus primarily on women's experiences with pregnancy, childbirth, and other maternity care services provided in Florence.

My original site-based research design also included the possibility of interviews with doctors. Through discussions with hospital administration it became clear that doctors were concerned with being identified in my research and might not be willing to participate. When I changed from a site-based approach to my final design, my focus on women's experiences, along with the stated difficulty in finding doctors to interview, caused me to reconsider the possibility of interviewing doctors. After completing 30 interviews, it became clear that my new focus on information seeking behaviors in healthcare recommendations moved the focus of women's experiences away from interactions with doctors and almost completely toward their interactions with midwives. Because of the time constraints at the end of my research, I decided that midwives would provide the most beneficial interviews to further elaborate women's experiences.

While my original project focused on pregnant women instead of new mothers, I quickly realized that expectant mothers could only answer the majority of my interviews within the last

\footnotetext{
${ }^{5}$ This was in fact confirmed, as one of the head midwives texted me a week before I had to leave the field, saying that I could start the process of getting approval to do research in the hospital. While I had changed my sampling method, I had continued to try to get access to the hospital I, however, could no longer stay in the field.
} 
two weeks of pregnancy or after birth. In light of this realization I changed the focus of my research to new mothers who had given birth within six months.

After having done preliminary research in Italy, I knew the adjustments I would have to make to my daily life and I initially welcomed many of them enthusiastically. Unfortunately, I did not expect that a midwife would only provide access to a hospital unofficially or that a hospital would be filled with a bureaucracy that nobody understood. I knew that the lifestyle was different, but it was almost as if I did not understand that this would seep so heavily into certain institutions. I naively saw these institutions were safe because of the nature of what they did and the fact that they were located in a Western country. As Michael Herzfeld (2016) reminds us, however, the West is an idea designed for a very specific purpose which does not always accurately portray life in individual countries.

These experiences also provide a reminder of the strange position anthropologists inhabit in the field. Nader (1972) recommended "studying up" as a counter to the plethora of anthropology focused on people who often were often seen as inhabiting spaces of less power or authority than the well-educated anthropologist wealthy enough to live in a community for a year. This idea though suggests that power and relations with people in the field are always hierarchical. My interviews with women showed both my inherent position of power as a researcher with the luxury of ample time and resources to conduct my interviews whenever and wherever necessary, but also as a person in need of the experiential expertise that only these women could provide. While conducting these interviews, I was also confronted with the reality that I had very little power in the face of a large institution like a hospital which required the navigation of a bureaucracy that was almost unintelligible to even the most powerful doctors and midwives. As Evelyn Blackwood (2000) reminds us, power is not always so easily mapped out or defined by hierarchical structures. As anthropology has moved from small villages and rural 
areas to the larger, sometimes unwieldy setting of major cities, the recognition of the multiple positions of power an anthropologist inhabits is crucial for the success of our research.

\section{Final Research Design}

\section{Recruitment and Sampling}

For the first three months of my research project, I sampled new mothers who had given birth in the preceding six months. A total of 14 women were sampled using this technique. It quickly became apparent that this time restriction was unnecessary; therefore, I expanded the search criteria to mothers who had given birth in the last year and a half. I decided to expand the amount of time after birth based on interviews done with women with more than one child. In these interviews, many women who have given birth to their first child two to three years prior to the interview talked about their previous births in enough detail to convince me that women could remember their birth experiences well after six months. I was convinced that six months was an unnecessary limit to put on my sampling strategy.

For women to participate in the research, they had to be a native Italian who had given birth in Florence within a year and a half of the interview. I used multiple methods to attract participants, which provided me with a rich sample of new mothers with different birthing experiences. The primary method I used to find women was through online posts on Facebook groups. I searched in Italian for groups using the words, "mother," "mom," "parent," "Florence," "child," and "birth" to find groups, although some groups were suggested by other research participants. For the majority of my research, I posted only to groups that seemed neutral when it came to birthing choice (excluding groups that promoted natural childbirth, for example); however, toward the end of my research, when it became apparent that the role of the midwife was integral for almost every woman in my study, I decided to expand my search to two 
midwife and natural childbirth related groups to better understand the experiences of women who sought extra care from private midwives. There were many online groups that did not require permission to post and I posted on these whenever I thought necessary. If a site was not open to general posts, then I asked permission from the administrator to post to the groups. None of my posts were ever deleted by an administrator or group organizer after posting, which leads me to believe that I never overstepped my bounds with regards to the appropriateness of my posts.

\section{Ethics Review}

All participants gave consent with a signature on a consent form written in Italian. Women were also verbally consented with a summary of what I considered to be the key points from the consent form. I made sure to verbally summarize the consent form to ensure that women knew that they did not have to answer any questions and could stop at any time. Women were assured that their participation was voluntary, and every effort was made to accommodate their time and wishes. Women were also offered compensation for their time in the form of money or coffee, but most women declined. Because the IRB considers pregnant women a vulnerable population, I was very cognizant of the need to maintain their comfort throughout my research. Utlimately, only two women were interviewed during pregnancy and after birth. My interactions with pregnant women also extended into observations in midwifery run classes and activities I, however, was not conducting an ethnography of highly sensitive subjects and maintained the similar level of courtesy to pregnant women as would be expected in any social exchange. 


\section{Recruitment Sites}

While most posts were reposted once every one to two months over the course of my research, some of the small groups yielded no interviews and were abandoned after three posts. Many of the groups which yielded several interviews in the first one to three posts, later dropped in recruitment numbers to only one or zero. Because of this, I constantly searched for new groups to post and often asked participants for group suggestions.

My second recruitment strategy was to ask participants to give my information to others they knew who had given birth recently. While Bernard (2011) notes this type of referral often does not produce a representative sample of the research population, to reach certain mothers it was necessary. One of the factors that creates a less representative sample in the referral method is the tendency for people to create relationships with other similar people. While many women in my research didn't have close friends or family who were pregnant at the same time, they did have access to groups of women in the same prenatal classes. Many of my participants attended prenatal classes with other expectant mothers in the same stage of pregnancy. WhatsApp, a popular messaging app in Europe, was commonly used by these mothers to chat create group chats. This allowed women to message each other through the app for advice and support. Most of the women whom I asked to give my information to friends sent a message to these group chats. These group chats based on prenatal classes were the primary way women referred me to other pregnant women they knew. Obtaining additional referrals through these numerous chat groups was essential because, as I was repeatedly told by my participants, Florentines often are suspicious of outsiders whom they do not know. Having a personal recommendation from a friend who participated in my research provided me with a final sample of participants who may not have replied to my other recruitment methods. These women would have been hard to find, which is one of the circumstances in which Bernard (2011) recommends referral sampling. 
While new mothers in Florence are not hard to find per se, many women were not motivated to participate without a referral. Referral sampling allowed me to mitigate the bias of having only participants who were highly motivated to contact a foreign researcher.

There were two other methods which yielded relatively few participants. The first was flyers I put up in announcement boards in local parks and at local schools. While I put flyers in every park I could find in Florence, there were two main parks that yielded the only participants I got from this method. This was most likely due to both of the parks' large size and the number of women who passed the signs at the gates. The other method of recruitment I used was personal interactions. Through this method, I was able to conduct one interview with a woman who showed me an apartment for rent. While I was able to recruit three women through face to face interaction (two who saw me putting up flyers and the one who showed me the apartment), communication with all other 51 participants and potential participants took place through email and text. Women were initially asked where they wanted to meet to accommodate their comfort level. If they had no preference, I recommended a place to do the interviews. All interviews took place at a participants' home, in a café, or a park based on their availability. While participants were told they could stop for any reason, no woman stopped due to emotional distress, although three women who started to cry were reminded of this option. One woman had to stop when she received a call from a frantic husband at home with a sick baby. This interview was resumed three days later. 


\begin{tabular}{|c|c|c|c|}
\hline $\begin{array}{l}\text { Facebook Groups } \\
\text { (Neutral Birthing) }\end{array}$ & $\begin{array}{c}\text { Facebook Groups } \\
\text { (Midwifery Birthing) } \\
\end{array}$ & Parks & Flyers \\
\hline $\begin{array}{l}\text { - Mamme a Firenze } \\
\text { Dintorni } \\
\text { Babbi e Mamme a } \\
\text { Firenze } \\
\text { Babbi, Mamme, e } \\
\text { bambini di Firenze }\end{array}$ & $\begin{array}{l}\text { - Figli Della } \\
\text { "Margherita" Centro } \\
\text { Nascita Firenze - } \\
\text { Careggi } \\
\text { - La Mia Ostetrica } \\
\text { Facebook Group }\end{array}$ & $\begin{array}{l}\text { Parco Pettini } \\
\text { Burresi } \\
\text { - Light Il Giardino } \\
\text { di Marte }\end{array}$ & $\begin{array}{l}\text { Elementary } \\
\text { School on Via } \\
\text { della Chiesa }\end{array}$ \\
\hline
\end{tabular}

In the end, I interviewed 54 women. Three interviews were excluded from data analysis due to the discovery during the interview that the women did not meet the criteria due to miscommunications about ages of the children and their Italian nationality. The data from one woman was excluded because she was only interviewed during pregnancy and she was interviewed too early in the second trimester to answer many of the questions. This left me with 50 interviews for data analysis. Two of these women were interviewed during pregnancy and after birth, one at the end of her second trimester and one a week away from her due date. All others 48 women were interviewed only after the birth.

In addition, three private midwives were interviewed. While I had wanted to interview some midwives from a public hospital, the barriers of not having access to a hospital made finding these midwives difficult. I was able to recruit private midwives through a relationship I had made with a local midwifery organization. 
Table 3.2: Number of participants interviewed in each time period before and after birth

\begin{tabular}{|l|l|}
\hline $2^{\text {nd }}$ Trimester & 1 \\
\hline Two weeks before due date & 1 \\
\hline Birth to 3 months & 2 \\
\hline 3 months to 6 months & 5 \\
\hline 6 months to 12 months & 23 \\
\hline 12 months to 18 months & 20 \\
\hline
\end{tabular}

Note: While I include 50 women in my research, the interview total adds up to 52 for the two women I interviewed both before and after birth

\section{Participant Observation}

There were several activities related to prenatal experience that I could easily observe and participate in. The most significant were the prenatal classes offered by a local midwifery group. While I was not participating as a pregnant woman, I was participating as somebody who wanted to learn more about pregnancy and childbirth in Florence. I was also able to observe the unique emotions experienced by pregnant women that allowed me to understand that pregnancy can be highly idealized in retrospective interviews.

I was also able to participate in certain group activities commonly frequented by pregnant women. I often met mothers for interviews in parks where they met other mothers to socialize. Parks were dotted with groups of three to six women and their children. I participated in prenatal aerobics classes offered by the midwifery group, commonly attended by women in their third trimester. In these classes, women often stretched, did mild exercise, and meditated. These were meant to prepare women's bodies for childbirth and relax expectant mothers. I also participated in prenatal yoga classes attended by a mix of women in their second and third trimesters, often as another means of relaxation. Like prenatal aerobics, these classes were designed to prepare the body for childbirth and relax the expectant mother but also provided slightly more strenuous 
exercise. Though I have never been pregnant, these activities provided me with a bit of relaxation from the stress of doing research. The added stress of living in a hectic Italian city was its own form of participant observation as well. Through living my daily life in Florence, I was able to observe how expectant and new mothers are treated in public spaces such as public transportation, stores, and parks.

My life living in a large city made traditional participant observation methods difficult. I lived in many different places in Florence, some due to the timing of my housing search and some due to my multiple shorter trips. Most places were in the center of Florence or near the center. I had decided on this because my research required me to commute by bus to many different parts of the city and the center was a much easier place to find central bus stations. On reflection, this was perhaps not the best place to live to do research on pregnant women, as most families had moved out of the center or been pushed out by rising prices due to study abroad programs. This meant that the majority of areas of the city where I lived were primarily inhabited by tourists or non-Italian students. Because Italian landlords are hesitant to rent to Italians (protections for renters mean any long-term tenant is hard to evict), I was only able to find single apartments or apartments with other foreign students.

Housing in Florence is very limited and there were very few ways to find rooms for rent from families, which would have been preferable. In the middle of my fieldwork, I researched possibly becoming a part-time live in nanny to provide more participant observation. After talking with a few other nannies, I decided against this search as many convinced me that problems that can come with being employed and living with a family would potentially interfere with my research.

Regardless of my living situation, there were two activities which I regularly did alongside other Italians: grocery shopping and riding the bus. Both grocery shopping and riding 
the bus showed me a glimpse of a very hectic Italian life. They both also showed me a glimpse into societal relations with pregnant women and children. I saw small Italian children in the store only a handful of times in the 18 months that I lived in Florence, no matter whether I was in the center or just outside of it. While seeing pregnant women or new mothers on the bus was uncommon, they were almost always accommodated even more so than the elderly who both shared special access to reserved seats. In fact, the elderly were almost always the ones to offer their seats despite young women's objections. This glimpse of life in Italy allowed me to see the unique ways in which pregnant women and new mothers are treated.

Anthropologists have long espoused the importance of "being there" (Geertz 1988) as a way of understanding just what life among the people we study. This often is not without its issues, as Cohen (2000) reminds us that where we live and who we associate with can potentially bar us from finishing our research. Geertz (1973) also reminds us that chance encounters, with the police in his case, can open up new connections as well. These examples remind us of the unforeseeable aspects of our methods. But they also suggest an anthropology in which chance plays a large part. I suggest that daily encounters are important for understanding "being there," but the small, rural settings of traditional anthropology provide the opportunity for chance encounters to be far more impactful than in urban centers. As Kenny and Kertzer (1983) reminded us over 30 years ago, urban anthropology in Europe comes with a different set of challenges and presents us with a different type of analysis. Most of my participant observation had to be much more deliberate. I had to make connections with local organizations to allow me access to their semi-private worlds of women's experience during pregnancy. Social engagements with participants outside of my official research had to be planned. Living in a city meant that spatial divisions and built environment mediated defined certain space of my research and I had to be more attentive to how they were used (Pardo and Prato 2016). Parks designed for 
social engagements provided multiple purposes: as a site for recruitment, a place for meeting for interviews, and a space for observing socializing among mothers. Traditional participant observation provided me a view of life, but intentional activities were absolutely necessary for a deeper understanding of my project.

\section{Interviews}

I conducted all interviews with expectant mothers, new mothers, and midwives using a semi-structured model. Questions were designed based on preliminary research but were adjusted based on pilot research after the site-based approach was discarded. The new set of questions was designed to compare women's experiences to recommendations from the Ministero della Salute (2010; 2012) and the Regione Toscana (2011; 2014; 2016a; 2016b). Documents were downloaded from the websites of both government entities. During the design of the research questions, these documents were preliminarily analyzed to find major themes. Themes included the connection between fear and childbirth decisions, the connection between different types of information and fear, women's interactions with healthcare professionals, and information seeking behaviors.

The interviews were divided into sections of questions related to pregnancy, childbirth, and opinions of maternity care services. The first eight interviews happened before the August holidays when almost all Italians left Florence for vacation. This natural break in my research gave me time to reassess. While certain questions were meant to elicit whether women experienced feelings of fear during pregnancy (a decision made to limit women's emotional distress), I decided the questions were too subtle and made them more direct. I also changed the organization to be based more on the natural progression from pregnancy to childbirth from a 
scheme based more on anthropological theories of choice and interactions with healthcare professionals. My interviews averaged almost 60 minutes, with a range from 31-87 minutes.

The structured part of the interviews allowed me to get both quantitative and qualitative data that was analyzable using quantitative methods, but the ability to depart from a rigid question structure allowed me to better understand women's experiences through their own explanation. It also allowed me to elicit birth narratives from the women (discussed later). This was not always easy, as some women were far more forthcoming than others, but departing from the rigid question scheme, I was able to get many very vivid stories of women's experiences.

The semi structured interviews were meant to triangulate certain types of information and certain questions were repeated in slightly different iterations to make sure I was obtaining nuance about women's experiences. This allowed me to find points in which women seemed to idealize their experiences and to provide multiple opportunities for women to remember more fully their experiences.

While retrospective data can present its own biases, many women claimed that an event like pregnancy is hard to forget even years after the event, which I believe mitigated some of the bias. Pregnancy, however, takes place over many months. While a longitudinal study of pregnancy would have mitigated the bias of retrospective data, this was not a type of research project I thought was feasible. Pregnancy was also not the sole focus of my research, which it would have become in a longitudinal study. My observation of pregnant women in social interactions and in the prenatal classes allowed me to clarify and expose some of these biases in women's accounts, such as the way pregnancy was retrospectively highly idealized. This has allowed me to engage with my data recognizing the complex emotions women have of such important life events. 
I also did not find my questions easily answerable by pregnant women unless they were in their last week of pregnancy. Finding women in the last weeks of pregnancy was not feasible given my methods. Because of this, the questions would have had to have been asked in an interview after birth, effectively making the data retrospective.

While this project was focused on childbirth and pregnancy, many women were concerned with other aspects of maternity care. The last question of all the interviews was, "is there anything else you would like to say about your experiences." Many women responded that I had asked them all the questions that they thought were relevant to their experiences, but some women provided more information. Much of this information was based on post-natal maternity care and threw into sharp relief the differences into prenatal and post-natal care and services in Tuscany. These issues are, therefore, taken up in detail in Chapter 7. Women's concerns over post-natal care were not unexpected since the women I interviewed were dealing with such issues at the time of the interviews.

During the last month of my research I discovered that my landlord's mother was a midwife. Due to her hectic schedule as a private midwife and her time at their second home outside of Florence, I was unable to officially interview her. I was, however, able to talk to her about my research and she offered me some information that helped me to understand my research and redesign my questions for the midwives I interviewed.

\section{Eliciting Birth Narratives}

Eliciting birth narratives was not always easy. My prompt for eliciting these stories was either "what happened after you arrived at the hospital" or "what happened when labor started". Either prompt was used depending on where women gave birth and how women responded to the questions preceding the prompt. Not all women responded to the open-ended prompt as 
readily as others. Some women responded with a very short timeline of the objective events. Some women had to be prompted through the entire answer until I felt I had enough information. Some women talked in depth about their experiences, their emotions, and their relations with others in the room.

For some women, I had to ask detailed questions before or after the prompt. Because of this, I have designated two different aspects of the birth narrative to deal with such an issue: the core narrative and the clarifying details. The core narrative is the moment women self-identified their labor started or when they responded to the prompt "what happened after you arrived at the hospital" until the moment of birth and the hour after. Many women also mentioned their false labor and the many days after labor, but since these were not always clearly or coherently tied to their birth narrative, (some women had contractions, went to the hospital, and were sent home), I claim they are important to the narrative, but as clarifying details. I agree with Mattingly's (1998) claims that coherence and timeframe are not necessarily the point of a narrative; however, her work deals with people constantly reshaping their narrative due to their constantly shifting identity as a recovering patient. This is not the case for birthing, which is a finite event requiring a more nuanced reconsideration of the relationship between time and the progression of the story. Clarifying details are contextual details which I considered important to my ability to understand and situate women's explanation of their lived experience. Clarifying details offer a glimpse of the points in which anthropological analysis meets lived experience

The birth narratives serve as a way to discuss not just the elements women experience in labor, but how they all fit together in a larger social context. I analyze these narratives in conjunction with specific questions I later asked about their experience. In doing such, the narratives become a way to explain not only what medical interventions women experienced 
during birth, but also how those interventions fit within women's concept of reality and subjective experience.

\section{Other Considerations}

\section{Language}

All interviews were done in Italian. I studied Italian for a year during my undergraduate studies, which is the same coursework taken in two years at SMU. I also travelled extensively through Italy and sharpened my speaking skills during my preliminary research in Florence. My professional Italian was improved through careful study before the language proficiency exam required by my department. I also completed a more extensive test for the Fulbright application, which required an intermediate level of comprehension in reading, writing, and spoken Italian.

The consent form and original questions were edited by a native Italian English-language teacher at a medical school in Salerno. Subsequent versions of the questions were edited by an editor at an Italian language school in Florence. The few questions that were added after both of the editing sessions were checked by Italian friends living outside of Florence at the time of my research. Even though this was the process, several others involved in my research, including a hospital midwife and administrator, an Italian tutor, and some participants suggested edits. Many of these suggestions, however, contradicted one another and I used my best judgment as to which recommended edit would be better for my research.

While language competency is essential for anthropological research, the ability to translate from one language to another is only one aspect of research. I had no trouble with participant's understanding of questions, but there were occasional communication barriers based on the types of questions I wanted answered. Some women didn't always understand how to respond to abstract questions about their opinions. Some questions that were translated 
correctly from English to Italian contained concepts that weren't so easily translated. In the end, all questions were comprehended even if some of the participants required a more significant discussion of what I was looking for. All women were cordial and helped when I stumbled with my Italian. Some women expressed support even when I struggled specifically because they had studied language and understood how hard it could be. As anthropologists such as Lee (1969) and Bohannon (1966) have shown, our desire to communicate is not only filled with our own assumptions of how to speak in another language but also the with the local cultural scripts that provide the foundation for communicating far beyond simple translation. Their examples also remind us of the generosity, kindness, and patience of the people who are willing to open up their lives to us strangers.

\section{Timing of the Project}

While I discussed earlier the departures of my project from traditional methods, it is worth noting the unique timing of my research. This research required significant use of technology (emails, texts, digital map navigation systems, Facebook) that would have rendered my methods impossible in the past. Just 15 years ago, I would not have had the ability to find new mothers via Facebook, as it was available only to university students until 2006, although I imagine that even 10 years ago, the use of Facebook groups would have been far more sporadic. Referral recruitment of participants took place through WhatsApp which required participants to have a smart phone, a technological development of only 10 or 15 years ago. I don't know how technology will develop and enhance my research techniques down the road, but it is possible that my methods will be rendered obsolete. This echoes the call of Margaret Mead ([1928]1973) claim that she would not be updating her famous work Coming of Age in Samoa because it showed Samoan life nearly 50 years earlier and that was her goal. While Mead's decision 
highlights the foundations of anthropology as an investigation of the exotic, this advice contains particular prescience in current times. New research and medical advancements change the landscape of birth every year and should be noted for any study undertaken in the future in the same city on the same subject. At some point, this dissertation becomes a cultural history of what I heard, saw and lived.

\section{Limitations and Bias of Research}

There were some limitations to the study. The most glaring is that I was not able to observe a birth. Even in my original site-based approach, I was unsure that I would be granted permission to observe such an intimate moment. After moving beyond a site-based approach, I came home from the field and analyzed my original data set. After doing such, I realized the importance of prenatal classes. When I went back into the field the second time, I discovered that there was a new head of the maternity department at the hospital from which I had originally sought approval. After meeting with him, I thought I would have access to observe the classes in the hospital, since he thought I did not have to go through a full ethics committee review for such observations. After nine months, however, it became clear that the hospital did not have a sufficient mechanism for accepting researchers who were not aligned with an organization in Florence, including even other Italians. The hospital bureaucracy in Italy was insurmountable even after more than 18 months of seeking approval.

To counter this, I gained approval from a local midwifery group to observe their prenatal classes and attend some midwife related events. However, upon my return to Italy a third time, the head midwife would not let me observe the classes again. Based on my interactions with her in the past, it is possible that she could not understand my desire to move beyond interviews into participant observation. 
I believe this was a larger issue due to the nature of my research. It was clear that some people thought it was strange that I was not aligned with an Italian university or conducting my research in a hospital. Independent research common to anthropology was clearly not well understood and I was often told that I should go to the hospitals to find women to recruit for my research. Based on conversations with some participants who suggested Florentines were particularly cautious relating to foreigners, I believe having a research project not easily understood in Italy may have biased my sample slightly towards women who were very motivated to participate, especially from Facebook groups with which I had no personal connection to. I countered this as best I could through finding people I had met in person or people through my other participants. There may also have been some bias since I was not pregnant and didn't have kids. Some participants asked me this and made comments that it was hard to understand the feeling of being pregnant without experiencing it. Being an expectant mother in a prenatal class would have also offered me a unique experience relating to that part of my research.

This also brings me to a final bias of time. It's very possible that certain women selfselected themselves out of my research because they thought they had no time. There were in fact a handful of women who had communicated with me interested in being interviewed, but with whom I could not find time to meet. The difficulty of time and new motherhood was even clear when two women had asked to become language partners only to later lack time to meet.

\section{Data Analysis}

\section{Interview Data}

Interview data was collected through recordings and participant observation data was collected through written notes. I transcribed half of the interviews and the other half were 
transcribed by a native-Italian speaker from Florence. All transcriptions were reviewed a second time to correct mistakes. Interview data was transcribed in multiple batches. The first 20 interviews were transcribed after the initial year in the field. During this transcription, themes emerged from the data. These themes were used to create a preliminary outline for further data analysis. After fieldwork was finished, the initial themes that emerged were again checked. There were several Yes/No questions in the interview and these were entered into an excel file for easy data analysis.

A codebook was created with 10 major themes, each containing 3-5 sub themes (see appendix). All data was coded using this codebook. Themes were extracted and frequency noted Basic counts and percentage calculations were used to convey quantitative data. All data is rounded to the nearest whole number. This process was also used to find example quotes for each theme. Data was primarily coded inductively, particularly for themes related to experience, however, data coded deductively was done to compare government recommendations to women's responses.

\section{A note about incomplete data sets}

While I tried to get a "yes" or a "no" answer, some women were reluctant to answer in such black and white terms. While this happened rarely, some women answered, "I don't know," or, more rarely, they simply declined to answer. Thus, some of my data sets do not equal 50 and this discrepancy is noted as a "note."

\section{Government Recommendations}

Government recommendations include documents from the Tuscan government and Italian national government. Recommendations were coded for general themes relating to 
women's decisions and behaviors relating to pregnancy and childbirth. These served as the basis for the creation of several questions. These codes were compared to the codes generated by the interviews

\section{Field Notes}

Participant observation data was collected in several ways. During observations in childbirth classes, notes were written in a notebook and later typed. During participatory events, such as yoga and prenatal aerobics, writing during the activity was impossible and notes were either written in a notebook or typed into an app on my phone. All other unexpected observations were typed into an app on my phone either during the moment of observation or at the first moment I was able. Field notes were initially coded deductively to compare to the codes from government recommendations and interviews, however, new themes were also noted.

\section{Conclusion}

The point of so many methodical strategies is to discover how women's experiences during pregnancy and childbirth subvert assumptions and incomplete resources behind maternity care recommendations. It has required a mix of qualitative and quantitative methods, including birth narratives, to show how the realities of maternity care do not reside in a simplistic causal relationship between certain factors. Instead, I hope to reveal the rich tapestry of women's emotions and experiences.

The research was sometimes difficult due to bureaucratic regulations beyond my control. Changing the methods that I spent three years designing in what seemed like the blink of an eye caused an unexpected re-evaluation of my research project and myself as researcher. Hurdles I did not expect appeared around every corner and often seemed impossible. But the changes to 
my research also caused me to confront some very important assumptions I had made before entering the field. While I was designing my research as a comparative project, I fell into the trap of making some of the same assumptions of the healthcare recommendations I was trying to discredit. I had subconsciously accepted that information was a means of empowerment for women and hypothesized that the difference in cesarean sections between the north and the south was due to differing social circumstances that impeded some women from receiving certain sources of information. Through my research I have found this to be a much more complex issue, but I may not have realized my own biases had I not had to change my research and confront my assumptions about Italy.

Some of these assumptions were rooted in the idea of the homogeneity of the western world. My assumptions of the relative homogeneity of the West or global north caused me to believe that institutions would function at a similar level of efficiency as in the U.S. I chose to do research in Italy particularly because it was part of the West. I thought this would afford me many of the same levels of efficiency of everywhere else I had lived

My initial research design was optimistically unrealistic, but in the failure and changes, I was able to see through my assumptions and see the larger picture. Seeing traditional forms of socialization in traditional spaces, like the park, allowed me to see the ways new modes of socialization, such as the WhatsApp group texts, created traditional forms of social support in new ways. This would not have happened had I chosen to use my original site-based approach. They also showed me how the different ways of doing anthropology in an urban setting open new avenues for looking at things such as my power and the power between women in my research and the hospitals. Through the unique experience of studying women's experiences in urban Florence, I was able to see the complexities of life and maternity in the city. 


\section{CHAPTER 4 \\ THE UNIVERSAL REPRODUCTIVE BODY: GLOBALIZED RATIONALITIES IN MATERNITY CARE DISCOURSE}

As I detailed in Chapter 2, the unique history of Italy has led to significant differences in economic development and public healthcare infrastructure throughout the country. This chapter provides an analysis of Italian and Tuscan maternal healthcare guidelines to better elaborate the ways in which global scientific discourse about maternity care filters into different levels of government documents. While Tuscany maintains some of the best maternal health outcomes in Italy, medical discourse does not reflect greater attentiveness to women's experiences with the healthcare system. By following State discourse on maternity care from the national to the regional level, I demonstrate how medical discourse in fact devalues women's experiences in order to create a universal reproductive body that is, theoretically, easy to control through healthcare intervention.

Discourse surrounding reproduction is often imbued with meaning far beyond simple medical recommendations (Wynn and Trussel 2006; Krause 2005). My analysis of these documents conforms to what Mary Bucholtz (2003: 57) defines as critical discourse analysis: "an approach to language as a primary for the production and reproduction of ideology". Studying the discourse of government documents is necessary because "institutions are of special concern to critical discourse analysts... because of their disproportionate power to produce and circulate discourse" (Bucholtz 2003: 57). Within the Tuscan context an analysis of the discourse requires the inclusion of not only national recommendations, but also regional recommendations. 
Local government documents can employ slightly different rhetoric and provide different recommendations that may push women's experiences aside. The focus on clinical trials and statistical data in this rhetoric diminishes women's complex subjectivities in pregnancy and childbirth. Women's agency is pushed aside in favor of simplistic models of women's reproductive behaviors. Women are construed as a set of characteristics and behaviors that must be managed in order to achieved desired health outcomes. Management of women by doctors, and to a lesser extent by other healthcare professionals, is the key to decreasing negative healthcare outcomes.

Institutional moves away from more subjective models of human behavior are also influenced by the increasing reliance on global sources of information to build guidelines and recommendations (Aginam, 2005; Storeng and Béhague 2014). Checklists and initiatives from other countries form the foundation of many of these healthcare documents. Differences created by wealthier countries or even regions within Italy, which invest more into their healthcare systems, are completely ignored as possible factors influencing maternal health outcomes. Regional variation in healthcare preferences and usage are glossed over as the use of clinical data creates an assumed universal reproductive body devoid of cultural context. The Ministry of Health considers clinical research and statistical analysis of population trends to be far more valuable than women's experiences in creating maternity care recommendations. Through a reliance on clinical and statistic data, the Ministry of Health is able to create a reproductive body that is presumably transportable anywhere without regard for local reproductive realities. Thus, in the rhetoric of global biomedical data, the erasure of women's experiences, and inadequate attention to regional variation constructs a very particular and limited reproductive body. My analysis of the medical rhetoric in this chapter will form the foundation of an argument that local 
Tuscan realities, even in places where health outcomes are good, are not necessarily able to penetrate increasingly global ideas about the reproductive body.

\section{National Recommendations}

As part of the European Union, Italy is a significant economic force on the world stage. With a GDP of 1.93 trillion dollars in 2017, Italy has the $9^{\text {th }}$ highest GDP in the world and the $4^{\text {th }}$ highest in Europe, behind Germany, the United Kingdom, and France (World Bank, 2018). While Italy is a major economic power, the recent low birth rate led some economists and demographers to suggest that such a birth crisis could have a negative economic impact (Krause 2005). Anthropologist Elizabeth Krause $(2005,2001)$ has detailed the way the government has tried to intervene in the crisis. By implying that a low birth rate could have disastrous effects on the economy, Krause argues that government officials and demographers portray the low birth rate is "irrational" and "pathological" to the further growth of the state (Krause 2012: 365). Krause further argues that this rhetoric surrounding the low birth rate ignores important aspects of women's lives, such as changing local economies and gender roles, which impact women's desires to have children (2005). Italy's declining fertility demonstrated the ways in which discourse and arguments concerning reproduction did not have a strong basis in women's actual experiences and behaviors.

Just as demographers' discourse surrounding fertility decline showed a lack of recognition of important factors, like economics and gender roles, government documents relating to maternity care, particularly cesarean sections, provide an unrealistic representation of the factors influencing women's reproductive decision making. As previously stated, Italian cesarean section rates are among the highest in Europe. Italian cesarean section rates vary along the cultural divisions between the North and the South of the country, with rates almost three 
times higher in some southern regions. The Italian Ministry of Health released two sets of guidelines meant to summarize available literature to develop the best possible recommendations for improving maternity care and decrease cesarean sections. While the guidelines acknowledge the regional difference in cesarean section rates throughout the country, these documents make assumptions similar to the discourse that Krause examined surrounding fertility decline that omits important circumstances that influence women's reproductive decisions. Analysis of these guidelines illustrates the alignments and conflicts between the local Tuscan context and the Ministry of Health guidelines of maternity care throughout the country.

In 2010, the Italian Ministry of Health released the first set of guidelines aimed at reducing cesarean section rates in the country. The guidelines are found in the "Clinical Governance, Quality, and Treatment Safety" section of the Ministry of Health website. It is a subsection under the topic of "Themes and Professions." On the page of "Themes and Professions," the Ministry of Health states that:

Information, data, activities, services, standards and all the essential documentation are collected here on the themes of the Ministry Offices. It is a constantly open communication channel in continuous development and improvement, dedicated to operators and stakeholders, but also to those citizens who wish to deepen topics central to the good functioning of public health.

While the statement above demonstrates the intended audience to be primarily comprised of healthcare professionals, the guidelines are also available to anyone with access to the internet. The guidelines are part of a larger effort on the part of the Ministry of Health to improve healthcare throughout the country.

The following section is a summary and analysis of the recommendations within these guidelines. The guidelines from the national government are divided into two parts: Cesarean Sections: An Appropriate and Conscious Choice (2010) and Cesarean Sections: An Appropriate and Conscious Choice Part 2 (2012). The first recommendation was not labelled as Part One, 
but for the sake of clarity, I have decided to reference the guidelines published in 2010 as Part One because the guidelines published in 2012 are labeled Part Two. Part One is a general review of the material published within these publications, which offer very broad recommendations that centered around interactions between healthcare providers and pregnant women. Part Two is a more comprehensive document that focuses on medical definitions and recommendations aimed primarily at healthcare professionals. In the section that follows I analyze Part One of these guidelines. I later analyze a small section of Part Two that is also relevant to this project.

Analyzing the discourse surrounding doctor-patient interactions highlights the larger cultural ideologies surrounding women's roles and behaviors in childbirth and pregnancy. The two sets of guidelines highlighted here were chosen because they specifically relate to a reduction in cesarean sections. They were also chosen because they are complex documents that detail a very intense process and the use of specific literature to come to the conclusions. These guidelines allow me to trace the types of knowledge that are used and valued in making healthcare recommendations. There are only three guidelines related to pregnancy and childbirth: Cesarean Sections: An Appropriate and Conscious Choice (2010); Cesarean Sections: An Appropriate and Conscious Choice Part 2 (2012), and Physiological Pregnancy (2011). I have chosen to analyze only the first document in its entirety and a section in the second that directly relates to doctor patient interactions. I have decided not to analyze the entire of Cesarean Sections: An Appropriate and Conscious Choice Part 2 (2012), and Physiological Pregnancy (2011) because there are no other sections in either of these documents that discuss doctor patient interactions. The documents are highly technical and because I did not do an ethnography of the development of technical knowledge, I am unable to make significant claims about these parts. A future analysis of all of these documents in their entirety could provide 
valuable information regarding what types of medical procedures are valued by healthcare practitioners in Italy, but that is not the goal of this project.

\section{Guidelines Part One: Cesarean Sections: An Appropriate and Conscious Choice}

The authors define the reason for the guidelines as such: "the guidelines represent an instrument that allows a rapid transfer of knowledge, elaborated from biomedical research, of daily clinical practice" and "represents a synthesis of the best available knowledge." (ii) The guidelines start with a discussion of the cesarean section rates in Italy. Enrico Garaci, president of the Istituto Superior di Sanità, suggests in his introductory note that cesarean section rates have "reached an alarming level." (2010: 3). The authors proceed to a discussion of the rise of cesarean section rates from $11 \%$ in 1980 to $38 \%$ in 2008 . The authors also recognize that Italy's cesarean section rate is higher than the WHO's suggested maximum of $15 \%$.

Research to create the recommendations for the guidelines was conducted through an online search through several databases (see List 4.1 in appendix for databases). The search was conducted by research experts in the document area of the Istituto Superiore di Sanità. The research criteria included a range of publications dates from between 2002 and 2008. Languages were limited to Italian, French, English, and Spanish. The research team's original document search produced 714 titles that were reduced to 50 using a methodological checklist from the Scottish Intercollegiate Guidelines Network. The original panel met to review the literature and make final recommendations, which were reviewed by a final panel of experts comprised of a coroner, a bioethicist, and an obstetric gynecologist.

The document is divided into six major sections: Summary, Introduction, Methods, Offering Information and Support to Women, Informed Consent for Birth Through Cesarean Section, and Maternal Request for Cesarean Sections. The last three provide the bulk of the 
relevant information to the analysis of this chapter. The guidelines start by discussing several differences in cesarean section rates throughout the country. First, regional differences in cesarean sections are acknowledged, which the authors note fall along the north-south divide.

The authors connect this north-south trend in cesarean section rates to a similar trend in perinatal mortality, which is also higher in the South. Second, the guidelines recognize the difference in cesarean section rates between private and public hospitals, with private hospitals having higher rates of cesarean sections. Third, they connect the rate of cesarean section to the size and births per year of the healthcare structure, (hospitals, birth centers etc.) such that structures with more births per year had a lower rate of cesarean sections.

The guidelines continue with a discussion of the processes used in creating the guidelines. The authors say that "the scope [of Part One] is to improve the relations between women and healthcare professionals involved in the course of assisting birth" (2010: 14). First, a panel was convened and was comprised of a general medical doctor, a specialist in gynecology and obstetrics, a midwife, an anesthetist, a neonatologist, a psychologist, a coroner, an epidemiologist, a methodologist, and a representative from an association for women who work in birth. The panel used the British National Institute for Health and Clinical Excellence guidelines titled "Cesarean Section" (2004) to aid in the creation of the topics to be included and researched in making the Italian guidelines. The final three sections, Offering Information and Support to Women, Informed Consent for Birth Through Cesarean Section, and Maternal Request for Cesarean Sections, contain the medical discourse the provides the material for further analysis. Each section is comprised of the medical discourse and final recommendations. For analysis of the documents, it is important to differentiate the two aspects. The medical discourse comprises the summary of research documents. The medical discourse is written in paragraph format and provides text for rich analysis of subtle beliefs about women's decisions 
and their interactions with the healthcare system. The recommendations are laid out in bullet point format and do not offer the same rich text of analysis. Because of this format, my analysis focuses on the medical discourse, but mentions the recommendations if and when they relate to the medical discourse. See table 4.2 in the appendix for the specific recommendations offered in each section.

The Disappearing Woman: Global Information and the Creation of the Universal Reproductive Body

Part One of the guidelines demonstrates several constructions of reproductive behaviors, both on the part of women and doctors. The following quote represents many of the assumptions and values about women and doctor's reproductive behaviors:

Among the factors most able to negatively affect the ability of pregnant women to express judgments on childbirth, tocophobia is reported. In several studies, in fact, the fear of labor and delivery is associated with a higher percentage of caesarean sections planned in the absence of clinical indications and is indicated as potentially capable of affecting the subjective experience of childbirth. On the other hand, the demand for caesarean section by women is often supported by the unfounded conviction of a more favorable balance compared to vaginal birth, in terms of the relationship between benefits and damage to one's own health and the child's health.

In this regard, several studies highlight the crucial role of the doctor, and more generally of health professionals, in guiding women towards conscious and informed decisions, even if this task is not always performed at best. In a Scottish study, women complain about the shortage of information received and a certain passivity of physicians in complying with their birth preferences, without proposing alternatives or providing elements to support one or the other decision. In other cases, it is the doctors themselves who direct the choice of women to the caesarean section, as an effect of a defensive practice (19).

The first part of this quote begins with the presentations of a phobia about birth. Tocophobia (tokophobia) is defined as a fear of birth that is so severe as to cause avoidance of birth (Hofberg and Brockington 2000). While Hofberg and Brockington's research represented the first attempt to accurately define tokophobia in medical literature (2000), other definitions also include "an irrational fear of birth" (Miller Keane, n.d.). By initially associating an extreme and irrational 
fear of birth with women's desires to have a cesarean section, the recommendations set up the connection between extreme fear and a desire for cesarean sections. Fear is considered the primary reason for which women make poor decisions in childbirth, leaving other social factors and personal preferences unacknowledged. Thus, information is seen as the means through which women can achieve optimal health outcomes in childbirth. As I will show in the next chapter, fear is a much more complex issue that has less of an influence on women's childbirth decisions that the Ministry of health implies.

Women's fear of birth is then connected to information, particularly a lack of. Women need information to be able to make appropriate decisions. But women must not just be given information, women must be "guided" by healthcare professionals. Doctors in particular are seen as the means through which women can overcome their fear and make appropriate decisions. By referencing the Scottish study specifically, the Ministry of Health suggests that women are actively looking for information and would like a more authoritative doctor to not only provide information, but to give to women guidance and opinions related to childbirth decisions.

Doctors, as an extension of the hospital, are also considered a source of authority. In discussing informed consent with pregnant women, doctors are not only meant to provide women with information about cesarean sections and the contents of the consent form but are also meant to "evaluate any problems that are difficult to resolve, including through specialist consultations and any second opinion" (2010: 24). The possibility of judicial intervention is discussed as an option for women who refuse the doctor's suggestion of a cesarean section, although the specific conditions under which this could be utilized are not stated. None of the recommendations, however, suggest that the woman is possible of making her own medical decisions or that she can appoint a family member as an advocate. The focus on the doctor- 
patient dyad in this document suggests that the doctor is the main actor during pregnancy and especially childbirth, while simultaneously negating the importance of the woman and her family. As I will show in later chapters, women's evaluation of their experiences demonstrate that the documents misrepresent the role of both the doctor and the woman's family. Only once does this document reference the importance of a woman's family member and that is through the suggestion that the "couple" to reflect on their childbirth decision.

Doctors' authority also extends into the area of knowledge control and dissemination. Doctors and healthcare professionals are considered the purveyors of appropriate information relating to childbirth. The authors use research to portray the decision to have a cesarean section as one based on women's fear and lack of information. The quote "diverse studies underline the crucial role of the doctor, and also in general healthcare personnel, in orienting women toward informed and conscious decisions," (2010: 19) demonstrates that doctors, above any other potential healthcare administrators, are the most important source of information for women's childbirth decisions. Information from healthcare professionals is construed in this medical discourse as the means through which positive birth outcomes are achieved. The term “information" appears 18 times within the article, although their own review of the literature found that research focusing on the connection between women being informed and a reduction in cesarean sections was inconclusive. Regardless of this, the authors portray information provided by doctors as the key to reducing cesarean section rates.

A crucial aspect of providing women with information to decrease cesarean section rates is the type of data used. The Ministry of Health states that "the guidelines represent an instrument that allows a rapid transfer of knowledge, elaborated from biomedical research of daily clinical practice" (ii). "Biomedical research" is also tied to randomized clinical trials (RCTs). RCTs are highly controlled experiments in which participants are randomly placed into 
either a control group or an experiment group. While anthropologists have critiqued the utility of the very narrow results created by RCTs, anthropologists also suggest that "the randomized controlled trial (RCT) is considered Western medicine's most rigorous scientific test of a clinical treatment" (Smith-Morris et al. 2014). The word trial is used 6 times in the article and refers to a type of study on which the guidelines are based. Words such as "clinical indications" and "clinical motivations" are also found throughout the document. The Ministry of Health even states that data beyond clinical trials is suboptimal:

The main problem, underlined by the experts, is the availability of non-conclusive efficacy tests on the damages and benefits of caesarean section (elective and emergency) compared to the vaginal birth, since randomized trials on the topic are not feasible. for obvious ethical implications1. Therefore, the informative contents on the benefit / damage profile of the elective or emergency caesarean section with respect to the vaginal delivery are based on observational studies, often conducted on selected populations (23-24).

The Ministry of Health presents the use of research that is not a randomized trial as a "problem" a problem in creating effective information to disseminate to patients. This preference for biomedical research and clinical trials prevents the use of other types of data that could more accurately portray women's complex behaviors and decisions surrounding reproduction. The use of biomedical research also promotes the idea of woman as devoid of complex subjectivities or local realities. The preference for biomedical research aids in the construction women's bodies as a universal set of simple behaviors that can be intervened upon. The use of biomedical research also promotes a view of behavior as highly controlled, which suggests women's bodies and behaviors are simple enough to be changed during a doctor's visit. The "crucial role of doctors" (2010: 19) in informing pregnant women of their childbirth options means that by providing the appropriate information to women, doctors are able to intervene to achieve optimal birth outcomes. Just as Emily Martin (1987) showed over three decades ago, the birthing body becomes reduced to a simple machine in need of a fix from the doctor, only this time the birthing 
body is replaced by a pregnant body. The reliance on clinical trials and biomedical data suggests that the recommendations are developed within the framework of women's bodies as simple and easily intervened upon to achieve optimal birth outcomes.

The use of clinical and statistical data in the guidelines also serves to push the focus of the guidelines away from the realities of maternity care in Italy through the use of research on non-Italian populations. Table 4.1 provides a breakdown of citations by place of country/countries involved. The sources are divided into three main categories: sources based on Italian data, sources from global sources (such as the WHO, sources comparing European countries, or reviews of multi-country data), and sources from individual countries outside of Italy.

Table 4.1 Number and Type of Sources in Each Section of Part One of the Guidelines

\begin{tabular}{|c|c|c|c|c|c|}
\hline & Introduction & Methods & $\begin{array}{c}\text { Offering } \\
\text { Information } \\
\text { and Support } \\
\text { to Women }\end{array}$ & $\begin{array}{l}\text { Informed } \\
\text { Consent for } \\
\text { Birth } \\
\text { Through } \\
\text { Cesarean } \\
\text { Section }\end{array}$ & $\begin{array}{l}\text { Maternal } \\
\text { Request for } \\
\text { Cesarean } \\
\text { Sections }\end{array}$ \\
\hline $\begin{array}{c}\text { Italian } \\
\text { Sources }\end{array}$ & 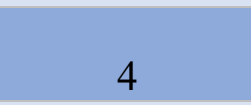 & 1 & 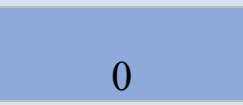 & 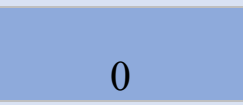 & 1 \\
\hline $\begin{array}{c}\text { Global } \\
\text { Sources }\end{array}$ & 2 & 0 & 0 & 1 & 1 \\
\hline $\begin{array}{l}\text { Extra } \\
\text { Italy } \\
\text { Sources }\end{array}$ & 0 & 2 & 18 & 12 & 18 \\
\hline
\end{tabular}

Table 4.1 clearly shows a preference in the guidelines for non-Italian sources. Out of the $60^{6}$ citations, 50 were based on data from other countries and four more were based on data from multiple countries. Only six sources were based on only Italian data and 5 of those sources were

\footnotetext{
${ }^{6}$ In the summary section I mentioned that the panel had decided on including 50 sources. The number 60 references actual number of citations, as some sources were cited twice
} 
in the first two sections, which did not form the basis of the medical discourse. In the three sections that formed the basis of the recommendations, only one source was based only on Italian data. The Ministry of Health's use of non-Italian sources to provide recommendations for Italians does not occur with a discussion of the impact of the differences in the healthcare systems or women's behaviors between other countries and Italy. Potential problems with comparing different healthcare systems is particularly apparent in the use of research from the United States where maternity care, and healthcare in general, are not guaranteed to all citizens. The economic and systemic differences could pose a significant problem in creating recommendations for expectant mothers and their interactions with healthcare professionals. The Ministry of Health could have conducted a research study or used expert knowledge from doctor's and midwives' practice, creating far more contextually appropriate guidelines.

Beyond the use of non-Italian sources to create the medical discourse, British and Scottish guidelines were used to inform the bibliographic search for sources. The guideline entitled "Caesarean Section" from the British National Institute for Clinical Excellence, was used in the first meeting to help establish the documents objectives. Articles in the bibliographic search were evaluated using guidelines form the Scottish Intercollegiate Guidelines Network. The very foundation of the guidelines was based on sources from outside of Italy. The problem with using these British guidelines is that the Ministry of Health does not suggest that the documents are used based on shared characteristics between the Italy and Britain. The Ministry of Health does nothing to contend with the divergent histories, politics, cultures, and languages of Britain and Italy, nor do they explain why the British sources were used. Such an oversight suggests that the Ministry of Health considers all biomedical research to be universal and notlocation specific. 
While the authors of the guidelines discuss clinical data that portrays the doctor as the ultimate authority figure relating to childbirth decisions, a few mentions of women as subjective human beings are mentioned. The Ministry of Health suggests that, "The solution proposed is that of an in-depth interview between the doctor and the woman, which will lead to a shared decision" (2010: 28). The meeting is one option in a series of multiple possible ways the authors suggest doctors can provide support to women. While this support is also tied to information and the interview is meant to "illustrate available knowledge" (2010:28) the language suggests a doctor-patient relationship that is much more equal. The authors also turn to the possible benefits to women when they suggest the interventions can "[reduce] the level of anxiety and fear related to birth, increase women's satisfaction with the information received, and improve the subjective experience of birth" (2010: 28). This section shows that while maternal health guidelines may focus on the ability of doctors to improve maternal health outcomes, the subjective experience of women is acknowledged at least in relation to consent. The lack of significant focus on women's subjectivities is not a new trend in research to move both medicine and public health interventions, especially maternity care, towards objective, evidence-based, medicine (Storeng and Béhague 2014; Wendland 2007). Within the Ministry of Health guidelines, a focus on objective and evidence-based medicine does not necessarily provide appropriate context specific healthcare interventions and recommendations.

Overall, these documents construct a reality of women's reproductive behaviors as relatively simple and dependent upon doctors. Doctors are portrayed as the most appropriate healthcare professional to provide knowledge about childbirth, even though my research suggests this is not the case in Tuscany. While women are portrayed as unable to make appropriate decisions about childbirth because they are emotional (i.e. irrational), doctors are meant to intervene during pregnancy to push women towards appropriate childbirth decisions. Reliance 
on statistical and clinical data, along with the presumed authority of the doctor, serves to suggest fear is the main reason women desire a cesarean section. Doctors can save women making these dysfunctional reproductive choices through targeted interventions meant to achieve a very specific set of goals. The use of globalized data further removes the recommendations from the local Italian context. While these themes suggest a move away from woman-centered care, a few brief acknowledgements of the subjective experience of women do suggest that the authors are somewhat aware of the humanity of their patients, a common theme I interrogate in the next section.

Guidelines Part 2: Cesarean Sections: An Appropriate and Conscious Choice Part 2

In 2012, the Italian Ministry of Health released a second set of guidelines. The Part One explains that a second set of recommendations was already being developed in 2010 and was meant to focus on biomedical indicators and practices rather than doctor-patient interactions. Unlike the first document, which was aimed at elaborating modes for reducing cesarean section rates through interactions between healthcare professionals and patients, the second set of guidelines was "dedicated to themes of appropriateness of surgical practice in care at birth." This guide skews far more toward the healthcare professionals' behavior rather than interactions with women. Because my research is based primarily on the experiences of women, I have decided to analyze only a small portion of the guidelines that deals directly with interaction between healthcare professionals and women during birth. Analyzing the medical guidelines as a whole could provide valuable insight into maternity care practices; however, that type of analysis is best suited for another project.

The sub-section I chose to analyze is titled "Emotional Support Offered to Women During Labor in Childbirth." It is part of a larger section titled "Interventions and Welfare 
Procedures During Labor in Childbirth.” The summary of data in this section starts with a discussion of the different types of support that women could receive in labor:

Common elements of this type of care support include: emotional support (continuous presence, reassurance and praise), information on the progression of labor and advice on coping techniques, comfort measures (contact, massage, hot and cold packs, appropriate intake of liquids) and support [for their decisions] (supporting women in expressing their preferences) (2012: 80).

While the Ministry of Health defines support in these ways, the authors are not always precise in which type of support they are evaluating. For instances in which the type of support is defined, I will indicate it; in all other cases, I will just use the word support and it can be assumed that the authors were also general in their writing.

Continuous support in labor is connected to a reduction in medical interventions in childbirth and to an increase in women's autonomy during birth: "Theories supporting the effectiveness of ongoing support are to improve the physiology of labor, control capacity and mothers' ability to reduce dependence on medical interventions" (2012: 80). Support is defined vaguely, only as "continuous," without any indication of the specific behaviors involved in this support. Social support is also valued not for the improvement of women's subjective experience, but the improvements to the biological process of birth. Reduced medical interventions are the only way in which women's choices and experience are deemed valuable.

The guidelines continue with a detailed review of birth support practices from Cochrane, a British group that "gather[s] and summarize[s] the best evidence from research to help you make informed choices about treatment" (Cochrane). Part 2 of the guidelines continue to a discussion of the different types of health outcomes that were assessed in this study. A list of those outcomes can be found in Table 4.3 in the appendix. The findings from this study showed that women given continuous support in labor were less likely to undergo a cesarean section or an operative vaginal delivery. Women were also less likely to use an analgesic or epidural, less 
likely to express dissatisfaction or negative judgments with the experience of birth. The authors are quick to note, however, that analysis of subgroups suggests that different types of support may be more effective for different women and that support from hospital staff had varying effects. The Ministry of Health summarizes research as follows:

If the person in charge of offering the support was a midwife, it was also assessed whether or not it belonged to the staff of the birth point, to check whether the concomitant additional workload and responsibility during the assistance could compromise the effectiveness of the intervention compared to that offered by personnel dedicated exclusively to support. A further analysis evaluated the early or late start of the offer of continuous labor support (2012: 80).

This is the first mention of a midwife in this section, but oddly, the research on midwifebased support is not given a specific conclusion. A conclusion to this research would be particularly salient to the Italian context since midwives are integrated into the healthcare system.

Benefits to women's healthcare outcomes related to continuous support are discussed. The research is concluded with:

Against the described benefits, no adverse events associated with the intervention were observed and the results of this review promoted clinical practice guidelines in the United States and the United Kingdom. However, the results of the primary analysis should be interpreted with caution: the analysis by subgroups suggests that the effectiveness in the practice of continuous labor support can be increased or reduced by policies adopted at birth centers, by the type of person offering the support and from the timing of its beginning. The effect of the support offered by health professionals was variable, with better results in the case of staff outside the birth point staff and dedicated exclusively to supporting women (2012: 81).

Again, we see a focus on research considered formative to clinical practice in the U.S.

and the U.K. This document, however, points to the more complexities of the groups that are researched. Unlike Part One, Part Two recognizes that differences in the policies of healthcare systems can affect the efficacy of support on maternity outcomes. Similar to Part One, however, the documents fall short of explaining why research from the U.S. 
and the U.K. was used. The lack of focus on Italian research, again, leads to a lack of specific ways in which research relates to the type of care women receive in Italy.

While midwives attend to almost all births in Italy (Basili et al. 2018), the Ministry of Health moves on from an incomplete discussion of midwives toward a more substantial focus on doulas. Doulas are patient advocates who help support women during pregnancy, labor, or new motherhood, but generally do not have enough medical training to be a birth attendant. Doulas often offer their services for a fee. The analysis of doula care discusses in depth, far more in depth than any other study, two pieces of research on doulas. Both pieces of research are RCTs conducted on populations in the U.S. The findings of the first study were summarized as such:

The doula-assisted group experienced shorter labor, greater cervical dilatation at the time of the epidural and higher Apgar scores at 1 and 5 minutes, but no difference in the percentage of caesarean section or epidural analgesia (2012: 81).

The findings of the second study were summarized as such:

The intervention of the doula was significantly associated with a lower rate of caesarean sections, even in the case of induction with oxytocin, and a reduced use of the epidural. Furthermore, the opinion on the support offered by the doula, expressed by women and their partners, was positive (2012: 82).

The Ministry of Health documents provide no discussion of why they focused on doulas or how doulas are or could be utilized in the Italian healthcare system. The focus on using RCTs as indicators of potential mechanisms through which the healthcare system can reduce cesarean sections presents evidence and research that is not specific enough to demonstrate utility to the Italian context.

The way these findings are presented also suggests a focus on specific medical outcomes rather than women's subjective experience. Even though this section is about support, the summary of the doula RCTs demonstrate a preoccupation with the decreased 
in medical interventions. Women's experiences with doulas are left out and a basic sentence stating women's positive experience is written at the very end of the document. This, along with the quote above summarizing research from the U.S. and the U.K. also demonstrate the unusual use of research that is not necessarily definitively effective in reducing cesarean sections. The summary of the U.S. and U.K. research, along with the summary of the first study on doulas which stated that "no difference in the percentage of caesarean section or epidural analgesia" (2012: 81) raises the question of why the Ministry of Health has chosen to use research that is both inconclusive and not clearly useful in the Italian context.

Analysis of Guidelines Part 2: The Healthcare System vs. the Universal Woman

Part Two offers very similar areas of critique as Part One. Just like Part One, Part Two relies on biomedical research with an even more pronounced focus on RCTs. In the analysis of Part One, I detailed the implications of the use of biomedical research, but I argue that the negative effects of using this type of data is even more pronounced in Part Two than in Part One. The title of the section in Part Two, "Emotional Support Offered to the Woman During Labor and Birth," suggests that women's emotions and experiences during birth will play a central role in the medical discourse and recommendations. Instead, women are still seen primarily as a means through which positive birth outcomes can be achieved. As the authors note: "Theories supporting the effectiveness of continuous support are concerned with improving the physiology of labor, the ability to control, and the competence of the difficulties" (2012: 80). Emotional support is meant to improve the physical, but not subjective aspects of labor. Table 4.3 in the Appendix shows the outcomes measured by the Cochrane study. Out of the 29 outcomes, only the seven highlighted outcomes are related to women's subjective experiences of birth and new 
motherhood. The rest are clinical outcomes easily measured to assess the medical efficacy of the healthcare intervention. This section is also laden with statistical terms, correlation coefficients, and confidence intervals from the Cochrane. Use of statistics here, as in Part One, serves to delineate what matters, specific healthcare outcomes such as the use of epidurals and cesarean sections, from the things that don't count, the emotions and experiences of laboring women. Unlike Part One, however, Part Two never uses the word "subjective,"; not in the section I've analyzed nor in the entire document. While I do not mean to argue that decreasing interventions with the potential for healthcare complications is a negative aspect, I do mean to argue that a focus on support would be best understood through the experiences of women. Understanding women's experiences could provide a more nuanced analysis of why certain types of support fail and under what circumstances they succeed. This focus on the statistical importance of support during childbirth shows that the authors consider support for women's subjective experiences as only of minimal importance in understanding maternity care outcomes.

The guidelines also show unusual trends relating to the validity and use of specific research. The author's caution against complete acceptance of the findings from the Cochrane study, as the findings were confounded by variables such as hospital policies, the timing of support, and the person providing the support. The first study on doulas did not show a connection between support in labor and a reduction in cesarean section and epidural use, while the second only showed minor differences. Just like Part One in which the authors noted several instances of research findings being inconclusive, Part Two shows an unusual reliance on data that is inconclusive or only shows a mild improvement in desired health outcomes. The Cochrane study and the two doula studies make up 6 of the 8 paragraphs in this section. The use of these studies, in light of the fact that some of the research is inconclusive, suggests that the 
authors are more concerned with having clinical, statistical, and objective data than in understanding women's local experiences.

The lack of attendance to the local context is seen, again, in the reliance on non-Italian sources and is particularly pronounced in the sections on the doulas. While the Cochrane study was a review of data from several countries, two studies on doula-based support were conducted in the United States. While the studies were RCTs, meaning patients were assigned doulas and did not have to pay for their services, the financial incentives are a large barrier to being able to compare these trials to the Italian context. Comparing these results to the Italian context is not only complicated by the private pay for use healthcare system in the United States, but by the fact that women in the U.S. are used to paying for services and may be more willing to pay for and accept the services of a doula. Private payment for healthcare services is important because women who can use a doula have the time and money to benefit from the doula's services. As the authors note, one of these studies followed women with "medium to high social status" (2012: 81). While the authors do not define what this means, it can be assumed that this means somebody with the means to pay for a doula outside of the trial. As I will show in Chapter 6, hospital midwives play an important part in offering support in childbirth and the reliance on research relating to doula-based care does not provide an accurate comparison to the Italian context.

Like Part One, Part Two shows the many biases present in women's childbirth recommendations. Biomedical research and RCTs serve to further disembody a woman's childbirth experience. Even when emotional support is the means of intervention, that support is only meant to create a specific healthcare outcome. The reliance on research that is inconclusive or not well suited to the Italian context shows that the author's valued scientific objectivity over 
quality. This objectivity, however, means that recommendations are only partially accurate and possibly not accurate at all to the Italian context.

\section{Regional Health Governance \& the Regione Toscana Website}

As government recommendations are translated from the national level to the regional level, government discourse surrounding maternity care becomes slightly more specific. Yet, as my research shows, this shift does not necessarily give greater attention to women's experience. In Italy, regional differences become particularly important because regional government controls much of the implementation of healthcare policy. Individual regions also have more control over the specific areas of healthcare to which the healthcare is directed. Understanding

medical discourse found in regional maternity care document provides more localized context in which to situate women's experiences during pregnancy and childbirth. Regional healthcare systems have the opportunity to recognize patients' behaviors that are far more specific to the local context of healthcare delivery. In the context of high-quality maternity care in Tuscany, regional documents also provide a way to understand how even more localized discourse does not incorporate women's experiences. While the Tuscan documents provide more specific information on the ways in which the healthcare system function, the medical discourse contains familiar omissions to those of the Ministry of Health. Similar to the Ministry of Health documents, the portrayal of the realities of maternity care presented in the Tuscan documents could be thoroughly improved through the use of research understanding women's experiences in childbirth and pregnancy.

The documents presented in this section are part of the healthcare section of the regione.toscana.it website. The section is overseen by the Regional Health Council, the goal of which is as follows: 
The establishment of this body stems from the will of the Tuscany Region to involve all those professional and technical figures of the regional health service, such as qualified interlocutors, in decision-making debates in order to ensure responsible choices and aware[ness] of health promotion and protection. The mission of CSR is to contribute to innovation and to the development of the quality of health services by providing advice on health planning and planning and advice on measures with a technical health content (Regione Toscana).

While the Council did provide several guidelines through the website, none of the guidelines were about pregnancy or childbirth. As such, I took a different approach in obtaining these documents. To obtain the Tuscan documents, the word "birth" was searched on the Tuscan region's website regione.toscana.it. While the Azienda Regionale di Sanità [ARS] is the Tuscan organization tasked with undertaking research on the Tuscan healthcare system, publications provided online are difficult to find due to a lack of search feature and are often published through the Regione Toscana website. This has been confirmed by a Google search for ARS documents related to maternal health, pregnancy, and childbirth. The search was done originally to help create questions when I redesigned my research project. The search as of March 25, 2018 returns 78 items. Results included photos of artworks, summaries of government proceedings, and documents that had the word "birth" in them but no reference to childbirth practices. Of the four items that discussed childbirth in detail, one was simply a reiteration of statistics and did not deal with the behaviors of healthcare professionals or pregnant women and was therefore take out of consideration for analysis. I discuss the remaining three in greater detail. Since the documents are very short and offer limited medical discourse, unlike my analysis of Ministry of Health guidelines, I analyze each of these documents together.

\section{Title of Articles}

- "Recommendations for Pain Control Methods During Labor and Birth in the Tuscan Region" - "Birthing According to Nature"

- "Birthing Free of Pain: The Contributions of Complementary Medicine, 
The first document is from the gruppo di lavoro istituito dal Consiglio Sanitario Regionale Toscano (GDL), a group which reviews literature and provides healthcare recommendations for the region of Tuscany. The title of the recommendations is "Recommendations for Pain Control Methods During Labor and Birth in the Tuscan Region." The recommendations are based on an accord drafted in the region of Trento in 2010 and accepted by the region of Tuscany in 2011, which focused on different ways to improve maternity care. The accord outlined 10 lines of action to improve maternal healthcare, but the GDL document focuses only on the one aimed at pain control management. This line of action is focused on

pain control procedures during labor and delivery that have, as objectives, the promotion of assistive procedures, pharmacological and non, for pain control in the course of labor and delivery, and the definition of shared diagnostictherapeutic protocols for pain free birth, giving assurance of the availability of this service with an anesthetist available/present on the basis of the volume of births in every birth point (1).

These recommendations suggest a "good level" of availability of pain control methods during childbirth in Tuscany, which includes the presence of non-invasive procedures such as traditional Chinese medicine and homeopathy.

The second two documents are both part of two separate regional news bulletins of complementary medicine edited by the Tuscan Network of Integrated Medicine from the Azienda USL 2 in Lucca, Tuscany. The first article titled "Birthing According to Nature" offers information about possible modes of birth throughout Tuscany from the "point of view of the operators [healthcare professionals]" (2011: 3). The article is based on the testimonials of healthcare professionals about their work in small clinics and birth centers that provide natural pain control techniques to pregnant and laboring women. The second article titled, "Birthing Free of Pain: The Contributions of Complementary Medicine," discusses the methods for pain control available to women in labor and suggests that the cesarean sections rates in some regions 
have "worrying" levels. There is also a section titled "Birth and Traditional Chinese Medicine:

Scientific Research" which discusses several pieces of research that show the efficacy of acupuncture in reducing pain in birth as compared to pharmacological pain management techniques.

In analyzing these documents major themes surrounding non-pharmacological pain techniques and women's autonomy emerge. First, all of these documents focus on pain management techniques, and, in particular, the natural ways in which pain can be managed. Since I did not search for "pain management/control techniques," but rather for the term "birth", these documents show a significant focus on the use of pain management as a way to improve birth outcomes and the quality of maternity care in Tuscany. Appropriate pain management techniques are considered the key to reducing cesarean sections. While the GDL is very specific, but cautious in noting research that shows a "limited efficacy" (2014: 6) of the nonpharmaceutical interventions like acupuncture in labor to reduce cesarean sections, the authors do mention that they "[intend] to encourage the use of non-pharmacological and complementary medicine techniques" (2014:6). "Birthing According to Nature" also suggests different ways that a general application of complementary medicine in all birth centers in Tuscany would lead to a reduction in cesarean section rates. One professional in a homeopathic clinic suggested "In pregnancy, the intervention of the homeopath is also useful to prevent the excessive medicalization that the "official" path often imposes" (2011:4). The availability of pain techniques, specifically non-pharmaceutical pain techniques are the predominant suggestion for a reduction in cesarean section rates.

These documents show support for non-pharmacological interventions in childbirth. This is no surprise from a complementary medicine publication, but the GDL recommendations also show favor for non-pharmacological pain management in childbirth, as they "intend to 
incentivize the use of non-pharmacological techniques and complementary medicine." (2014: 7) The sub section in "Birthing Free of Pain" titled "Birth and Traditional Chinese Medicine: Scientific Research" explains the scientific evidence behind Chinese medicine. Both articles show not only a preference for non-pharmacological pain control techniques, but the claims are made using science research with large, non-local data sets. "Birthing According to Nature" also ties the use of complementary medicine to the research on a limited number of health and economic outcomes. Midwives are heralded as the purveyors of non-pharmacological methods, whereas women's evaluations of care from midwives is not acknowledged. One healthcare professional said about her clinic: "The courses are attended by women of all gestational stages, thus demonstrating (emphasis added) that they are pleased to seize an opportunity that is becoming a reference space for pregnant women and to accommodate a more general vision of health education" (2011:4). I add the emphasis to demonstrate that midwives are making their own assumptions about how midwives themselves believe women are valuating available services. While the recommendations for care are becoming more local to the Tuscan context through the use of provider evaluations of patient services, assumptions about women's motivations are still given more attention than women's experience or narratives.

Women's subjective experiences and choice surrounding pain control techniques are also addressed but referenced only minimally as a potential means through which to improve care. The GDL document begins, "The experience of pain during labor and delivery is highly subjective, a result of processing of stimuli of different intensity through emotions, motivations, cognition, social and cultural conditions typical of every single woman." (2014: 1). The GDL document has a total of 26 recommendations under specific subjects and five final recommendations (recommendations can be found in the Appendix) Yet out of these 31 recommendations, only three contained language that suggested women should be active agents 
in the pain control process. For example, the GDL suggests that the "Women's choices of method to control pain in birth must occur with awareness, as an informed free choice." (2014: 2). They also suggest that "Women who consider it appropriate to labor in pain during birth utilizing non-pharmacological techniques must be supported in their choice." (2014:3) All other recommendations were aimed at structural changes to the healthcare system, such as better education for healthcare professionals or the availability of specific pain reduction techniques in each hospital. Women's choice is recognized as an aspect of pain control management but at the same level of importance as other factors. The word "choice" is used only six times between the three documents. In the article "Birthing According to Nature," the authors state that the recommendations are from the point of view of the healthcare professionals. Even though the focus of the article is about birthing according to nature, women, who are the main actors in the birth, are not given a specific focus. Women's choices and subjective experiences are recognized as an aspect of pain management but are given as an almost obligatory reference without any specific mention of their involvement in birth or how their subjective experiences could influence appropriate medical interventions. The main focus, healthcare workers and services offered from the hospital, show that women's subjective experiences are recognized, but undervalued.

Unlike the national recommendations, the sources for these documents were not as easy to analyze. While the GDL document provided a bibliography, "Birthing According to Nature" and "Birthing Free of Pain" did not. The GDL document cited 12 articles or sources of data. These sources were split between Italian, and extra-Italian sources. Five of the six extra-Italian sources are in English and the other is in French. The country of origin of the sources in the complementary medicine documents were harder to ascertain because there was no bibliography. In "Birthing According to Nature," there are only two sources, one citing the WHO's 
recommended maximum cesarean section rate of $15 \%$ and one citing L. Ginocchini 2010, a small study of the efficacy of moxibustion. It is unclear where the latter study was set but based on the author's name it is possibly set in Italy. The document "Birthing Free of Pain: The Contributions of Complementary Medicine" is divided into two parts. The main text has three citations. One is the GDL document, one is the accord used in the GDL document, and one is a publication from Toscana Medica offering the results of a survey of complementary medicine techniques used in labor in Tuscany. The next section of the document is the section titled "Birth and Traditional Chinese Medicine: Scientific Research.” Again, it is difficult to tell where some of this research was conducted; however, one is based on research in China, one is a British study cited in other recommendations. The other two citations (Jones et al. 2012 and Chaillet et al. 2014) seem unlikely to be Italian sources based on a document search in Google Scholar, however, without full citations, this cannot be verified completely. Just like the national documents, the Tuscan documents show a preference for scientific data over women's experience. This is perhaps even more disturbing given that the focus of these documents is on pain management, a process that has a highly subjective component.

\section{Discussion: National vs. Regional, The Disappearing Subjective Woman}

The Ministry of Health guidelines and recommendations have several similarities and differences with the Tuscan sources. The most prominent similarity is that women are not construed as highly active agents able to impact their birth outcomes. Their experiences and knowledge are unacknowledged, albeit in different ways. With the Ministry of Health guidelines, women are construed as passive agents who doctors can "orient...toward informed and conscious decisions" (2010: 19). Outcome producing behaviors based on simple attainment of information are meant to overcome inherent flaws in women's subjective experience of 
pregnancy and childbirth. While Part Two of the guidelines suggests the importance of women's emotions in the birthing process, this is not for the benefit of their subjective experience, but for the benefit of optimal healthcare outcomes like a reduction in the use of cesarean sections and epidural. An entire paragraph is dedicated to explaining the statistical significance of support on outcomes listed in Table 4.3. As I showed above, these outcomes placed very little importance on the subjective experiences of women in labor. The use of statistics to identify the significant outcomes in the study effectively reduces women's complex experience to a set of numbers.

In both the Ministry of Health documents and the Tuscan documents, healthcare providers are the focus of creating optimal birth outcomes but in different ways. In the Ministry of Health Part One, doctors are considered the purveyors of information able to improve negative healthcare outcomes. In Part Two, nurses and midwives are recognized as potential providers of support, but doulas are focused on as a means through which positive birth outcomes are achievable. Women's roles are diminished in the shadow of the healthcare providers. In the Tuscan healthcare recommendations, women's behaviors as active and autonomous agents are recognized as an important aspect of childbirth, but the woman's role in childbirth is overshadowed by the focus on healthcare providers and healthcare structures. Even though these articles are about pain, a subjective process, women's role in the use of pain control techniques is diminished. Creating articles from the point of view of the healthcare providers and making recommendations that primarily focus on interventions at the level of the healthcare provider imply that the women's subjective experience of birth, particularly as related to pain are best understood at the level of the healthcare system and providers instead of the individual. Women's experiences and emotional needs remain unacknowledged as a significant part of an optimal birth. 
Recommendations, whether from national or regional documents, are highly unspecific to the local context. This might be expected from national guidelines; however, the national guidelines recognize a significant variability in cesarean section rates throughout the country while not recognizing how the research chosen for the guidelines might not fit into the Italian context. Since differences between healthcare in Italy and other nations is not recognized, regional differences in maternity care go completely unacknowledged. This lack of specificity extends to the Tuscan documents as well. The Tuscan documents place more emphasis on the role of the midwife in reducing the chance of medical intervention in birth, but not the specific ways in which midwives operate to promote non-medically invasive childbirth. As I will show in Chapter 6, women consider midwives essential in pregnancy, a connection that is not significantly interrogated in any document. While "Birthing According to Nature," mentions midwife run clinics, these clinics are often only a small part of the healthcare systems and there is not significant discussion of women's valuation of that care. One key interaction between midwives and pregnant women is through free prenatal classes run by a midwife. While the prevalence and attendance at the classes may vary between regions, this was an essential activity in Tuscan women's experiences in childbirth, not just for information attainment, but for social support. Women in my research also expressed an importance of midwife support during childbirth, which was not brought up in any significant way in any of the documents. The lack of significant attention to midwife-based care throughout the Italian healthcare system in both national and Tuscan documents, is puzzling and potentially counterproductive to care aimed at reducing the amount of medical intervention in childbirth.

The comparison of Italy to other countries also serves to generalize women's reproductive experiences across national contexts. In the national guidelines, women are portrayed as fearful; this fear is related to the decision to choose a cesarean section. These 
findings are based on statistical data from research outside of the Italy, with no Italian sources being used. As I will show in Chapter 5, fear of childbirth was rarely associated with the desire for cesarean section. The Tuscan documents, while more focused on healthcare at the regional level, also suggest that interventions effective in other countries, like China, will be effective in Italy, regardless of the level of acceptance these non-Italian healthcare techniques are accepted in Italy. The reliance on clinical and statistical data facilitates the utilization of non-Italian sources through the elaboration of a universal body. Biology trumps the subjective in the attempt to control health outcomes.

As transnational sources of information and recommendations become more prominent in maternity care guidelines, we can see a shift away from understanding the impact of local structural, economic, and historical differences in leading to healthcare outcomes. While Part One of the Ministry of Health guidelines recognizes regional differences in cesarean section rates, the reason for these differences is glossed over. A universal model that is based on the new global universal reproductive body and considered applicable anywhere provides a barrier to understanding maternity care as mediated by local cultural environments and healthcare systems. Medical recommendations and women's healthcare behaviors are seemingly located in a vacuum where society has no impact on behaviors or outcomes. A dichotomy between correct and incorrect medical practices is created devoid of any acknowledgement of the constraints imposed on the practice of desired healthcare behaviors, both from healthcare professionals and expectant mothers.

The foundation for this homogeneous one size fits all model is transnational clinical data and the statistics used to define and redefine biological realities for whole populations. In Part One of the Ministry of Health guidelines, 714 sources were narrowed to 50 based on specific criteria. Sources relating to childbirth were valued for their scientific objectivity rather than the 
inclusion pertinent contextual circumstances. Systematic reviews of the literature and clinical trials became the cornerstone of the recommendations. Women are reduced to a statistic and complex behaviors are reduced to a simple set of pathways between variable $\mathrm{X}$ and outcome $\mathrm{Y}$. Behaviors are increasingly portrayed as open to being operationalized and sanitized for easy understanding. By using biomedical data, the documents add to what Wendland (2007) calls the "vanishing mother" in which women's experiences and subjectivities are replaced with statistical data and evidence-based medicine. Storeng and Béhague (2014), in their work on evidencebased advocacy, suggest that,

evidence-based advocacy is related to the broader shift in the 1980s and 1990s toward evidence- based medicine and evidence-based public health, both of which have contributed to the growth in monitoring of health targets in so-called developing countries (Greenhalgh 1996; Justice 1986) as well as the impetus to render health policy- making more objective, effective, and economical and less subjective and ideological (261).

As women become increasingly reduced to a statistic in biomedical literature, their complexity as human beings is reduced to a set of easily manipulated human behaviors meant to overcome all of the side effects of human subjectivity. Complex analysis of local healthcare contexts is reduced to the generalization and simplification of the human body to conform to global standards. Through the simplification of human behavior, countries become easily compared. Information about the reproductive body completely transferable between countries with different healthcare systems. The inclusion in Part Two of the Ministry of Health guidelines of an analysis of doula-based care in the U.S. is particularly baffling since doulas do not have a major role in the Italian healthcare system. The significant focus on the doula RCTs demonstrates, once again, the relative value given to biomedical data over contextually-specific information. 
The simplification and universalization reproductive bodies leads to the creation of specific behaviors which women must do to achieve ideal birth outcomes. In the Italian context, rationality is deemed an important behavior to achieve positive birth outcomes. By overcoming the "irrationality" of fear of childbirth, women are able to make appropriate decisions through their medical decisions. In this iteration, the use of medical information, particularly that provided by the doctor, is seen as the rational behavior. As Krause and DeZordo (2012) suggest, the rationalities found in different modes reproductive cross the lines of the global North and global South. My research points to the need to understand the movement of rationalist reproductive discourse within a Western context and to further understand Herzfeld's (2016) assertion that the West may not be a cohesive political entity like we assume. While many anthropologists have focused on the flow of goods and information globally, medical anthropologists have shown how these global forces often led to disastrous consequences for the health of those in the global South. The groups and communities often affected the most are the more vulnerable to begin with, such as indigenous tribes in Venezuela (Briggs and MantiniBriggs 2006) or HIV patients in poverty in Brazil (Biehl 2007). Less is known about how information circulates and is valued within the global North itself. More research is needed to understand the ways in which Western countries themselves prioritize research from other countries.

It is unclear why recommendations and healthcare documents almost exclude Italian sources of information (including doctor's own clinical practice), especially since even the authors caution the findings of many of the studies. The only indicator of why certain research is used is based on the Ministry of Health guideline's specific focus on highly scientific data, specifically clinical trials. Further research could focus on the creation of these guidelines, particularly focusing on why certain sources are included over others. While I consider this a 
rather preliminary analysis of maternity care documents, I believe it shows themes that are significant not only to my specific research on women's experiences in with pregnancy and childbirth in Florence, but that could be used in a larger analysis of the landscape of maternity care in the entire country. A particularly fruitful future project could be comparing the recommendations of southern regions with those of the north. A more specific study of the implementation of these policies would also be a fruitful avenue for further study. Each of these specific projects would create a more comprehensive picture of the impact of healthcare information in Italy.

\section{Conclusion}

As I have shown, the foundation of Italian maternity care documents and recommendations are global, scientific, and clinical data. Local sources are unacknowledged as emphasis is placed on scientific data, clinical trials and statistical analysis that create an objective birth experience presumed to be portable to all different circumstances. Specific local histories are ignored in favor of a presumably correct universal model of healthcare. National and regional healthcare documents may differ in certain aspects, but the heavy reliance on a global data set leads to certain similarities in how the healthcare documents represent expectant mothers and the experience of maternity care.

Women are considered minimally active agents, both in national and regional healthcare recommendations. The woman disappears in favor of focusing on the behaviors of healthcare professionals and the functioning of the healthcare structure. This type "vanishing mother" aligns with clinical research which increasingly reduces reproductive women to statistics.

Women are considered a mixture of different characteristics to be manipulated by the healthcare system to achieve desired healthcare outcomes. Women's subjectivities sanitized in preference of an easily controllable rational being. Scientific information and appropriate behaviors from 
healthcare professionals are all women need to have a good birth. Women's subjectivities, however, are not considered an important aspect of the birthing process.

As I will show in the following chapters, women's subjectivities are inextricably tied to the quality of care they perceive. The dichotomy set up by these healthcare documents suggest that there are appropriate behaviors for pregnancy and appropriate behaviors for childbirth, but women's subjectivities cannot be tied to a specific set of behaviors. Recommendations that are unspecific in the role of healthcare professionals are undermined by the recognition of the many significant roles the midwife has throughout a woman's pregnancy and childbirth. This role relegates the doctor to a position of limited importance in the eyes of women. Women's experiences with maternity care in Florence show how these recommendations fall short in recognizing essential aspects of women's positive experiences. Even recommendations promoting the importance of social support, something expectant mothers expressed as important, are only important as tools to achieving positive birth outcomes. But as I will show, there are many other aspects of pregnancy and childbirth that are significant to women's experiences. 


\section{CHAPTER 5 \\ LOCAL BODIES, SOCIAL BODIES: REPRODUCTIVE SOCIALITIES IN FLORENCE}

In Florence, pregnant women often sought out several different types of social relationships. The many ways that pregnant and birthing women seek out others, either for information, support, or simple engagement, is what I call reproductive sociality. The desire to socialize, especially with other expectant mothers provides the foundation for women partaking in the maternal health behaviors that the Ministry of Health recommends. I will build the argument that women's motivations for interactions with specific healthcare practitioners are influenced not by the importance of the information itself, but by the social relationships created between practitioner and expectant mother. Women's motivation for interacting with specific practitioners in specific settings are complex but also based around the same desire to have a good relationship and experience with that practitioner.

In the last chapter, I analyzed the discourse of both national and regional documents surrounding maternity care in Italy. I showed that these documents favored global data to construct medical discourse surrounding very local healthcare issues. In this chapter, I will demonstrate the experiences women deem valuable during pregnancy that go unacknowledged in Italian maternity care documents, particularly those from the Ministry of Health. While this chapter focuses specifically on pregnancy, Chapter 6 provides a more detailed explanation of women's experiences in childbirth. By focusing on pregnancy, this chapter provides an understanding of women's social behaviors and experiences that impact their decisions relating to childbirth. 
My framework of reproductive sociality highlights the way in which the individual self and social bodies are not easily separated. Women consider certain individual behaviors of selfcare to be essential, but those behaviors are not always easily detached from the desire for sociality. Group and fitness activities provide women with the ability to relax, an aspect of selfcare, but are done in a shared environment. The unique demands of pregnancy meant that a woman had to simultaneously be aware of her individual limitations but partake in extra activities such as medical visits. The need to alleviate individual fears often came in the shared environment of the prenatal class. For pregnant women in Florence, sociality permeated even individual self-care and medical interactions in ways that demonstrate the futility of medical research and discourse that focuses on the individual or the doctor-patient dyad.

\section{The Healthcare System and Women's Information Seeking Behaviors}

As I demonstrated in the last chapter, one of the most prevalent interventions promoted by the Italian Ministry of Health and Tuscan Region to reduce cesarean sections is providing women with information. This information is meant to reduce women's fears and their desire for a cesarean section. In the Ministry of Health guidelines, doctors are portrayed as the primary source from which women are meant to obtain childbirth related information, but the women in my research did not share this opinion. When asked what information women received during their doctors' visits, most of the 50 women I interviewed responded by saying they were given results about their exams or about the health of the fetus. When asked about what information they received about childbirth, several women responded with "nothing" or "little."

To understand the other ways in which women searched for information, I asked an openended question of what sources they used to gain information. If not specifically stated, women were asked whether they talked to family or friends and whether they searched on the internet or 
through books. The following section discusses in more detail women's responses to the question What was the most important source for your decisions in pregnancy/ childbirth and why?"

While most women gave only one source as important, some gave multiple sources, and some women even responded that all were important. Women also gave multiple reasons for placing importance with each source. As such, the numbers in the response section exceed the number of participants. It also should be noted that three women did not respond or gave unclear answers to the questions and the responses in Table 5.1 come from 47 out of 50 women.

Table 5.1 Women's $(n=47)$ Responses to the question "What source of information was most important for your choices in pregnancy and childbirth?"

\begin{tabular}{|l|l|}
\hline \multicolumn{1}{|c|}{ Source of Information } & \multicolumn{1}{|c|}{$\begin{array}{c}\text { Number of } \\
\text { responses }\end{array}$} \\
\hline $\begin{array}{l}\text { Midwife (through course, care through pregnancy, and through } \\
\text { family connections) }\end{array}$ & 23 \\
\hline $\begin{array}{l}\text { Gynecologist (included a response that was a generic "hospital } \\
\text { visit") }\end{array}$ & 8 \\
\hline All & 4 \\
\hline Books & 3 \\
\hline "I decided by myself" & 3 \\
\hline Internet & 3 \\
\hline Friends & 3 \\
\hline
\end{tabular}

Table 5.1 represents the number of times an individual or activity was deemed an important source of information form women's decisions relating to childbirth and pregnancy. Some responses were left out of the table for brevity as they were only mentioned once. Those responses were "partner", "hospital informational sessions", "yoga", "water aerobics”, and "sister". It should be noted that the question was grouped with the pregnancy sections of questions. Most respondents' answers related to their interactions with healthcare professionals and informational material during pregnancy and it is possible that women viewed certain sources of information as more valuable during pregnancy rather than labor. While the focus on 
informational sources during pregnancy was a function of the organization of the questions, further research should be done to ascertain the appropriate time frame (i.e. pregnancy vs. labor) when specific information is sought, and decisions are made.

Table 5.1 makes clear that the source women most commonly cited as most important was that of a midwife or the prenatal courses primarily facilitated ${ }^{7}$ by a midwife or midwives. Along with the classes, women had the choice of being followed in pregnancy by a midwife instead of a doctor, however, few women took advantage of this option. The far more common form of interaction women had with midwives was in the prenatal courses. As one woman noted, "I trusted her, I had complete trust in her....We decided together based on my needs." This quote sums up many of the different reasons women preferred interacting with midwives rather than doctors.

The following three tables show the reasons women gave for deciding which informational source was most important. I have divided these responses into three general tables: "Midwives"; "Doctors"; and "Other." I have chosen to combine all of the miscellaneous sources into one general table titled "Other" because none of the individual miscellaneous sources had a high number of women suggest them. Table 5.2 shows most of the reasons women gave for why they considered the midwife as their most important source. While there is no one reason that a majority of women provided, they fall into three general areas: Characteristics and Behaviors of the Midwife, Women's Preferences, and Information Seeking Behaviors. I also added a section titled "Other" for the miscellaneous responses that did not fit into any category. While "Characteristics and Behaviors of Midwives" and "Women's Preferences" are almost equal in the number of responses they drew, "Information Seeking Behaviors" was far less common as a reason for preferring midwives as a source of information. Women were more

\footnotetext{
${ }^{7}$ I intentionally use the word "facilitated" instead of "taught" because the word taught conveys a traditional learning environment that does not convey the importance of relationships and social connections made.
} 
concerned with the quality of their interactions and experiences with the midwives. Table 5.2 shows that women's reasons for attending these classes were based less on information seeking than on the way midwives and expectant mothers interacted. It seems that women view their interactions with midwives as a form of social support, even when specifically asked about their informational authority.

Table 5.2 Reasons why women $(n=23)$ chose midwives as most important source

\begin{tabular}{|c|c|c|c|c|c|c|}
\hline $\begin{array}{c}\text { Characteristics } \\
\text { /Behaviors of } \\
\text { Midwives }\end{array}$ & 11 & $\begin{array}{l}\text { Women's } \\
\text { Preferences }\end{array}$ & 10 & $\begin{array}{l}\text { Information Seeking } \\
\text { Behaviors }\end{array}$ & 4 & Other \\
\hline $\begin{array}{l}\text { Explained things } \\
\text { well }\end{array}$ & 3 & Trusted & 3 & Scientific & 1 & Near to me \\
\hline $\begin{array}{l}\text { Make choices } \\
\text { together }\end{array}$ & 2 & $\begin{array}{l}\text { Created calm } \\
\text { experience }\end{array}$ & 3 & Logical & 1 & $\begin{array}{l}\text { To cope with } \\
\text { various moments } \\
\text { [in pregnancy and } \\
\text { birth] }\end{array}$ \\
\hline In sync & 1 & $\begin{array}{l}\text { Childbirth is } \\
\text { natural }\end{array}$ & 2 & $\begin{array}{l}\text { Needed specific } \\
\text { information about } \\
\text { birth clinic }\end{array}$ & 1 & $\begin{array}{l}\text { I'm not a person } \\
\text { who informs } \\
\text { myself much }\end{array}$ \\
\hline Highly prepared & 1 & Talk to directly & 1 & $\begin{array}{l}\text { Information not } \\
\text { found elsewhere }\end{array}$ & 1 & $\begin{array}{l}\text { She gave valid } \\
\text { recommendations }\end{array}$ \\
\hline $\begin{array}{l}\text { Have more } \\
\text { experience }\end{array}$ & 1 & $\begin{array}{l}\text { Shared } \\
\text { experience }\end{array}$ & 1 & & & \\
\hline A main source & 1 & & & & & \\
\hline Most competent & 1 & & & & & \\
\hline $\begin{array}{l}\text { Convinced to } \\
\text { follow feelings }\end{array}$ & 1 & & & & & \\
\hline
\end{tabular}

Table 5.3 shows the responses women gave for stating the doctor was their most important source. Because there were so many fewer responses than the midwives table, I have organized the table into one column. Even so, some clear divisions occur. One key theme is that women preferred somebody they knew or who knew them. As one woman put, "I always trusted my doctor, I was followed very well at [the hospital] I know another mother who did not like [the hospital], but I was fortunate because I found someone who always remembered my name, 
my situation." Just like women's reasons for choosing midwives as the most important source, trust and a personal rapport were important, perhaps even more so than with midwives. Even more important is what the table does not hold: information seeking behaviors. Women respond that they did not consider doctors to be a source of specific information or that they had more information than other sources, like midwives. The lack of discussion of the importance of information coming from doctors, as well as the paucity of discussion in relation to midwives, suggests that women seek out healthcare professionals for reasons other than information.

Table 5.3 Reasons women $(n=8)$ gave for stating doctors as their main source of information.

\begin{tabular}{|l|l|}
\hline \multicolumn{1}{|c|}{ Doctors } & $\mathbf{1 3}$ \\
\hline Trust & 4 \\
\hline Known for many years & 2 \\
\hline Qualified & 2 \\
\hline To know about health & 1 \\
\hline Someone who remembered personal information and specifics about birth & 1 \\
\hline Followed through other births & 1 \\
\hline One of the main sources & 1 \\
\hline Advised specific hospital to get woman's desired epidural & 1 \\
\hline
\end{tabular}

While women considered midwives to be a more important source of information than doctors, the two areas for which women did see the doctor as an important source of information were about the health of the baby and about potential health problems for the expectant mother or the baby. As one new mother recalled, "They explained with [my] risk of preeclampsia, I could have a premature birth. [They told me] to be very careful." Not all women stated they were told about the risks of birth. In fact, many women stated they received little to know relevant information about birth or pregnancy beyond test results. In response to the question, "What information did you receive about pregnancy and childbirth during the doctor's visit," Elena, a mother of one, responded, "Not much...the doctor checked that everything was going well. Rather than teach me, he evaluated that everything was going well, that the baby was well." Doctors were 
primarily seen as a source of information on the progression of pregnancy and the health and development of the baby, but not for information about women's experiences during pregnancy and childbirth.

Table 5.4 shows the variability in responses women gave for choosing the many different important sources of information beyond medical professionals. The focus on experience of friends and family as the most important source of information shows again the importance of social relationships in women's decisions. The table also shows that things like feelings, wellbeing, and being calm are an important part of the experience of being pregnant and making decisions about childbirth. It seems that experience, in its many variations, is a key aspect of pregnant women's decision-making processes.

Table 5.4 Reasons Women Considered Non-Medical Sources to be the Most Important Source of Information

\begin{tabular}{|l|l|}
\hline \multicolumn{1}{|c|}{ Other sources } & $\mathbf{1 7}$ \\
\hline Experiences of friends and family & 5 \\
\hline Sorted through information and decided for myself & 3 \\
\hline Book encouraged her to follow her feelings & 1 \\
\hline Felt friends knew what was best for wellbeing & 1 \\
\hline Book that discussed breastfeeding & 1 \\
\hline Partner was calming & 1 \\
\hline Found information online and confirmed with gynecologist/midwife & 1 \\
\hline Informational sessions at hospital were logical & 1 \\
\hline Yoga was important for last part of pregnancy & 1 \\
\hline Used internet because just moved and had few friends in Florence & 1 \\
\hline Too personal to talk with doctors/midwives & 1 \\
\hline
\end{tabular}

As I have shown in this section, the value women place on knowledge and childbirth is not as simple as the Ministry of Health guidelines portray. The value women place on different sources of information demonstrate that scientific and medical evidence are not a significant influence on women's behaviors during pregnancy and childbirth. Even the reasons women gave for preferring doctors as a source of information were not always for the information itself. 
Information, while important to some degree, is not a primary motivator in women's interaction with healthcare professionals. Doctors especially are not seen as a source of information, but as a trusted healthcare professional. Midwives are a far more important source for women, however, the Ministry of Health guidelines barely discussed their role. As I will show in the next section, the importance of midwives as a source of information was not always based on the information they gave, but on the quality of interactions and women's search for reproductive sociality.

\section{The Sociality of Reproductive Bodies}

\section{Individual Choices, Social Connections}

I sit in a café on the outskirts of Florence. Like so many cafes in Florence, modern architecture and music is juxtaposed against traditional menus and décor. The large windows let in far more natural light than I was accustomed to in the narrow streets of the historic center. I'm sitting across from Giada, a new mother in her late 30s. As she enthusiastically talks about her experiences in one of the famous natural childbirth centers of Florence, a woman behind us stands up and walks over. She asks Giada about her experience in a midwife-assisted birth clinic and reveals that she had tried to give birth in the same clinic but had to have a cesarean section. They both started talking about the experience until the topic of the prenatal classes surfaced. Surprisingly, they were both still in contact with the women from the prenatal classes. In fact, the woman who had come up to us had just finished meeting with the same group. Giada replied that even after a year, she was still in touch with the group and talked with them frequently.

The extended relationships these women developed is a form of reproductive sociality made possible by shared experience and the promoted through interactions in the classes. Reproductive sociality was the foundation for a myriad of activities and relationships that 
provided women with personal connections that were highly social, rather than biomedically individual. This reproductive sociality was not unusual. I often met women for interviews in some of the larger parks in the Florence area. The parks were dotted with small groups of women as intent on talking as helping their children play. From 10am to $12 \mathrm{pm}$ and again from $3 \mathrm{pm}$ to $6 \mathrm{pm}$, the parks filled with mostly mothers. This was unsurprising given the importance that women placed on the group of women they met in the courses. The women they met in these courses were sometimes the only other mothers women would come to know, as some participants did not have any other friends who were pregnant or had children. ${ }^{8}$

Several research participants were also found through these groups. As I wrote in my methods chapter, these groups of women often had a group message on WhatsApp. At the end of several interviews, the women would immediately take out their phones and texted my information to the group. As the vignette above showed, women considered these prenatal social groups to be so valuable that mothers stayed connected well into new motherhood. One respondent even noted that she loved texting the group because the nighttime feeding schedule of a newborn meant that several group members were up at a time when most people aren't. The creation of these groups was highly intentional and required effort from women to make and maintain new friendships. The prevalence of the groups in and of themselves shows that significance of women's desire for social connections with other pregnant women.

It was, in part, a desire for these types of social bonds that caused women to seek out the prenatal courses. The majority of women who attended prenatal classes, $57 \%$, said that they did so to "condividere" or "share" the experience with other mothers as compared to only $37 \%$ who said they came to learn about pregnancy and childbirth. While women had varying reasons for attending the prenatal classes, many women considered the most important aspect of the class to

\footnotetext{
${ }^{8}$ It should be noted that this was not a question but came up in response to another question. It is possible that a significant number of women in the study found themselves in the same circumstance.
} 
be socializing with other mothers. As Sofia, a mother of three told me, "For me, it was more a way to be together [with other mothers], to share our anxieties and our fears of childbirth, rather than learn something." This was not an uncommon response.

The social aspect of the classes was not just a means to meet other women, but other expectant mothers. I commonly heard women say that they wanted to share with women in "le stesse circostanze," or in "the same circumstances." The need for a group to socialize was very specific to pregnant women. As one participant said, "[pregnancy] is a delicate time. Having support from somebody who is feeling the same sensations and the same developments is very important." While I discuss the uniqueness women feel about pregnancy in a later section, the uniqueness of pregnancy was a key motivator for women's desire for social interactions in the prenatal classes.

The prospect of meeting new expectant mothers was not the only act of socialization pregnant women found important. Sharing information, doubts, and asking very specific questions to the midwives was also an important aspect of participating in the pre-natal classes. Many participants said that they liked having specific questions answered by peers, and these answers often helped to soothe women's anxieties related to pregnancy and childbirth. I saw this in one particular session I observed in the local midwifery organization. The session, like most others, started with a general lesson on the topic of the day, which was the body's hormonal response in pregnancy and labor. While the midwife often fielded questions during the lesson, there was always a time at the end set aside for questions. One woman started asking a question about how she was nervous about the birth. As she talked, she leaned closer to the midwife and her sentences came faster and faster. Her anxiety drew the other women to chime in with their anxiety too. Like an anxiety domino effect, the room quickly filled with a half dozen Italian women all talking at once about their anxieties. Finally, they all quieted and the patient midwife 
calmly gave her answer to their questions. The women all nodded, a sign that her answer satisfied the women's need for reassurance. In this instance, a woman's specific anxiety became a group anxiety that was calmed by the response of the midwife. The social aspect of the class both kindled the fire and calmed the flames.

While socializing was their primary motivation, all but two women (who stated they learned "poco" or "little") asserted that they learned something about pregnancy or childbirth in the class. The most common responses from women of what they learned were breathing techniques to reduce pain, information about their changing bodies in pregnancy, the general hospital processes during birth, breastfeeding, and what to expect after the child is born. While the classes were designed to provide women with information about pregnancy and childbirth, what really drew women to attend was the possibility of support from other mothers. The social factor of the class facilitated the spread of useful information.

As this section shows, information seeking behaviors, like attending a midwife-facilitated prenatal class, were often motivated by non-information related factors. Pregnancy was a time when women felt their bodies changing and they desired socialization with other women going through the same things. Women sought out support from other women in the "same circumstances," but also from midwives who could provide specific advice on the unique aspects of pregnancy. This uniqueness of pregnancy is a theme that I cover in the next section in order to show how the social aspects of pregnancy give way to the individual needs each woman experienced.

\section{Self-Care and the Unique Pregnant Body}

It's an overcast Tuesday morning. Spring had brought weather warm enough to keep windows open in the late morning. As a breeze wafts into the small room, I sit ready for the 
midwife to guide the group in our prenatal aerobics class. I settle into my mat on the floor as the midwife puts on a CD with soothing sounds. I'm told to put my legs vertical on the wall, close my eyes, and breath. For the next two hours, I put my body in a series of positions that are meant to stretch and relax my body. For the pregnant women in the class, the exercises are also meant to prepare their bodies for birth. We end the class with our eyes closed, breathing deeply. As I open my eyes, I see the women around me sitting with their bodies relaxed, eyes sleepily opening. The midwife asks how everybody feels and one woman jokes that she could take a nap. We all slowly stand up, still in a daze. This course is one of the many types of physical activities that pregnant women attended. Understanding the reasons why women participate in these activities reveals the myriad of ways in which women engage with their changing pregnant bodies.

When asked what women should do if they are pregnant the participants provided a range of answers. Many of these answers included things women should not do. Often these were related to food, echoing Counihan's (2004) analysis demonstrating the fundamental nature of food to the lives of Florentines. Women were very concerned with not eating raw meat to make sure they did not get toxoplasmosis. As one participant commented, "Here in Italy, we are very concerned with toxoplasmosis." Women also expressed the need for pregnant women to stop drinking alcohol or at least to severely limit the intake of alcohol. Women were also not supposed to smoke or do drugs. This list shows the many activities that women should stop in pregnancy, however, most activities were not deemed too volatile to stop altogether. The following paragraphs show a trend in women's expected behaviors in pregnancy that usually did not require drastic behavior modification.

One activity participants said was important for pregnant women to do was exercise. The most common exercise was walking. Walking was meant to be relaxing and not strenuous. In 
fact, physical activity in general was considered important, but only if not too strenuous. For many women strenuous activity was even considered too difficult because of the added weight of pregnancy. This is why many women turned to water aerobics for pregnant women. For women who attended water aerobics classes the course provided the opportunity to relax and to feel "lighter" in the water. Especially during the summer months water aerobics were seen as very refreshing. Women expressed similar attitudes about the physicality of prenatal yoga, another popular activity among prenatal mothers. When looking at women's activities during pregnancy it's easy to see that women considered activity to be important, but it was also a potential source of relaxation. Thus, physical activity served the dual purpose of improving a pregnant woman's physical health and her mental wellbeing.

Women also saw individual time as another means of relaxation. Women considered pregnancy to be a period in which to take time for themselves. Women described the importance of self-care in a transitional period that can be difficult. One participant said it was important to relax because "You needed time to transition because everything will change after the baby [is] born." Elisa a mother of three from Florence said it's important for women to "Move away from worries, from [negative] thoughts and take some time for themselves." Many women spoke of the difficulties of pregnancy, either as a time of continual change or as a time of anticipation for even more change after the birth of the baby. One participant even recommended extended maternity leave for women with very difficult jobs. Over exertion, especially when related to work, was to be avoided during this time. Time to themselves was meant to compensate for the added difficulties that came with a changing body. When comparing how women discussed these regimens of self-care as well as the need for a certain amount of physical activity, pregnancy can be viewed as a period in which women should be doing not too much and not too little, but just enough. 
Despite the recommendation that women should relax in pregnancy my participants also thought their lives shouldn't change too much. Giudita, a mother of three from Pistoia, a small city in the greater Florence metropolitan area, said "Your life remains normal but with small precautions to seek a little better well-being." Many women said that they did not change their physical activities in which they participated before they were pregnant, although some women had to modify their workouts. Participants also stressed that women should not see pregnancy as a sickness but as a change. In fact, many women said that one of the things that they like the most about pregnancy was that they felt healthy. Again, this portrayal of pregnancy as a time of change, but not excessive change paints the picture of a search for an almost Goldilocks type lifestyle. You shouldn't do too much, or too little, but just the right amount of activity and rest is beneficial for the pregnant body.

While women suggested viewing the pregnancy as healthy and not a sickness was important, many women expressed the importance of going to the doctor or midwife during pregnancy. Over the course of a pregnancy, women often undergo many blood draws and sonograms. For Angelina, a first-time mother, one test in particular offered a special memory: "The first time I had a sonogram where I heard the [fetal] heartbeat, it was the most exciting thing." Many women thought the tests and visits meant that they were "well followed" in pregnancy, which refers to receiving the appropriate amount of care from healthcare professionals. For many others, however, the visits were an annoyance. When asked what she didn't like about pregnancy, Alberta, a mother of one, responded, "The tests. All the blood tests. I gave a lake of blood". For some women, the experience during the tests were fine, but the doctor's behavior was not. As Delila recalls of her pregnancy with twins, "I was not a fan of the doctors. They were good when doing the echography, but at the time of the [doctor's] visit, they were too impersonal." Many women also lamented the excessive number of tests and visits. 
The self-care required changes of certain positive activities, such as relaxation and time for yourself, but the increase in certain annoyances.

As Delila's example shows being "well followed" and treated well by the healthcare system during pregnancy was an important part of having a good experience. The desire to be "well followed" by healthcare professionals was the part of a larger theme of the attention women received during pregnancy. Pregnancy was a time when women received more attention, but from healthcare professionals and others like friends and family. Many women stated that it was nice to get extra attention, even from the strangers. I saw this first hand when I was in public. It was rare to see pregnant women where I lived, but when I travelled throughout the city on public transportation, I saw pregnant women occasionally board the bus. Those buses had several seats designated for pregnant women, new mothers, the elderly, and the disabled. Several times when I boarded the bus, I saw the elderly individual get up from one of these seats and insist that the pregnant woman takes their spot. Even if the pregnant woman protested, the elderly individual did not take no for an answer. The woman always ended up sitting down. The uniqueness of pregnancy provided women the ability to maintain regimes of self-care not just through their own care for themselves, but through the care of strangers. While self-care is often considered an individual(izing) set of activities, the examples above demonstrate how sociality and individual behaviors are not so easily disentangled.

The uniqueness of pregnancy was also connected to the realization of having life growing inside. Many women said that they loved "sentire il movimento" or "feeling the movement" of the baby inside their growing bellies. Women loved knowing that there was "una vita dentro" or "a life inside [of me]." I was told in several interviews that the feeling of growing the baby was so unique that it was impossible to describe for those who had not been pregnant. Many women said that they took time not only to relax for themselves, but also to relax together with the baby. 
Pregnancy was considered a unique time in which baby and mother were together without anybody else. This example and the one above, however, demonstrate that self-care and the behaviors women consider important in pregnancy were not always completely individualized. Self-care and the individual body were often inseparable from socialities surrounding pregnancy, demonstrating the varied ways in which socialities weave through women's experiences.

\section{The Complexities of Fear}

In the last chapter, I showed how Italian Ministry of Health documents portrayed women as fearful about birth and that this fear relates to a desire for a cesarean section. The Ministry of Health simplified the causal outcome between women who experience fear and their maternity care outcomes. In my research, women expressed a much more complex view of their own fears. Out of the 50 women in my research, 27 women expressed experiencing fear during pregnancy, while 14 expressed experiencing no fear. Nine did not answer. While no women in my research had requested a cesarean section, none desired one during their pregnancy, regardless of whether they were afraid of childbirth or not. In fact, for one woman, the cesarean section her doctor said was necessary was actually her source of fear. The Ministry of Health documents suggested that fear was a monolithic emotional state which could be easily traced to the desire for cesarean section rates, but my research paints a different picture. Table 5.5 shows all women's reasons for being afraid or not being afraid of birth. It should be noted that some women gave more than one answer and the total number of responses exceeds the women who answered the question. 
Table 5.5 Women's ( $n=41)$ reasons for why they did or did not fear childbirth

\begin{tabular}{|l|l|l|l|}
\hline \multicolumn{1}{|c|}{ Fear of birth } & \multicolumn{2}{c|}{ No fear of birth } \\
\hline Not sure what will happen & 9 & Really wanted to give birth & 2 \\
\hline Pain & 8 & First birth wasn't that bad & 1 \\
\hline $\begin{array}{l}\text { Knew what was going to happen (had given } \\
\text { birth before) }\end{array}$ & 4 & Thought fear would harm baby & 1 \\
\hline Suffering & 3 & Millions of women have done it & 1 \\
\hline Worried about baby & 2 & Unique experience & 1 \\
\hline Wouldn't be treated well in hospital & 2 & Had a good pregnancy & 1 \\
\hline Episiotomy (laceration) & 1 & Psychologically prepared & 1 \\
\hline Difficult birth & 1 & Prepared for a natural event & 1 \\
\hline Risk of operation (cesarean section) & 1 & Not fear, but anxiety of unknown & 1 \\
\hline Risky & 1 & $\begin{array}{l}\text { Thought hospital workers would be } \\
\text { calm }\end{array}$ & 1 \\
\hline Problems in pregnancy & 1 & Didn't want to think about it & 1 \\
\hline Wouldn't go well & 1 & Women made to do it & 1 \\
\hline Had a bad past experience & 1 & Was very calm & 1 \\
\hline Afraid of having cesarean section & 1 & Was told labor would pass soon & 1 \\
\hline Afraid of Death & 1 & & \\
\hline
\end{tabular}

One of the most interesting connections between these two groups is that women were concerned with the same aspects of pregnancy and childbirth but conceived of these aspects differently. For example, one woman was confident about birth because she had "lived well" during pregnancy. For another woman, a pregnancy riddled with problems caused fear. While some women were worried about the safety of their babies through an uncertain event, another woman thought fear would harm the baby. Two first-time mothers thought that they had prepared sufficiently for birth, whereas many others thought that birth was too unexpected, and you couldn't prepare for it. A preoccupation with the same aspect of pregnancy caused fear in some and not in others. These examples show how women are thinking of the same things but are reacting differently to the future possibilities.

Perhaps the most interesting connection between women's fear and women's non-fear is past experiences in childbirth. Two first time mothers said that they really wanted to give birth 
and one woman said that her pervious birth had prepared her to not be afraid. Far more common, however, was women being afraid based on their past experiences. Five women who were afraid of birth said that it was because they knew what was going to happen or they had had a bad experience. As one woman put it, “The first time I didn't know what would happen, but [the second time] I was afraid." Even positive first experiences were not necessarily an indicator of whether a woman would not be afraid. Giudita, a mother of three who was pregnant with twins, had many health problems with the second pregnancy: "I had more doubts about this pregnancy than the first...In this pregnancy I had many problems, diabetes, asthma, pain, nausea. All things that I didn't have in my first pregnancy. So, I had a lot of fear.” For many women, experience in a previous birth was a reason for fear but fear also came from other sources. For these women, fear was a complex set of emotions based primarily on the uncertainty of pregnancy. These fears, however, stemmed from more than just a general fear of the unknown. Women feared the possibility of suffering, of not being able to stand the pain, or of being treated poorly in the hospital. While the Ministry of Health guidelines speak of the concept of fear as binary emotional state (either you are afraid or you aren't), the reasons for being afraid are motivated by very different possibilities in birth. Ignoring these variations in fear leads to an incomplete portrayal of women's experiences and motivations in childbirth.

\section{Discussion: Reproductive Socialities}

A key aspect of women's experiences during pregnancy in Florence are the search for social connections. These social connections are based on the women's biological state, connecting their experiences to Paul Rabinow's work. The importance women place on socializing relating to reproduction is part of what I call "reproductive sociality." Like Rabinow's (1996) biosociality, I maintain that the unique state of pregnancy has encouraged 
women to engage in reproductive sociality. Reproductive sociality encompasses all behaviors in which women search for meaningful connections with other people, particularly those in the same reproductive circumstances, to improve the experience of reproduction. While this project is based primarily on childbirth and pregnancy related behaviors, other reproductive states, such as infertility, the use of reproductive technologies, and reproductive migration, all fall under the category of reproductive sociality. Reproduction is not a pre-requisite for social behaviors, but behaviors relating to reproduction are the potential site for an understanding of how social connects are remade and reimagined based on a woman's biological and reproductive experiences. Unlike anthropologists who have discussed the social body as a " the representational uses of the body as a natural symbol with which to think about nature, society, and culture" (Scheper-Hughes and Lock 1987) or "the construction of society as an organic body" (Horn 1994), social bodies in my context refer to how women's changing reproductive bodies lead to the desire for social behaviors.

While similar to biosociality, reproductive sociality has two important distinctions. First, unlike Rabinow who envisioned biosociality to be facilitated primarily by medical categories created by new technologies, such as genetic sequencing, reproductive sociality is based on reproductive behaviors that have always been a part of human life. In most places, technology is often used in several parts of an individual's reproductive process, but for many women, reproduction can happen without technological intervention. Like anthropologists such as Franklin and Rapp have shown, reproductive technologies can certainly be a mode through which sociality occurs, but it is not always necessary, particularly in the Florentine context. While sociality was facilitated by recent appearance of WhatsApp, reproductive sociality encompasses social behaviors on the spectrum of no technological intervention to complete technological intervention, thereby broadening the scope of reproductive behaviors already 
accepted under the premise of biosociality. This focus on technology, however, is a major point at which biosociality and reproductive sociality diverge.

The second way in which reproductive sociality and biosociality diverge is through the way Rabinow defines sociality in relation to medical diagnosis. Rabinow conceived of a not too distant future in which genetic technology would advance to the point of linking certain diseases to specific genes. Rabinow thought these new technological connections would usher in an age in which social and kin groups would be created around these new gene/disease categories. Social groups would be created around a newfound medical status potential: the disease or potential for disease. Pregnant women, however, are not diseased. Pregnant women, like those with newly revealed gene sequences, are exposed to the change that comes with their new medical diagnosis. This change, while not physically damaging like a disease, is still a change that requires at least a minor reconfiguring of the patient's previous life. A disease may not be desired, but the desire to have a child does not lessen the difficulty in doing so. Just like somebody who has a new-found disease, women seeking out reproductive solutions experience anxieties and fears. The search for reproductive sociality becomes a potential way to mitigate some of the doubts and fears women have about the unknown, which is exactly what some expectant mothers in my research said. Regardless of women's previous reproductive experiences, reproductive sociality, particularly for women in Tuscany, presents an essential way through which anxieties and doubts can be managed. The Ministry of Health guidelines depict information as the "antidote" to the "sickness" of fear. But pregnant women are not sick and reproductive sociality becomes a way for women to live their new lives without being relegated to the category of the sick. Reproductive sociality provides women with the ability to create their desired reproductive experience. 
The importance of experience in relation to information brings into questions the very ways in which we talk about authoritative knowledge. As Brigitte Jordan suggests, "the power of authoritative knowledge is not that it is correct, but that it counts" (1997:58), but authority is not always so clearly enacted. As Martin (1987) showed, biomedical knowledge about reproduction and the female body is not necessarily completely accepted by all groups. Abel and Browner (1998) show that the acceptance of medical knowledge is often selective. They place specific importance on acknowledging that utilizing non-biomedical forms does not necessarily constitute resistance:

It is important not to romanticize women's resistance to biomedical authority. Much of the recent emphasis on resistance stems from a desire to describe patterns of domination without casting subordinate groups solely as victims (Abel and Browner 1998:324).

I believe this to be the case in Tuscany. While Florentine women considered social relationships to be the main motivation for going to informational classes, information about pregnancy and childbirth provided by the midwife was also a motivation. But these relationships were not a form of resistance to biomedical knowledge and in fact prompted women toward information seeking activities.

Many anthropologists have discussed experiential knowledge as a means of displacing biomedical authority. The New Oxford American Dictionary provides one definition of authority as: "the power to influence others, especially because of one's commanding manner or one's recognized knowledge about something" (2017). Women in Florence considered midwives' manner to be the opposite of commanding and did not necessarily recognize midwives as having expert knowledge. Such power-laden discussion of relationships that stem from the use of the word "authority" does not accurately depict women's experiences with and evaluation of midwives. Midwives, and even doctors, were preferred for the creation of personal relationships. These relationships drove women to information-seeking behaviors, but 
knowledge about pregnancy and childbirth was always a secondary goal. In Florence, it seems that the connection between authority and reproductive knowledge is supplanted by the ways in which women sought out social relationships.

Anthropologists have suggested that experiential knowledge is a way to counter biomedical knowledge or as another source of knowledge available (Abel and Browner 1998; Ketler 1997; Browner and Press 1997). Ketler (1997) shows how this is particularly important to pregnant women on the Italian island of Sardinia. Ketler suggests that Sardinian women use the knowledge fostered and shared in the childbirth classes as a way of reintroducing the experiential familial knowledge no longer shared in Italy. In discussing the ways in which identity for mothers had changed from one rooted in a shared sociality to one of individual experience, Ketler suggests that

the unfortunate and unintended result is the loss of the shared experiences, special relationships, and social solidarity between mothering women that were once so important. Although not the expressed purpose, childbirth education courses sometimes helped women to partially recover these losses (144).

Ketler connects experience, relationships, and social aspects, but through her focus on experiential knowledge, she implies that a search for sociality is the same as the search for experiential knowledge, but I would contend that these two concepts should have at least some degree of separation. While sociality can facilitate the spread of experiential knowledge, women in Florence separated the search for knowledge from social support. In Chapter 6, I discuss how sociality during labor demonstrates women's desire for personal relationships over information, but women's experiences in pregnancy demonstrate the problems with automatically combining experiential knowledge with acts of sociality.

Women's experiences with reproductive sociality became blurred in discussing their habits of self-care. The further women progress in pregnancy, the more attention the individual body receives and, in some cases, self-care is facilitated by social interactions. This connection 
between the individual self and the attention of others shows how the social and the individual are not always easily divided. I divided the concept of the social and the individual self into two different sections, however what is social and what is individual is often blurred. Individual anxieties can be shared and ameliorated in a social group. Women's pregnancy experiences demonstrate that when discussing the connection between the individual and the social, a spectrum emerges that runs from complete individual isolation to complete social integration. Women's experiences in Tuscany show that the individual is not always so easily delineated from the social context.

This integration of the individual self and the social is an aspect of women's reproductive experiences that the Ministry of Health guidelines do not acknowledge. Instead, they chose to focus on the individual who can be provided information to ameliorate her individual fears. This portrayal of reproductive decision making, however, ignores the many different social activities pregnant women partake in to decrease their fear and anxiety. Fear is not a monolithic emotion felt equally by all women or easily ameliorated by individual medical interventions. Moreover, fear did not necessarily mean that women desired a cesarean section. Even though the majority of the women in my research expressed some fear of childbirth while they were pregnant, none expressed the desire or asked for a cesarean section. Only one woman said she would want a cesarean section if she gave birth in the future. Understanding the complexities of how fear influences women's decisions and how social interactions ameliorate fear is essential in creating appropriate guidelines that accurately portray how women's experiences impact their decisions.

The women in my study also demonstrate that fear is not mitigated by information. Almost all of the women in my research attended a midwifery class; however, most were still afraid. Women's fear was based on many perceptions and potential futures that were unknown to the women. These types of fears cannot be mitigated by knowledge alone. Women sought 
out different forms of social connection not to gain the medical information the guidelines recommended, but to share in an experience. Social connections with others, as well as the positive experiences facilitated by different means of sociality, provided women with the type of support they desired. While these different types of sociality did not necessarily quell fears, fear did not lead to an increased desire for medical interventions in childbirth. As I will show in the next chapter, support was essential for women's positive birth experience as well, although through a smaller number of people than in the prenatal classes. In Florence, fear was not connected to obtaining scientific information about birth, nor was it always decreased through social behaviors. Fear was simply an emotion that women had based on the unknown.

It's worth noting that while women were very active participants in their own individual experiences and socialities, many of these experiences were facilitated by the government. While some women paid for the prenatal class, they were offered in all of the neighborhood health clinics at no charge. The abundance of free classes alone meant that women in Tuscany are offered a service that not all countries, or even regions in Italy, provides. Because Italy provides paid maternity leave that must start no later than two months before the due date, expectant mothers are able to attend the prenatal classes that start around that time. It is ironic that the government can facilitate the very behaviors that improve women's experiences in childbirth while not acknowledging the impact of these services.

\section{Conclusion}

As I have shown, sociality is an essential part of women's experiences with pregnancy in Florence. Reproductive sociality provides the foundation for many health and information seeking behaviors deemed essential by the Ministry of Health guidelines. This search for sociality also means that women preferred the interactions with midwives to doctors. Women 
felt that midwives and the classes they taught better fostered a sense of sociality that women craved in pregnancy. Regardless of a woman's desired health practitioner, however, personal characteristics that made women feel supported were a much larger motivation for women's preference for a doctor or a midwife as a source of information. Women's desire for a positive relationship with the healthcare practitioner was of greater importance than which source would provide information. The importance of information is not entirely dismissed by women, but it is a secondary motivation. Women's desire for sociality in pregnancy shows that in at least one place in Italy, sociality should be focused on as a key aspect of appropriate medical care.

The desire for a social experience becomes complicated by the importance women place upon the self. Women's discussion of self-care behaviors demonstrates that pregnancy is a unique time for women. An expectant mother's life will change, but not too much, as they search for the Goldilocks of lifestyles. But the unique time and changes an expectant mother experiences, are not always so individual. While certain aspects of self-care are important to pregnant women, the individuals cannot detach itself so easily from their socialities. The individual collides with the social requiring an understanding that the two are not dichotomous, but often linked to varying degrees under varying circumstances. Increased attention to the individual, the social, and how they intertwine is essential in understanding women's experiences during pregnancy

Just as we see a rich connection between the individual self and the social body, this chapter shows the complexities of childbirth-related fear. Unlike the simplistic, monolithic, representation of fear in the Ministry of Health guidelines, women's experiences with pregnancy in Florence suggests that fear is much more complex. Women's fear does not necessarily come from a lack of knowledge about childbirth, but fear of the unknown. Even past experiences of birth did not necessarily ameliorate women's fears, although social groups did help alleviate 
some anxieties. Even though the women's fears of childbirth were complex and varied, fear still had no relation to women's desire for a cesarean section. As I will show in the next chapter, certain beliefs about childbirth could be a stronger indicator of women's desire for cesarean. 


\section{CHAPTER 6 \\ BIRTH IN THE HOSPITAL: MEDICAL INTERVENTIONS AND WOMEN'S EXPERIENCES DURING BIRTH}

Women's experiences with pregnancy in Florence reveal the relative importance of midwives over doctors, highlighting the significant departures in women's experiences during pregnancy from the government maternity care recommendations. This chapter focuses on similar themes relating to women's experiences specifically in childbirth. Several aspects of childbirth remain unacknowledged as a potential means through which maternity care policy could be improved throughout Italy. Women speak again about the relative importance of midwives over doctors, not as a source of medical expertise, but as a source of emotional support and women praised midwives for specific positive personal characteristics. The type of midwifebased care women experienced in Florence suggests that the anthropological analysis of (de)medicalization requires a clearer update and definition to understand the demedicalization as a process that happens on a spectrum.

Women's experiences as individuals during pregnancy can also be found in women's narratives in childbirth. But women's experiences in childbirth also show some new, albeit seemingly contradictory, dimensions. Women's emphasis on social connections in birth are not always acknowledged in their narratives, as women had to be asked about the roles of others in birth after they had discussed their own experiences. Just as in the last chapter, women move between discussing their individual and social experiences, blurring the lines between the two.

I first discuss how women perceive doctor's, midwives', and their own roles in childbirth. The importance of the midwife was not always based on their qualifications, but again on their 
personal characteristics. Even personal connections with doctors, however, were used when women considered them appropriate. I then discuss how women chose their place of birth. Risk played a large role, as home birth was often seen as too dangerous in case something went wrong. I move on to discuss a theme acknowledged less often in anthropology: space. Women's experiences in childbirth demonstrate the many different ways in which space is construed relating to birth. I move on to discuss how women perceive pain management techniques and technological interventions in childbirth. Women prefer births with low technology, but their risk aversion leaves room for the use of epidurals and cesareans under certain circumstances. Finally, I discuss three birth narratives. These narratives demonstrate certain aspects of women's care that are not easily discovered through other questions during the interview and demonstrate the complex mental connections women make as they move between discourses of individual and social experiences.

\section{Protagonista, Fondamentale, Niente: Different Actors' Roles in Childbirth}

Much like pregnancy, women in labor in Tuscany had interactions with both midwives and doctors; however, the quality and quantity of the interactions were perceived very differently by my participants. During pregnancy, doctors often had very little influence on women's decisions relating to birth. When asked if there was any decision they had made about birth or pregnancy that their doctors did not approve of, the majority 35 (70\%) women I interviewed said no. Of the $15(30 \%)$ that said yes, only five women said that their doctor's opinion changed their mind about where to give birth. During labor and delivery, women considered doctors to have a very minor role. In fact, when asked about the general role of the doctor in birth, almost all women (44 out of 50) said doctors had very little or no role. When asked about the doctor's role in labor many women responded with "niente" or "nulla," meaning "nothing." Most women, 
however, considered doctors to be important if there was an emergency or a problem, as one woman remarked: "Birth is not under the expertise of the gynecologist. The gynecologist must intervene when the midwife considers that there is a problem." This comment demonstrates that women consider doctors to have both limited utility or utility under only certain circumstances during birth. It also shows the commonly held belief that midwives were the primary healthcare professional responsible for birth.

Women's conceptions of midwives' roles varied, but most women considered midwives to be "fondamentale" or fundamental to the birth process. Women's praise of midwives' work often was based on three general areas of assessment: general evaluation of care, medical care, and personal characteristics. Women generally evaluated their midwives as "brave" or "good." Women felt like they were "trovata bene" or "well followed" by midwives during birth. Women's role as a medical professional was often delineated by the "consigli" or "advice" they provided to women to aid in the birth. Women also thought that midwives were attentive and helpful. But these characteristics were only part of what women desired in a midwife.

When discussing her own experience in childbirth, Sara, a mother of two from the south of Italy, said that her experience with the midwife was "exceptional" because she received care "at a humane level, not only at the professional level." Sara's words demonstrate a more general desire among women to receive care not only at the medical level, but at more personal level. Women often commented on the personal characteristics that impacted women's interactions with midwives. Positive personal traits of midwives included that they were "carine" (kind), that they were "accogliente" (hospitable), or they "ascolte" (listen). Even more telling were the traits women described as negative for midwives. These were almost all limited to personal characteristics, not quality of care, and included "cativi" (mean), "indifferenti" (indifferent), and "sgradevli" (unpleasant). 
It should be noted, that while women overwhelming considered midwives to be more important than doctors in their childbirth experience, some women mentioned the importance of a doctor in circumstances particular to their own birthing experience. One woman described how she had such a bad experience in which she had to call her doctor to help her through her birth. Several other women also mentioned choosing the hospital based on the fact that they knew a doctor that worked there. While women did not consider doctors to have a fundamental role in a normal pregnancy, women's bonds with specific doctors resulted in roles that were more subtle. Doctors' roles were valued in a much more personal and specific way by some women, underscoring the fact that what women desired were personal connections during birth, whether with midwives or doctors.

Along with midwives, birth partners were considered important as well. Women were often accompanied by romantic partners or husbands during birth, although a few women had their parents present at some point and one woman was accompanied by no one. Partners were particularly important, as $82 \%$ of women stated that their partners helped in some way. Birth partners were often praised for their "supporto psicologico" or "psychological support." They were often a help to the midwife or helped with little things such as getting food. Even the women who said they did not consider their partners to be a help said that their partners did small things in labor

While midwives and birth partners are seen as important, most women consider the role of the woman in labor to be of utmost importance. When asked about the expectant mother's role during birth, women overwhelmingly stated that they had some kind of a primary role. The most common response was "protagonista" or "protagonist," but other responses included "principale" (principal), "primo ruolo" (main role), "centrale" (central), "fondamentale" (fundamental), and "tutto" (everything). Some women discussed how as a woman you do most 
of the work, albeit with some help. As Francesca puts it, "you can do...90\% because 5\% is the person next to you and 5\% is the midwife". Women consider the people around them to be helpful during birth, but women clearly consider their own roles as fundamental.

\section{Choosing Where to Give Birth}

Women's experiences with healthcare professionals demonstrate that women desired a certain level of personal interactions rather than just medical competence. Midwives often filled the role of personal care provider, but when that failed within the hospital, doctors were sometimes called upon too. It's important to note that, in my research, the majority of women's birth experiences took place within the hospital. In rare cases, women called their doctors to the hospital in times of need. Doctors' place of work in a specific hospital was an important factor in deciding where to birth for a few women. Few women sought out a private midwife for care during pregnancy $(n=10)$. Only one woman in my research gave birth at home. Her home birth was due to a quick labor; she had planned to give birth at the hospital. For women in Florence, the hospital was the most common place women desired to have birth.

There are three main hospitals in the Florence area. Although one is technically located in Bagno a Ripoli and outside of the Florence city limits, it was the hospital several women chose for birth. When asked their reason for choosing or not choosing each of the three main hospitals, all women were familiar with the hospital in Bagno a Ripoli, demonstrating that women understood it to be a possible option for birthing in the Florence area. The location of the hospital in Bagno a Ripoli, however, was often an important influence on women's birth decisions, as distance was a key factor. Fifty-eight percent of women said that they chose their hospital because it was "vicino" or "close" and 30\% of women responded with "vicino" as their 
first response to the question. Thirty-two percent of women also responded that they did not choose to go to Ponte a Niccheri because Bagno a Ripoli, was "troppo lontano" or "too far." While distance was one of the most salient factors in women's choice in place of birth, several other factors were important as well. One key aspect was a personal connection with the hospital. Thirty percent of women said that they chose their hospital based on their previous interactions. This was especially prevalent for women who chose Careggi as a place of birth. Many women received their prenatal care at Careggi and used this experience to evaluate whether they would like to give birth in the same hospital. There were also a few cases of women who attended a tour of La Margherita, the midwife-run birth structure connected to Careggi, and used this experience to decide on birthing there. Several women explained that they saw the structure and decided to give birth there if possible. Other personal connections women used to choose birthing hospital were the presence of doctors they knew or personal stories they heard from friends and family. Personal connections and experiences were clearly fundamental to women's decisions regarding place of birth.

Another key aspect of women's decisions on place of birth was risk. Many women considered birth to have a certain small level of risk for either themselves or the fetus. Risk colored women's decisions, particularly for those who chose to give birth at Careggi or La Margherita. Careggi is a "terzo livello" hospital, meaning it is able to accept patients with potential risk to the expectant mother or fetus during birth. The potential for intervention in case of emergency provided women with a sense of security while experiencing a potentially risky event. The same risk aversion was present in some women's decisions to give birth in $\mathrm{La}$ Margherita. La Margherita offered the possibility to give birth in a place that felt like home, but with the possibility of quickly being transported to Careggi if medical intervention was needed. 
The presence of the pediatric hospital, Meyer, at Careggi also provided women with a sense of security in case an unexpected problem arose with the baby. For Giorgia, a mother of one who chose to give birth at La Margherita, risk for her child was important. While several women suggested that they wanted to give birth at La Margherita because it was close to Careggi in case of any unforeseen problems during birth, Giorgia did not state this. She did, however state that potential risks to her baby made the closeness of Meyer essential: "Careggi is close to Meyer. I knew that if anything could happen it was important that my baby was safe." Women considered hospitals to be safe because of the potential for any unforeseen problems that were possible in the course of birth. In the next section I discuss more about the hospital as protective space.

Vicino: Closeness and Space in Women's Birth Experiences

The previous section began the discussion of the hospital as a desired space of birth for women in Florence. In discussing their choice of hospital, women mentioned different aspects of birth as they relate to space. Space became a subtle, albeit recurring, theme of women's experiences with childbirth. I've already shown how women associate hospitals with the potential for intervention during any problem, but the hospital space was more deeply entrenched as the site for a safe birth. While anthropologists have looked at space in home birth (Cheyney 2011; Hazen 2017), the hospital as a site of both safe and midwife-based care requires a departure from other birth analyses. By integrating a discussion of space and place into my analysis, I add to a small amount of literature that integrates an analysis of space into larger anthropological projects.

There was nothing more indicative of women's preference for hospitals than how they discussed home birth. I have already shown that women prefer midwife-based care; however, I 
will later detail how women prefer a natural childbirth or births that use only complementary medicine for pain relief. While anthropologists have focused on how women search for these types of experiences in home births (Cheyney 2012; Hazen 2017), women in Florence did not make the same connections. Rather, they overwhelmingly consider home birth as inherently risky. When asked if they thought home birth was safe, $70 \%(n=35)$ of women said no. While some women recognized the comfort with giving birth at home, most women focused on the possible problems that could not be attended to outside of a hospital. One woman even went as far as saying "I think the women who [give birth at home] are a little crazy unless they are in front of the hospital. It is to be avoided, too risky." This quote demonstrates simultaneously the belief that home birth is risky and hospital birth is safe. Even for women who thought home birth was a nice idea, there was still a lot of fear of giving birth outside of a hospital:

[Home birth is] beautiful, I could have [given birth at home], .... but I'm a bit scared, it doesn't seem to be very safe. Because if something happens it's a good idea to be in the hospital. The doctors are ready to intervene. At home, where you have to go to the hospital, you could possibly have a hemorrhage.

The contradictory sense of a "beautiful" home birth and the desire to give birth in the hospital was one of the reasons that so many women preferred La Margherita. La Margherita represented a compromise between the comfort of giving birth at home at the safety of having giving birth in (or within 20 feet) of a hospital. As on woman put it, "[La Margherita] seemed to me to be an ideal compromise. I felt protected in a hospital environment, but it recreated a home environment." Women's opinions about home birth demonstrate that the hospital is seen as a space in which risks can be confronted in a timely manner through trained professionals.

Space is a concept through which women in Florence discuss risk and childbirth; however, the concept of space was also present in how women talked about their experiences during birth. Hazen (2017) suggests, "central to this cultural meaning [of childbirth] is a fundamental spatial component to birth, with place critical to the narratives associated with birth 
as well as its politicizing nature" (556). While Burns (2015) and Hazen (2017) recognize that discussions of place are fundamental to discussions of birth, especially home birth, my research shows that space and place cannot be defined solely through the physical built environment. One key aspect of how women talked about space in their birth was the concept of "closeness" of those in the labor room. Only one woman was not accompanied at birth. The majority of women were accompanied by their partners or husbands; however, family members such as mothers also arrived at the hospital during labor. When discussing the utility of their partners during birth, $62 \%$ of women said that their husband helped them. Ironically, when asked what their partners did, many said "nothing" or "little." Of the $38 \%$ of women who said their partners didn't help during birth, when asked what they did, they mentioned that their partners helped with talking to the doctor, getting them food, or giving them massages. Regardless of what the partner did or didn't do, one thing that was clear between both the groups of women who did and didn't think their husbands helped was that the partner was "vicino" (close) or "sempre con me" (always with me). For some women, just being "vicino" was enough support. Women often said their husbands provided emotional or psychological support. When asked what her husband did during birth Giudita, a mother of two from the south said, "Just the fact that he was there with me was important." Regardless of whether women considered their partners to be a help during birth, having someone near was important. While some women praised midwives for their ability to stay close, it was the partners that were discussed far more in terms of "vicino."

One last aspect of space that women discussed was the characteristics of their room or of the hospital. Forty percent of the women who chose to give birth at La Margherita did so, in part, because of the rooms. Women primarily liked that the rooms were private; however, specific furnishings in the room were important too. The rooms were equipped with birthing tubs (which even women who did not choose La Margherita mentioned) and a birthing chord 
hung from the ceiling (which women held on to give birth in a more vertical position). Very important to some women were the private bathrooms. In fact, for one woman, the room furnishings were enough to make her doubt giving birth at Ponte a Niccheri: "I was a little

worried, because my friend gave birth at Ponte a Niccheri....It was old. The beds didn't raise up, there weren't bathrooms in the room." When she took a tour of the hospital, however, she realized it had been updated and she was less afraid.

The complexities of space are present in Italian women's experiences and choices surrounding childbirth in Florence, although it receives little attention in the anthropology of childbirth. Women's perceptions and preferences relating to birth are often tied to the way in which space is viewed. The hospital is the "just in case" space, the space where women feel safe and sheltered from the potential risks of childbirth. Closeness to a partner is also a way in which women can protect themselves, but instead of medically, partners offered psychological and emotional support women needed. Concepts of space, whether they are related to risk or the desire to create a comfortable environment are essential in understanding women's views of childbirth in Florence.

\section{The Connection Between Birth and Medical Interventions}

This section looks primarily at women's opinions about different pain control methods and medical interventions in childbirth. Women were asked about their opinions of 5 topics: pain control with only complementary medicine, pain control with epidural, natural childbirth, home birth, and cesarean sections. It should be noted that women were given examples of complementary medicine that included water birth, massage, and breathing. Breathing was used as an example in later interviews after I had realized that women commonly discussed breathing as a form of pain control. Both breathing and massage were considered important forms of pain 
control to women, although Tuscan recommendations never mentioned these. Showers were also often considered both a form of pain control and a mode through which birth could be accelerated. While no questions were asked specifically on these pain control methods, $82 \%$ of women stated in their birth narrative that they did one of these activities.

Women overwhelmingly considered natural childbirth to be the ideal mode of birth, although throughout my interviews, it became clear that women's definitions of natural childbirth may have varied slightly. This variation aligns with MacDonald's (2006) discussion of the difficulty with discussing natural childbirth as an objective category. For example, a couple of women mentioned that they wanted a natural childbirth "with an epidural," an intervention not always considered "natural" among anthropologists studying birth. I began to ask women to define natural childbirth during my last interviews, but definitions varied significantly, a not uncommon trend found among anthropologists interrogating the concept of natural birth (Logsdon and Smith-Morris 2017). The most common response was a birth "senza intervento" or "without intervention." Other responses, however, included following the signals from the body and acting "piu animale" or more animal. Regardless of these different definitions, natural childbirth was the most commonly supported type of birth. Women often describe this mode of birth as "bello" (beautiful) or "meglio" (better). Most women (56\%) said natural childbirth is "come dovrebbe essere" (how it should be) or "l'ideale" (the ideal). Out of all the modes of birth, this and the use of complementary medicine were the modes which were considered safe by the most women.

Almost all women had a positive view of using only complementary medicine for pain relief, some women even stating that pharmaceuticals were being overused. Most women said that pain management using only complementary medicine was "positive" (positive) or "meglio" (better). Giudita, a mother of two from the region of Lazio, said that using complementary 
medicine "is the ideal. It would be a perfect birth." This ideal use of complementary medicine, however, was based on a specific set of circumstances, as Giudita also said that this "always [be done] if there aren't any physical complications. Complementary medicine is ideal, but only under ideal circumstances."

The focus on when to use specific interventions was a theme throughout women's discussion of each interventions and modes of pain control. The majority of women considered all interventions safe, or safe under certain conditions. Table 6.1 shows the percentage of women who considered each intervention or mode of birth as safe. While most women considered natural childbirth to be the ideal, other medical interventions were considered safe; however, mostly under specific circumstances. When asked if these interventions were safe, women often answered, "Yes, but..." This was a time for women to explain the specific circumstances under which each intervention or mode of birth was safe. Particularly relating to epidural or cesarean section, women often followed their answers with stating the inherent risk of each. Women were quick to note that cesarean sections carried all the risks of an operation. Even with natural childbirth and complementary medicine, women also responded that a laboring woman should utilize these modes only if there were no complications with the pregnancy or labor. Again, we see risk as an area of concern for women.

Table 6.1 Percentage of Women Who Consider Each Pain Control Technique or Mode of Birth Safe

\begin{tabular}{|l|l|}
\hline \multicolumn{1}{|c|}{$\begin{array}{c}\text { Pain Control Techniques/Mode of } \\
\text { Birth }\end{array}$} & $\begin{array}{c}\text { Percentage of Women who } \\
\text { Consider Each Safe }\end{array}$ \\
\hline Natural childbirth & $86 \%$ \\
\hline Birth with complementary medicine & $84 \%$ \\
\hline Epidural & $74 \%$ \\
\hline Cesarean & $70 \%$ \\
\hline Home Birth & $24 \%$ \\
\hline
\end{tabular}


Table 6.1 also shows that women considered home births to be less safe than all other interventions. While I previously discussed women's opinions of home birth vs. the hospital, comparing women's opinions of each different intervention and mode of birth shows a slightly different iteration of this issue. Regardless of the idealization of natural childbirth, the potential risks of not being at a hospital during birth outweighed the potential birth experiences of a home birth. As women discussed the use of epidural and cesarean, it became clear that women considered medical interventions to be more important than natural childbirth in risky or complicated births. Several women considered epidurals or cesarean sections to be "abusata" (abused), however even these women considered certain circumstances to be appropriate for the use of these medical interventions. These conditions were usually very strict for cesareans. Women considered the use of cesarean sections to be appropriate when there was no other option or when the woman's life was in danger. While most women considered cesarean sections to be a last resort, women were far more supportive of epidurals as a "grande risorsa" (great resource) or a "scelta valida" (valid choice). Women considered epidurals to be acceptable when the pain was "insostenibile" or "unbearable." Unlike cesarean sections, which required a much more dire set of circumstances, epidurals were considered reasonable to use depending upon women's subjective experiences of pain and birth.

For women who did not want an epidural, pain was actually an important part of birth. Teresa, a mother of two from Tuscany, explained, "I want to feel everything that happens to me. Also, the pain, in my opinion, is useful in birth.” This quote shows two major themes I hear from women who did not want epidurals. First, women often said they didn't want an epidural because they wanted to "sentire tutto" or "feel everything" during birth. Feeling the baby being born was emotionally powerful to some women and they considered an epidural to interfere with this process. Second, women considered pain to be helpful, a way for the body to birth the baby. 
Pain was the body's natural way of progressing the birth. Suffering, however, was not the point of pain. While other anthropologists have noted that women sometimes consider the pain and suffering during childbirth to be a kind of just punishment (Van Hollen 2003), pain was as a necessary part of a desired birth, which is similar to what Logsdon and Smith-Morris (2017) found in their research on natural childbirth in The Netherlands. It was not seen as a punishment, but as a natural part or an aid to a birth without pharmaceutical interventions.

Opinions about interventions and mode of birth varied to some degree among women, but natural childbirth or childbirth without pharmaceutical interventions were the ideal. Regardless of this ideal, women did not stick staunchly to the necessity of a natural childbirth. Women's risk aversion demonstrates how they view birth as a potential site of risk. This risk is best attended to in a hospital with highly medical interventions. These medical interventions, however, were not to be abused, as medicalized pain management techniques and interventions were only considered appropriate during difficult births. Elucidating women's views on pain management and modes of birth demonstrates the complexities with which women engage with medicine and birth.

\section{Birthing Stories: Interactions and Events at the Hospital}

Previous sections have primarily detailed women's thoughts and opinions about childbirth based on responses to specific questions. This section analyzes women's stories about their own births. I use three birth narratives to illustrate the key themes present in women's stories about childbirth. I detailed many of the difficulties of eliciting birth narratives in Chapter 3. Writing about narratives also presents some problems. Many women talked for several minutes about their experiences, providing me with multiple paragraphs of rich data to analyze. I started the elicitation of most women's birth stories with the question "When you arrived at the 
hospital, what happened?" Some women spoke as briefly as Patricia, a mother of one from Tuscany whose response to the question was, "I had [my water] broken and they immediately put me in the room because I did not have any contractions. And then they led me [to the labor room] in the morning." This required several follow up questions to elicit more information. For women with such short responses, one of the most common follow up questions were "What happened in the labor room?" and "What happened in the delivery room?" While responses were still usually short, they allowed me to get a picture of every woman's experience during birth.

Analyzing narratives requires far more than the analysis of just the objective events. The stories often show deeper ideas about women's desires and priorities surrounding birth. I have categorized the narratives into short, medium, and long. The short narratives encompass no more than 4 sentences and no more than 3 lines of text. The medium encompasses 5 to 10 sentences and from 4-6 lines of text. Long narratives encompass more than 10 sentences and more than 6 lines of text. Table 6.2 shows the percent of each in my research sample.

For narrative analysis, I have chosen to focus on medium and long narratives. I have also chosen to reproduce entire, uninterrupted narratives for the reader, rather than a string of quotes. In using both longer and uninterrupted narratives, I am able to present how women told their stories. Representing women's birth narratives in this way provides material for a rich analysis of how women perceive the care they received as a process. I also chose the three narratives because they represent different levels of medicalization of birth and different places of birth. One woman had a birth in La Margherita, with no medical intervention beyond the care of midwives. One woman gave birth in Careggi with moderate medical intervention. The final woman gave birth by cesarean section after trying to give birth in La Margherita. The first two are typical of many birth narratives that I heard. The last is not so typical but represents the ways 
in which women received highly medicalized care. By using these three different types of narratives, I demonstrate the range of experiences women had in birth.

Whenever analysis of aggregate data is necessary, I use the answers from all of the questions and all participants meant to elicit a birth narrative. I also use some text from follow up questions; however, this will be noted. While story telling does not always have a clear flow or follow a linear timeline (Mattingly 1998a), I have chosen to use certain women's narratives because of the ease in following their story. I include only narratives that did not require several follow up questions. These women provided incredible depth into what happened during their birth and my elicitation of further information was not always to create a narrative, but to elicit specific information. Some women stopped at certain points in their story and I used the follow up question to ensure the woman knew that I was interested in a complete story of her birth experience. When asked, the follow up question is noted in bold.

Table 6.2 Percentage of Different Lengths of Birth Narratives

\begin{tabular}{|l|l|}
\hline Short Narratives & $18 \%$ \\
\hline Medium Narratives & $52 \%$ \\
\hline Long Narratives & $30 \%$ \\
\hline
\end{tabular}

The first birth narrative I chose to analyze is, in many ways, typical of the births stories I so often heard. Greta a first-time mother who was 32 at the time of her birth chose to give birth at Careggi. Greta considered Careggi the "best hospital in the city." Like many other mothers, she considered Careggi to be best staffed for any potential problems her baby might have. She also liked that the maternity wing was new. Greta did not have problems during pregnancy, but her birth was labelled as risky because she was still pregnant past her predicted due date. Greta had wanted to give birth at La Margherita but being past her due date disqualified her from their rigid standards. Greta had no disagreements with her doctor regarding her choices surrounding 
birth, although she did find the many tests to be annoying. Below is Greta's narrative. One

follow up question is noted in bold.

[We went to] the emergency room. We waited there. They did an echography and a checkup. Then, at some point, the took me to the [maternity] wing. Then, during the afternoon, checkup. Then they said, "tomorrow morning, the morning of the 26th, the gynecologist will come to do a checkup and he will decide what to do, if you wait, or if you get the IV for induction. During the checkup, the gynecologist did a maneuver "dissection of the membrane," [water breaking]. With that, the contractions started, for more than 12 hours, $13,14$.

\section{During this time, what happened?}

I had contractions, already a bit of labor, I had it. It was only that, the delivery rooms, there were at least three, they were full, so they made me stay in the room. I was there, I had lunch, ate something. In the meantime, the pain went on and then when delivery room was free, they took me to the delivery room. In that time, I went through all the parts of labor and then gradually the contractions came on. When I went to the delivery room, they thought to give me an IV oxytocin, but when I got to the delivery room, there was no need, because it had already been several hours that I'd had contractions, and the dilatation was going forward, and therefore there was no need for [oxytocin]. They suggested to me to move, or, in short, positions for helping her head go down. Then they made me try to push, in a few positions. then there was a student midwife. For an hour, she massaged down, I have pain, I have here [pointed to lower back]. And every time they did a checkup, to see at what point, and then at a certain point, [they gave me] a bit of oxytocin, in the IV, because I had arrived at nine centimeters and the last one [centimeter] was left. Then they put me on an IV of mineral salt, I think, because I had eaten little, in short, [I was] a little tired. Then, when I arrived at 10 centimeters of dilation, then I began to push. The midwife, that was always with me, guided me, when to push and how much, for how long.

Greta's birth narrative shows several themes common in other narratives. Most common was strong adherence to the objective events. Like so many other narratives, Greta's descriptions of a linear stream of events suggests a more or less coherent timeline of the events during birth. Greta's timeline relied heavily on her physical, rather than emotional, experiences during childbirth. Greta focuses primarily on the physical progression of her labor, discussing dilation and the different positions she was asked to try, more so than the pain she was experiencing. It was so common for women to describe this type of narrative that almost all 
women followed the same timeline of movement through the hospital: arrival at the emergency room, checkup, placement in the labor room, and finally the move to the delivery room.

A relatively surprising omission from Greta's narrative, however, was a discussion of midwives and their behavior. While I detailed earlier the many personal characteristics women praised in their interactions with midwives, that information came primarily from a follow up question about midwives' behaviors. Almost half of the women in my sample described their interactions with midwives in a highly medicalized manner. Greta's use of the general pronoun "they" to signify something done by the hospital staff was common in these narratives. It should be noted that many women used their narratives as a means through which to discuss their positive interactions with midwives. A high number of women, however, discussed midwives and their behavior in very general terms. As I show in the next example, even women who wanted to give birth in the midwife-run structure, La Margherita, didn't always discuss the positive qualities of their midwives.

The lack of focus on interactions with midwives was also present when discussing birth partners 9 . When later asked about what birth partners did, only $30 \%$ of women said "nothing," however, very few women mentioned the behaviors of their partners during birth. In contrast to their discussions of reproductive sociality throughout the rest of the interview, many women focused on their own individual experience during their birth narratives, referencing the roles as "protagonista" (protagonist) of their own birth. In focusing on the objective events of birth, women often also focus on their own feelings and behaviors. Interactions with partners and midwives were noted, but the focus was on what women did. This comes as no surprise given

\footnotetext{
${ }^{9}$ Women often called boyfriends, fiancés, and husbands as partners, however, this is not necessarily the intent of this word. I choose the general term "birth partner" because a small number of women had their mother in the room at some point during delivery
} 
the high number of women who said that a woman's role in labor was the "protagonist" or primary role.

The following narrative is from Benedetta, a mother of one from Florence. Benedetta wanted to give birth in La Margherita for the "intimacy." Like most other mothers, Benedetta also felt secure in the fact that there was a neonatology department at the adjacent hospital in case anything went wrong. Benedetta's doctor supported her decision to give birth at La Margherita.

I was outside of Florence, I was in Umbria. My water broke and I called La Margherita because they had all my clinical records and they told me to go to them and have a checkup. I arrived in a couple of hours and they did my checkup. They saw the broken water, but I still hadn't had [strong] contractions and they admitted me at 3,4 in the [morning]. At 4 [in the morning] they gave me a room and I tried a little to sleep. Then, around 7:30 [in the morning] they had me take a shower for an hour. Or rather, first they did a checkup and I was not dilated and I took a shower for an hour. When I exited the shower, she asked me if everything was normal, if I wanted to push. They did another checkup and they saw that I was already dilated and the took me to the bed and they started, they put, the thing for hearing her heart, and I started trying to push when I had a contraction and relaxed when I didn't have them. They made me change positions. They gave me a big pillow. [I was on] the side or was squatting with the midwife, she helped me. They gave me a stool. They made me try to go to the bathroom because I had strong contractions. Then I pushed, then the contractions finished and I relaxed. They also had my friend [at La Margherita]. She tried everything too. And then, at the end, after an hour, hour and a half, I had tried everything. They took me to the bed. They did a checkup, [with] her hands supporting my feet and like this I did the last push, to push [the baby]. A midwife also helped me push, pushing on my stomach and she was pushed out on the last one.

While Benedetta gave birth in a midwife run clinic, her narrative shows many similarities to Greta's. Like Greta, Benedetta's narrative focuses primarily on her as the individual experiencing birth in a linear timeline. The timeline was a little different, however, because she birthed at La Margherita, where she did not have to go to the emergency room or into the labor room (rooms in La Margherita are not separated into labor and delivery, instead a woman is given a single room for the entirety of labor and delivery). She did however, discuss the checkup 
and being taken to the delivery room. This timeline also contained, albeit slightly more than Greta's, a discussion of the different positions in which she tried to give birth. While not all women discussed this part of delivery, many women did. Benedetta's narrative also contained more time markers than Greta's, showing, again, the importance of a linear timed narrative, such as the point in which she stops to say she had a checkup, and then a shower. The linearity was common in women's narratives in which birth was relatively easy, suggesting that women expected and experienced a certain progression of events. This focus on linear time could have been based on the language of the prompt ("When you arrived at the hospital, what happened?") which subtly suggests a sequential time frame.

Even though Benedetta described her desire to give birth at La Margherita because of the "intimacy," she does very little to talk about the intimate environment of her birth. She describes more of the actions of the midwives than Greta but discusses little about the personal characteristics of the midwives. In a follow up question, however, Benedetta praised the midwives for being "carina" (kind), "dolce" (sweet), and "disponibile" (available). She said they were so good that she "disliked having to leave and go home." Despite this praise for her midwives, Benedetta included very little of their behaviors, especially their positive personal characteristics, in her narrative.

Benedetta also discusses pushing at the end of birth. This was another aspect of birth that not all women discussed, including Gretta above. As I discussed above, pushing, and feeling the push, was some women's motivation for not getting an epidural. Other women, however, discussed this aspect of childbirth very little or not at all. A lack of discussion of pushing was far more common in the short narratives, however, it was a theme that occurred throughout all narrative lengths. 
The next birth narrative comes from Giorgia, a first-time mother from Florence. Giorgia was 40 at the time of the birth of her daughter. Giorgia's case covers several different aspects of birth, as she started to have a natural birth in La Margherita, and then was transferred to Careggi for an eventual cesarean section. Giorgia chose La Margherita because it seemed like a "beautiful experience." Like the other mothers, she also liked the idea that La Margherita was close to the pediatric hospital. In the three days preceding her daughter's birth, Giorgia went to the hospital several times thinking she was in labor and was sent home. Her narrative starts at her final arrival at La Margherita.

They gave me a room at La Margherita and a midwife came with me to check at what point [labor] was. Fundamentally, [she came] for moral support. After, there was also my husband. And then they went later to find my gynecologist. [She was] almost at the level of a friend. She came to see how I was and she gave me a little company.

\section{And the midwife recommended going to Careggi?}

The midwife in La Margherita, after trying several modes [to stimulate birth], sent me [to Careggi] because they did not know what to do. They could not do it with natural methods. They sent me there. First, they tried to make me an epidural, because it seems that sometimes it helps to make childbirth go. But did not go ahead and the doctor who I had seen told me that I have to do a caesarean because [the baby's] heart rate had started to slow. She was tired. And she was in a [bad position]

Giorgia's narrative departs significantly from Greta and Benedetta's. Giorgia's narrative shows a clear move from demedicalized to highly medicalized birth. Giorgia's narrative focuses far more on her specific interactions with medical professions in their attempts to intervene in birth. Giorgia's birth timeline focuses primarily on how and which medical interventions were suggested. In fact, the first part has very little timeline and is focused primarily on the presence of medical professionals. This focus on medical staff and interventions also makes apparent that Giorgia's narrative focused very little on herself as an individual, which can also be seen in her reference her daughter's low heart rate. The discussion of risk was present in several women's 
narratives, but Giorgia's shows the ways in which medicalization has the potential to take over a narrative. Her sometimes sporadic narrative is indicative of the many changes and transfers she had to undergo.

Unlike the other two narratives, Giorgia spoke briefly of the positive qualities of the midwife. Ironically, Benedetta spoke more positively about the doctor. When asked later about the behaviors of the midwife and doctor, Giorgia said that the doctor was "bravo" because he very quickly conducted the cesarean section after the fetus's heart rate decreased. While both Benedetta and Giorgia had experience giving birth in La Margherita, comparing these two examples show that choice of midwife-based care did not necessarily mean that women's narratives would focus on this care. Such findings make narratives an invaluable part of understanding women's experiences, especially in interviews with a primarily semi-structured interview format. Using birth narratives demonstrate how women perceived of the care they received during a single event (birth) versus when prompted with more specific questions.

Unlike Greta and Benedetta, Giorgia’s narrative was not necessarily representative of other births, but it shows the variability that women can experience while giving birth in Florence. Where Benedetta and Greta followed a similar birth path, Giorgia's path was ever changing, which is perhaps why the focus of her narrative departed so much from the others. Regardless, each narrative highlights the different experiences women can have during labor. Whether natural, induced, planned or unplanned cesarean, women all received substantial care throughout labor. While some women complained that they did not receive the care they would like, very few women were unhappy with their experiences. The narratives represent a way to understand labor and birth as a process, rather than a series of discrete events. Through describing birth as a process, these women demonstrate how their experience were influenced by their care. 


\section{Women's non-narrative evaluation of birth}

Birth narratives are a means through which to understand hidden meanings and values relating to women's births. There were several other ways that I obtained information about birth. One of those was simply asking if women were generally satisfied with birth experience, which $84 \%$ responded to as yes. Women were also asked whether or not they would choose the same place of birth again. Eighty percent said yes. The main reason women considered giving birth at the same place was because in the end, their first baby had been born safely. For women who did not want to give birth at the same hospital, the most common reason was the inability to birth the way they had wanted.

Women also were asked what they liked and didn't like about their birth experiences. By far, the most common response for what women did not like was the pain, although women also discussed different medical or hospital procedures that they didn't like. What women did like was far more varied. Most women referred to something related to "il finale" or "the end." Women liked feeling the baby being born or holding the baby in their arms. For one woman, the end was the only part she liked. When I asked what she liked about birth, she responded, "In reality, not much. Nothing. Clearly, when the baby came and that's it." Other women also liked the fact that they were able to handle giving birth. Many women described feeling "forte" (strong) or "potere" (powerful).

\section{Discussion: Hospitals, Space, and Roles in Childbirth}

The picture of childbirth in Tuscany shows many similarities with women's experiences during pregnancy. Chief among these was the importance of midwives. As discussed in Chapter 5 , midwives were the primary healthcare professional women saw as important in pregnancy. Doctors were only considered important during problems or emergencies. These problems and 
emergencies often required the use of medical interventions like cesarean sections and epidurals. The importance of doctors in explaining medical tests in pregnancy coupled with their need for interventions only during emergencies (i.e. the need for technological interventions) shows that women perceived doctors as the highly medicalized healthcare professional in relation to maternity care.

Midwives, however, were seen as the healthcare practitioner who gave "humane" care. Just like during pregnancy, women searched for midwives not just because of their medical expertise, but because of their specific personal characteristics. The "humane" care women receive from midwives is based upon their ability to aid, not dictate, what happens during the birth. Understanding the value women place on the care they receive in labor provides a new avenue with which to interrogate midwife-based care, as the focus among anthropologists of midwifery is often the midwives themselves or women's decisions for home birth. Anthropologists of midwife-based care have often focused on midwives' resistance to difficult living conditions (Sesia 1997), or to medicalization of birth (Szurek 1997; Davis-Floyd and Davis 1997). While anthropologists have begun to note the difficulty in moving beyond the dichotomy between biomedicine and midwives, more recently there has been an emphasis on understanding how midwives adapt practices to biomedical realities (Davis-Floyd, Pigg, and Cosminsky 2001). Many works focus on the midwife, especially midwives who were chosen to provide specialized and individualized care throughout pregnancy and labor. Other works that adopt a woman's perspectives on midwife-assisted home births focus primarily on women's choice to birth at home (Hazen 2017; Cheyney 2011). Analyzing women's experience with care from midwives who work as shift workers in a hospital provides a way to understand the characteristics that women who do not want homebirth value in their midwifery-based care. 
By focusing on women's entire childbirth experience and not just their experience with midwives, I found, somewhat paradoxically, that support for natural childbirth, and to some extent the idealization of home birth, was paired with some strong aversion to that type of birth. Risk aversion relating to childbirth in Florence played a particularly important role in women's decisions. While natural childbirth was ideal, women were unwilling to risk safety, particularly of their babies. The home was seen as a place of danger which most women were unwilling to face. Women's childbirth experiences in Florence showed that understanding the care provided by midwives must contain recognition of women's opinions about the site of that care. The fact that so many women wanted a natural childbirth with a midwife, but not in the home, shows that women desired a very certain type of demedicalized birth.

Understanding a woman's desire to give birth in a place like La Margherita, or any birth structure, also requires an understanding of how women view the space of birth. Women's view of risk and place of birth aligns with the common mode of analysis among anthropologists studying space. As Setha Low suggests: "When studying space and place, social science researchers often begin with a social constructionist perspective that highlights the role played by social interaction, symbols, and language in giving form and meaning to physical space (2016: 10). In Florence women's concepts of space include but also go beyond this social constructionist perspective. An analysis of women's responses suggests the mixing of three different conceptualizations of space. First, there is the construction of the hospital as a safe place to birth, a place where (potential) risk can be mitigated by medical intervention. Even though women consider natural childbirth and minimal medical interventions to be ideal, the belief in the hospital as a place to mitigate risk was so strong that the home became imbued with concepts of risk. The second spatializing aspect of women's experiences is their evaluations of the physical settings. Characteristics like the age of the structure and design of the rooms 
impacted how women viewed their potential future birthing experienc, which connects to materialist understanding of space (Low 2016). Third, is the category of geospatial distance. The concept of "vicino," or "close," impacted both women's practical choices (choice of where to birth) as well as their sociality (the closeness of partners). In fact, the concept of "vicino" demonstrates the connection between emotional constructions of spatial relationships and practical decisions. Women's discussion of "vicino" in relation to their husbands helped demonstrated that women wanted their husbands to be near for support, regardless of whether women felt their husbands were helpful or not. Support was not necessarily based on hands-on activities. The connection between "vicino" and the decision to give birth in a hospital, however, represents a more practical aspect of space and women's decisions. For women, being close to the hospital made the process of birth easier. This focus on the practical decision of where to birth is mirrored in anthropological inquiries into the influences of space on actions in everyday life (Low and Lawrence-Zuñiga 2003; Hirsch 1995). In these studies of space, everyday life becomes code for people's practical decisions that are imbued with meaning based on the space around them. Women's decision of what hospital to attend, departs from this view slightly. While a practical decision, it was not an everyday decision, suggesting that anthropologists must expand our understanding our analysis beyond daily decisions towards understanding the way space and place influence larger, short term, decisions. The analysis of how women construe space in relation to their childbirth beliefs and decisions would help the Ministry of Health guidelines to better understand how space and place impact women's desire for technological intervention in childbirth.

While hospital-based care was deemed ideal by women in Florence, the highly medicalized experience of care from a doctor was not desired or considered appropriate in all cases. Understanding the level of demedicalization of birth among women in Florence requires 
defining the term "demedicalization." The term demedicalization, and to some extent medicalization, is not always well defined. Anthropologists often use the term in passing, almost to signify the opposite of medicalization (Ketler 1997; Béhague 2002), but as even Georges (2008: 275) notes in her research on maternity care on the Greek island of Rhodes, "despite a more or less common package of discursive and technoscientific features that tend to travel together, medicalization is not a simple one-directional process or a juggernaut of inevitable uniformity and standardization." Even so, Georges defines medicalization as "the increasingly global process by which biomedicine has achieved the authority to redefine and treat an expanding array of individual life events and social problems as medical problems and ultimately to make exclusive claims over the body" (2008:1). George's goes on to say:

Today in Rhodes, as throughout Greece, pregnancy and birth have become thoroughly and intensely medicalized. That is, they are understood as pathological or potentially pathological conditions and events that require the surveillance and intervention of certified biomedical experts, guided at every turn by technology to ensure a successful outcome (2008:187).

Georges's definitions, however, do very little to discuss hospitals which are commonly seen as spaces of medicalization, particularly relating to birth. How can you measure biomedical authority in the case of Florence where women do not consider birth as a pathology, but want to give birth in a hospital "just in case"? Is it medicalization if women give birth in a hospital, but are not "guided at every turn by technology"? Women's experiences with birth in Florence suggest that medicalization and demedicalization, are not so easily defined in opposition to each other.

A more specific definition comes from Béhague (2002). In discussing the work of Johanson and Newburn (2001) on birth practices in England and Sweden, Béhague provides a definition of demedicalization: "In England and Sweden, efforts to 'demedicalize' the birthing environment by reducing the number of technological interventions as a whole and providing a 
supportive friendly environment seem to have positive effects on reducing c-section rates." (2002:500). If demedicalization can simply be the "reduction of technological intervention," thinking of demedicalization both as a spectrum of technological and pharmaceutical interventions, and as historically and culturally unique to specific locations provides a more inclusive definition of medicalization and demedicalization. For most women in my research, demedicalization meant a reduction, but not the absolute absence, of certain technological interventions. Demedicalization meant that natural childbirth was the ideal, but Italian women's risk aversion caused them to prefer the availability of certain medical interventions, primarily located in the hospital, in case of emergency.

For women in my research, the focus on institutions, like hospitals, as a site of demedicalization stems from women's desire to receive maternity care with few to no medical interventions, preferably no cesarean section or epidural, but within a healthcare institution. While most women desired few medical interventions, the possibility of these interventions caused women to prefer the medical institutions (in the case of Florence, hospitals) as a place of birth. In relation to places of medicalization and demedicalization, the definition of medical institutions does not need to be confided to hospitals. The definition of institution could extend to structures such as medical organization (like the American Medical Association or Center for Disease control) or the authority that comes from the certification organizations like universities (See Robbie Davis-Floyd et al. 2009 for a summary of debates surrounding nurse-midwives and direct-entry midwives). Trust in these institutions suggests a level of acceptance of medical authority afforded to each group or organization, a finding that contradicts some research on efforts to demedicalize birth through midwifery-run clinics and home birth (Davis-Floyd 1992). The Florentine context represents a departure from discussion of demedicalizing birth outside of a hospital. 
Regardless of the shifting definition of demedicalization, a focus on women's concepts of care can provide elucidation of birth models that meet women's needs. For example, understanding women's relationship to pain and pain management techniques illuminates reasons why women accept or reject certain medical interventions. As Callister et al. (2003: 150) remind us "Culture plays a significant role in attitudes toward childbirth pain, the definition of the meaning of child- birth pain, perceptions of pain, and coping mechanisms used to manage the pain of childbirth". Many researchers studying pain in childbirth have noticed an acceptance of the pain as a part of childbirth, but the significance of that pain changes in context (Van der Gucht 2015; Logsdon and Smith-Morris 2017; Van Hollen). Logsdon and Smith-Morris (2017) found that Dutch women valued birth without pain medication as a form of autonomy and that pain medication would interfere with the body's own natural birthing capacity. Logsdon and Smith-Morris also found that autonomy to choose meant that birthing with medication was fine as a choice. My research adds to this argument by demonstrating that Florentine women also thought that a woman birthing pain medication was fine, but only under certain circumstances, mostly of necessity. For women who sought to feel the baby being born, epidurals were not considered an option for pain management. Pain was seen as an aid for birth, much like Van Hollen (2003) showed in her work on childbirth in India.

By comparing Florentine women's experiences with pain in birth to Van Hollen's research, I highlight the intersection of privilege and demedicalization in developed countries. Van Hollen found that women in the Tamil Nadu region of India wanted pharmaceutical birth induction because they felt that they needed to suffer through pain for the birth to happen quickly. Underfunded hospitals often meant that women were left to birth under-suboptimal conditions, either at the hospital or at home. In Florence, women wanted pain to help labor progress, but not necessarily to suffer. Florence is located in both a developed country with 
national healthcare, and a region of high-quality maternity care. Florentine women have access to high quality, continuous care during childbirth. Women in Florence also have the privilege of birthing within a system that makes available all forms of birth, including medical interventions, should the woman choose them. This type of privilege is rarely seen in the anthropological literature on childbirth, as much research focuses on the myriad of constraints women experience in relation to maternity care. I delve into some of the specific constraints that occurred in women's births in Florence in my final chapter. However, compared to women in most other locations, even within the same country, women in Tuscany enjoy many privileges relating to birth that most women in the world do not. Even so, these privileges go unrecognized in the government recommendations discussed in Chapter 4. In favor of promoting a simplified connection between fear and medical interventions, the Ministry of Health ignored regions like Tuscany which have demedicalized aspects of childbirth. In Florence, women's use or rejection of medical interventions was related to women's more complex view of space, hospital care, and their desired experiences in childbirth.

Women's preference for cesarean sections or epidurals only when absolutely necessary suggests that most women in Florence do not desire medical interventions pregnancy. On the other hand, women suggest that natural childbirth is safest when there are no problems with the pregnancy. Women's simultaneous praise for natural childbirth with trust in the hospital suggests that structures like La Margherita, which offer non-pharmaceutical births with the safety of the hospital, are an important way through which demedicalization could occur. Of course, one of the State recommendations mentioned the importance of La Margherita for natural childbirth. But this recommendation did not recommend care from the point of view of women's acceptance of the model of care. Understanding women's views of the circumstances under which medical interventions in birth are necessary reveals attitudes that could improve healthcare policy. 
Health policy experts, however, should focus on the way women throughout Italy perceive of a structure like La Margherita.

Analyzing not just what is said, but the subtler themes of health within birth narratives provides a glimpse into the women's place within their social context (Maynes et al. 2008; Mattingly 1998a). The narratives show the relative privilege that Florentine women enjoy in their childbirth experiences. Care is not just continuous, but often supports women's desires during birth. This privilege allows women to see themselves as the protagonist in their birth stories. Greta and Benedetta's narratives show the relative lack of disconnect between the healthcare professional's behaviors and the laboring woman's desires. Almost ironically, the sociality of pregnancy fades away as the figure of the individual comes into focus. Women's experiences show that during a good birth, the individual laboring woman becomes the most important figure. On the other hand, Giorgia's narrative structure revealed a less linear birth experience, one structured around her interactions with, and the behaviors of, healthcare professionals. Giorgia's presence as an active agent faded into the background, suggesting that highly medicalized births may take away the individual aspects that make women's experiences so positive. Given these ties of women's satisfaction and autonomy to lower rates of cesarean, attention to the woman as an individual may be the key to future maternity care policy in Italy.

As I have shown in this chapter, interactions with healthcare professionals in both pregnancy and childbirth are based on similar ideas about maternity care and the body. The highly medicalized figured of the doctor plays only a small role in both pregnancy and childbirth. The figure of the midwife is considered by my informants the more useful healthcare professional in childbirth. Midwives were praised and sought after for their personal attributes, and for their support to women who want to achieve a natural birth. Clearly, Italian health policy experts can better harness midwifery as a means through which to demedicalize birth and reduce 
cesarean sections rates. The state's utilization of anthropological research, not just in Tuscany but in other regions, would provide a better understanding of how women's values surrounding birth are impacting their acceptance and use of medical technologies. 


\section{CHAPTER 7}

\section{WHEN THINGS FALL APART: WHEN MATERNITY CARE FRACTUES}

I sit in a courtyard next to the local health clinic. I'm finishing up my interview with Alessandra, a new mother who had given birth only a few months before. Alessandra is standing, rocking her fussy baby. I asked her if there was anything else about her experience that she wanted to talk about. She thinks for a moment and realizes that she does have something to say. Alessandra had not yet gone back to work, but she was worried because of the stories she heard from other new mothers. She recounted one such story in which a friend who went back to work and she no longer had a desk. The more Alessandra spoke, the faster she paced. She explained that she was afraid her own employer would retaliate in a similar way. As we finished the interview, I was worried that I had left her in an agitated state, anxious about her future.

Alessandra was not the only woman to be concerned about her future. While not all women expressed negative views about future employment (not all women in my research had decided to go back to work), the precarity of working as a pregnant woman or a new mother was a common theme that several women chose to discuss. From employers who were angry when women had to stop working, to not getting work contracts renewed, ${ }^{10}$ work experiences during pregnancy and after birth demonstrate the precarity in new mother's lives. The ideal circumstances of pregnancy were not always present after women gave birth. The high-quality maternity care women were so used to often transformed into fragmented searches for any kind

\footnotetext{
${ }^{10}$ In Italy, it's common for people to have temporary work contracts through their employer. Unlike the U.S. where a worker is hired and terminated at will, if an employee is hired on a permanent contract, they are very hard to terminate. As such, temporary contracts ensure work only for a specific amount of time after which employment is not guaranteed.
} 
of care. The value of pregnancy and bringing a new child into the world was replaced, sometimes within moments after birth, by insufficient care.

These changes in the quality of care and motherhood display the many fractures in the façade of the high-quality maternity care that women championed. In this chapter, I explore the many ways and modes through which the idealized, well cared for, pregnancy and childbirth experience gives way to examples of discontent and fractured care. Attending to this fractured care demonstrates the many ways that the Tuscan healthcare system, and parts of the local healthcare ideologies as a whole, do not always support women's reproductive goals. Midwives occasionally presented barriers to women's request for a more medicalized birth, suggesting that midwife-based care is not always synonymous with woman-centered care as anthropologists have suggested. Moving from women's difficulties in birth to post-partum care, demonstrates how women's experiences of high-quality care during labor did not always extend to after birth. The lack of sufficient maternity care after birth often caused deep psychological issues as women were not able to align with idealized views of new motherhood.

I also more deeply interrogate women's evaluation of the Tuscan and Italian healthcare system. While women's evaluation of their own experiences in healthcare suggested that sociality and social support provide women with the foundation for high-quality care, women's own experiences go unrecognized when evaluating different healthcare systems in Italy. For example, when Florentine women evaluate healthcare in the South, they ignore their own experience and invoke stereotypes of the "backward" southerner. The relative privilege of being able to identify as a Northerner provides women in Florence more flexibility in how they define their own healthcare decisions compared to the decisions of others. Women's own ideologies about birth are sometimes contradictory and sometimes only seem to be. Uncovering women's contradictory opinions about childbirth and healthcare services reveals the repetition of 
medicalized discourse about birth. These medicalized narratives meld with moral evaluations to reify existing ideological divisions between northern and southern Italy.

\section{'They're Fascists About Natural Childbirth': When Women's Choices Clash with the Local Healthcare System}

\section{Birth and (Lack of) Care}

In the previous chapter, I showed how Tuscan women displayed a preference for natural childbirth and a lack of medical interventions in childbirth. Natural childbirth was seen as the ideal mode of birth, even among women who had chosen not to have one. This focus on natural childbirth, however, left some women with unmet needs during childbirth. One such woman was Ilaria, a mother of one from Rome whom I had interviewed less than two months after her birth. Ilaria had wanted an epidural and had asked for one but was told she shouldn't have one: "I told [the midwife] that I really needed [an epidural] and she said that it's not so good because I will give the medicine to the baby and there was no need. I was in a mountain of pain....30 hours of labor." In describing why the midwife didn't approve of the epidural, Ilaria replied "they're fascists about natural childbirth" and she felt that there was no reason for women to "suffer" when there were several pain control options available.

Ilaria was one of a small minority of women who had asked for an epidural and was told by midwives that it wasn't safe or necessary. Her experience represents the small number of cases in which care from hospital staff was lacking and expectations were not met relating to care received in labor. In discussing care, I mean the health services provided by hospital staff, but also the expectations that women have concerning the behaviors of healthcare professionals. In the last chapter I detailed how women were not necessarily interested in receiving healthcare from only medically competent individuals but were interested in receiving a certain level of 
support. For women in Florence, support as a form care is expected as a part of healthcare and when I discuss care, I include women's expectations of both these issues. While other anthropologists have discussed modes of caring for people outside of the hospital context, which Kleinman and Hanna 2008 describe as "caretaking," my discussion of care in this context remains within the hospital. My discussion of care also does not take up what Miriam Ticktin (2011) calls "regimes of care" or Didier Fassin's (2007) similar inquiry into the way in which the right to healthcare is built on a foundation of suffering and politicization. My discussion of care in this context is more akin to what Mol et al. (2015) call a "practice of care": the specific behaviors that are a part of healthcare professionals' interactions with patients. I add, however, that this care must include women's expectations of what behaviors should accompany their interactions with healthcare professionals.

Out of the 50 women in my research 13 women asked for an epidural. Out of those 13 women 5 women were not given an epidural. Of the remaining 8 women, two were satisfied with the time between her request and receiving the epidural. Most women who asked for an epidural were discouraged from using it. Most were met with urging from the midwives that it wasn't necessary. One woman described a midwife who tried to talk her out of having an epidural, but even after the midwife agreed, the doctor did not come quickly, and the baby was born more than an hour after the on-shift doctor had been called. Women described having to wait and ask several times, which caused one woman to cry. Rachele, whose circumstances I describe in more detail later in the chapter, said that she finally received the epidural after an "insistenza molto forte" or "very strong insistence" to the midwife. Both women who received and were denied an epidural were met with significant barriers, often stemming from a lack of action or modes of dissuasion from hospital staff, particularly midwives. Women like Ilaria and Rachele felt they were being unduly discouraged from having an epidural. It's worth noting that 
to have an epidural, women must attend an informational session about the procedure and sign a consent form stating that they understand the risks and would like the possibility of giving birth with an epidural. Women who are asking for epidurals are not uninformed by local healthcare standards. But Ilaria's case is a representation of barriers women often faced after a request for an epidural.

Rachele had a similar experience to Ilaria. Rachele is a mother of two who gave birth to her first child in Rome and the second in Florence. She was 39 at the time of her second birth. Rachele was convinced to stay in the hospital before labor because she had a fever and had been vomiting. When she was significantly dilated, she could not take the pain anymore and asked for an epidural, but the midwife tried to dissuade her by talking encouragingly about her progress. After much insistence, the midwife, a doctor, and an anesthesiologist agreed to do a spinal block instead of an epidural, but it was not completely successful, and Rachele blacked out. When she woke up, she started to ask for a cesarean section but was denied that as well. Only three women recounted asking for a cesarean section and all three were denied. Two women, Rachele included, discussed dismay over the lack of receiving the desired intervention, and the third was satisfied because she felt she was not lucid enough to ask. The number of women who asked for an intervention and were denied is only 8 out of $50(16 \%)$, but women detailed many instances in which barriers existed. While epidurals were added to the "essential levels of care" list of services required to be provided by the healthcare system (Federfarma 2016), even Alessandro Vergallo, the president of the Association of Italian Anesthetists, says the birth with an epidural "will remain a 'phantom right' in many hospitals" (Monella 2018). Women's narratives provide a key piece missing in an evaluation of barriers women receive in care. As Inhorn (2006) suggests, giving voices to women's stories is exactly how anthropology highlights the lived experience of women beyond simple statistics. 
Despite the significant barriers to receiving specific medical interventions, most women were satisfied with their births. Even Rachele and Ilaria expressed they were satisfied. Rachele expressed satisfaction with her birth and the behavior of the hospital staff because she felt that the hospital staff did, in fact, help her. Barriers to receiving medical intervention did not necessarily cause women to be unsatisfied with birth or healthcare workers, as satisfaction was not measured only in the difficulties of birth. Only 8 women were unsatisfied with their birth and the most common reason women gave for being satisfied was that, in the end, the birth went well and the baby was healthy.

While the number of women who were unsatisfied with their birth was low (8 out of 50) there were several instances in which women's expectations of care were not met. Perhaps the worst was the story of Angela. Angela is a mother of one I interviewed about a year after the birth of her first child. Angela was in labor for two days until they gave her oxytocin to try to induce the labor. It did not work and she was given an epidural. Finally, the doctor did an echography and decided the baby was, as Angela puts it, "too twisted" to come out. At that point she was rushed into a cesarean section; however, during the cesarean section, the doctor accidentally cut the baby. He also cut Angela's uterine artery but did not tell her that this could become an issue and she almost bled to death in the weeks immediately following the birth of

her child. Angela has pursued legal action. While Angela's case is the most egregious of any women in my research, it demonstrates the few examples in which care during birth was not always adequate.

\section{After Birth}

I sit on a beach outside of Florence with Giudita. Giudita had moved from Florence to a coastal city in Tuscany after the birth of her first child, but still continued to receive care and 
gave birth for her second pregnancy in one of the Florentine hospitals. We had just gotten done with our interview and she invited me to meet her children and husband at the beach. The day was still young and her three children still had hours of playing left. Her two youngest children who had been born only 7 months before still needed to be carried, so I helped her when she wanted to walk to an event further down the beach. As I walked, people stopped to smile at the baby I was holding. A few people came up to me and asked how old the baby was. There was barely a moment when the babies did not garner some kind of attention. We walked back to our seats and a group of people, mostly women much older than Giudita, came up to us to talk about the babies. They positively gushed about how cute the babies were and gave Giudita some advice. I sat down next to Giudita and asked if they were friends. She leaned over and whispered, "No, I don't know them. I have people coming up to me, all the time. They all want to give me advice. It's very annoying." Giudita's experience was surprising given how positively she and others had discussed their experiences with during pregnancy. In Chapter 5, I demonstrated how women preferred the positive attention they received during pregnancy. Having attention from others was a key delineation women experienced from their pre-pregnant lives to their pregnant selves. Giudita's example, however, demonstrates the division between how women perceived their interactions with others pre and post birth. The attention women had spoken about so positively had morphed into an annoyance to Giudita after she had given birth.

As this vignette and the one at the beginning of the chapter show, life after birth was a significant departure from the idealized, relaxed reality of pregnancy. While women often spoke fondly of their time during pregnancy, and to some extent their experiences in childbirth, the difficulties women faced once becoming mothers were often unexpected and presented a significant departure from what women had previously experienced. In this section I focus on the different ways in which the changes new mothers faced were not always met with support or 
services from the healthcare system. The transition to motherhood can be difficult, but women in my research felt that their care and treatment (both among healthcare professionals and within their communities) had changed from supportive to ignorant or even discriminatory. The idyllic lifestyle most women experienced in pregnancy faded into one of fragmented care and negative social interactions unlike what most women experienced during pregnancy and birth. The three areas in which women discussed this change most often were care after birth, breastfeeding, jobs or career paths. My interview had no questions related specifically to after birth, but some women clearly were concerned about the issues they were facing.

\section{Maternity Care}

The difficulties imposed on women often start immediately after birth, some while still in the hospital. Rhoda noticed a large difference in care between the birth and after care: "I was followed well during birth, [but] I suffered a lot after because they cut me....I felt bad immediately after because, in reality, it took an hour, an hour and a half, for them to sew [me]". While Rhoda's example shows an extreme form of difficulty after birth, the lack of attention after birth was the most common negative aspect of care women reported. It should be noted that women were not asked directly about after birth care. Women often offered this voluntarily when asked other questions or during an open-ended question at the end of the interview allowing women to discuss anything they thought I had missed. Women's focus on this issue despite having no direct inquiry on the topic demonstrates that the lack of afterbirth care was clearly of concern to my participants.

Women were also concerned about care after they left the hospital. Several women suggested that support was lacking once they left the hospital, but they wish there had been good services like they had received during pregnancy and birth. Some women suggested that the 
difficulties of life required extra care that the healthcare system did not provide. Barbara suggested just that:

They should have more information on everything [and] follow women after. After birth there's not a post-partum course, no one who assists you. It would be very important because I know there's a form of depression, the baby blues. There's a new condition and situation at home.

The lack of care extended to doctor's visits as well, as Katerina suggested the doctors became very disinterested and unavailable after birth:

Women must not be abandoned after birth. One doesn't finish everything there. If you ask me, there should be assistance for breast feeding. We did some doctor's post-partum meetings at the health clinic, but [there were] 30 people in one room with 30 neonates and every [doctor] had 10 minutes of time [to ask] what's happening, what's not working.

Women often felt abandoned or ignored after having received such attentive care during pregnancy and childbirth.

\section{Assistance with Breastfeeding}

Katerina's experiences also demonstrate another problem that women focused on: the lack of help for breast feeding. While many women were encouraged to breastfeed, the lack of support and medical care after birth was often cited as an impediment. As Katerina suggests, "As far as I'm concerned, even in the hospital there should be a lot of attention on how breastfeeding is going, what the problems may be, because the theory is easy, the practice is difficult, and they don't tell you enough about this." Katerina went on to describe her experience with midwives in which she was constantly assured that she was doing everything well, but in reality, she felt she wasn't. In the end, she had to rely on her friends for help. Like Katerina, women often recounted the difficulty of not having a lot of resources for breastfeeding and wished that there were more resources, like home visits from midwives, for help. 
The lack of care was often discussed as abandonment and for some women caused a lot of emotional distress. One such woman was Henrietta, who had a relatively uneventful birth. On reflection, she had wished that she would have received an epidural sooner, but she was happy with the assistance provided by the midwives. She, however, had difficulty with breastfeeding that caused psychological issues:

I breastfed but I wasn't prepared, like my other friends in the course, for the possibility of helping the baby with artificial milk. Because sometimes the milk doesn't arrive right away and the midwives said absolutely no artificial milk, only mother's milk. It was very difficult for everybody, for me and others, at the beginning in which one is very psychologically and physically fragile, to have to accept the baby needs artificial milk for a few days.

Henrietta shows that the discontinuity in care often started not just with care after birth, but with false expectations propagated during pregnancy.

This is what Serafina calls the "pressure to breastfeed." Serafina had a positive birth experience but felt that the pressure to breastfeed was overwhelming. When asked about her experience with the midwives, Serafina responded,

Psychological support [was] the best, medical assistance [was] the best...during my birth I was followed by midwives who were very nice and kind. I was truly followed well. Post-partum assistance [was] the best. Even during the night if I needed pain medication, they gave it to me, there wasn't a problem. The only negative thing of which I could speak for two days is the pressure to breastfeed. [It's] excessive. Too much pressure on breastfeeding. Too much psychological pressure on the new mothers. You have to breastfeed. It's not true, you don't have to. They pass on this message because it's good for you and for the baby, but if a new mother has a problem feeding, can't give milk, [the baby is] not suckling, there are grave psychological repercussions. It's not right that in the first days, when the new mother has a storm of hormones, and in the successive months, there is this fixation on breastfeeding, finding the way, trying, retrying. [If] it doesn't go well, [there's] too much negative and heavy pressure.

Serafina clearly considers the fixation on breastfeeding to be detrimental to women who cannot partake in such behaviors, suggesting a heavy burden placed on women who do not conform to the larger ideological beliefs of the local healthcare system. 


\section{Employment}

When I first met Grazia, she was keen to discuss aspects of life in Italy beyond my research. Grazia was a mother of one who had given birth in Florence less than 6 months previously. She had a great job and had not considered quitting, but her hectic schedule coupled with a minor health problem caused her doctor to recommend going on maternity leave early. When she did, she said her boss, also a woman, became very irate and started yelling. Grazia assumed the woman had not found Grazia's replacement and was mad over the abrupt loss of a senior worker. Grazia loved her work but said that her days were long and she couldn't imagine working and having a child. Grazia has since decided not to go back to work but said she might consider it when her child was in school. For Grazia, both her experiences during pregnancy and her transition to motherhood have caused her employment situation to change. While she once loved her work, the issues she had with her supervisor coupled with her realization that long hours would have been impossible as a mother, kept her from considering going back to work.

Grazia’s experience with difficulties at work was not unusual to hear from women. Similar discrimination was experienced by women at the moment their employers found out they were pregnant. Pamela, a mother of one, considered her work situation to be affected by her new status as a mother. Pamela, who worked in marketing for a fashion company, did not have a permanent contract with her company. When her boss discovered that she was pregnant, Pamela said he became annoyed. After the birth of her child, her work contract was not renewed, and she was still unemployed after 18 months. This type of retaliatory discrimination was of concern to many women in my study. Just as Alessandra's vignette at the outset of this chapter displays, women felt that they were targets or potential targets of retaliatory discrimination by their employers. 


\section{Amelia: Fractured Care}

The examples above paint a picture of the fragmented care that can occur after birth. High quality care during pregnancy and childbirth repeatedly gave way to less than adequate care after birth. Anthropologists have shown a similar trend in transitioning healthcare systems in which adequate care shifts to fragmented care after certain economic or political transitions (Janes 2004a; Molina and Palazuelos 2014). This fragmented care, however, is often set within low income settings, making the Tuscan example a departure from previous literature. I suggest the term 'fractured care' to mean poor care patients receive in an otherwise high-quality healthcare system. As Janes (2004b) reminds us, anthropologists often do work on low income or vulnerable populations where fragmented care is exacerbated by economic and political shifts. But in the Tuscan example, I demonstrate how fractured care can happen when a woman's expectations do not align with birth ideologies of the medical staff or when care becomes interrupted.

Here I present the case of Amelia who had problems throughout her pregnancy, birth, and post-partum periods. Amelia is a mother of two from the region of Lazio. She was 35 at the time of her second birth. Amelia had reservations about giving birth at Careggi, but she felt pressured by her husband. She would have preferred to go to Ponte a Niccheri because she knew a gynecologist there, but her husband insisted that Careggi was much closer and newer. At Careggi, however, Amelia felt "very alone because you are just a number."

From the moment Amelia arrived, she felt that there was a lack of communication about what was going on. She was told that she needed to be induced but was not given a clear reason. Because of this she was scared and had to wait for longer than expected for a doctor to break her water. Amelia also asked about getting antibiotics for a previous infection, but the doctor was 
unwilling to confirm whether she had an infection and told her to wait until the morning. Amelia asked for an epidural repeatedly until she was finally told it was too late. During this time, Amelia expressed being scared and crying because she was unsure of what was going on.

After birth, Amelia was kept in the hospital for 5 days where she experienced pain from her episiotomy stitches. On the third day of her hospital stay, during the visit by a gynecologist, she asked for something to manage the pain and was told she should have the drug, paracetamol, but was not given any. She had to ask a passing midwife when she was going to receive the medicine she had asked for from the doctor. Later, because of the stitches, she did not feel well and asked a midwife to look at them. The midwife said she was ok although in Amelia's words, "[the midwife] didn't even touch me" implying that the midwife's examination was too brief to make an appropriate evaluation. Amelia describes much difficulty, especially with using the bathroom, because of the stitches and felt "traumatized" by the experience. She felt that the midwives were ignoring her, even when she walked through the corridors bent over in pain. She felt that they did not interact with her with "empathy." She said, "In the days of my stay, I wasn't properly followed, the people [were] totally indifferent."

To add to the physical difficulties she was experiencing, Amelia also experienced problems breastfeeding, which she was told was common among women who are induced. Luckily, she felt that the midwife who helped her was very kind. This kindness, however, did not extend to the doctor she visited after leaving the hospital. Amelia was concerned that she was not healing properly and asked the doctor when she would feel better. Amelia felt that the doctor was too quick to dismiss her discomfort.

Amelia's case is a story that shows all of the different points at which women in my research did not receive the maternity care they expected. By attuning to these points of fracture, as I term them, in women's experiences, we see the specific points at which care is weak. While 
most women who had negative after birth experiences had positive birth experiences, Amelia had neither. Amelia and the other examples in the section are a reminder of the ways in which quality maternity care will never be seamlessly provided throughout the entirety of a woman's experience. Despite the positive picture I presented in the past two chapters, fractures in care are always present. Attuning to points of fracture in an otherwise high-quality care setting demonstrates the points at which women are most vulnerable during their reproductive experiences.

\section{Contradictions Within the Healthcare System Ideologies}

Thus far in this chapter, I have shown different ways in which women's expectations for care during and after birth were not met. While women's care was fractured and distressing, their own beliefs about childbirth and the healthcare system are often fragmented or (seemingly) contradictory. In discussing how women's experiences do not align with their own evaluations of the care they received, I display how women mirror dominant medical discourse about the individual and rational decision making. Women's evaluation of healthcare, both in Tuscany and throughout Italy reifies existing concepts that label undesirable reproductive behaviors in Italy as backwards. Women's lack of acknowledgement of their own experience unveils deep seated ideological divisions between the north and south of Italy.

\section{The Complexities of Ideology: A Case Study}

Above I discussed Rachele, who continuously insisted on an epidural even though she was never given one. By placing Rachele's experience in a broader context, I am able to show the conflicting beliefs within her own story and opinions. Rachele was not very happy with her first birth, which took place in Rome. She felt that there was a significant lack of care from the 
midwives: "There was a lack of a fixed presence together. Here [in Florence] I had a midwife with me always. There [in Rome], every time someone came to ask, 'Is everything ok? Is everything ok? Bye.' They didn't empathize with the patient, they didn't attempt any kind of rapport." Rachele motivations and priorities in birth were related primarily to her interactions with midwives. While Rachele felt that her interactions with midwives in Florence were superior, she was still upset about her attempts to get an epidural: "I don't like the insistence on natural childbirth. If a woman asks, insists, to want, perhaps, some help, to use an epidural, spinal block, shower, water birth, she shouldn't have to loudly ask 30 times."

Rachele's experience and opinions show a strange type of contradiction in women's opinions about their care. While she insisted on an epidural, and while an unsatisfactory response from midwives was something the Rachele stated that she didn't like, she was still satisfied with the birth. Rachele's case became even more complex when coupled with her opinions relating to different modes of birth. When asked about the use of complementary medicine, Rachele responded with "that's the ideal, it would be a perfect birth" and when asked about natural childbirth, she responded "[that's] how it should be," respectively. When asked about her opinion of epidurals, she responded, "Positive. For me, it's a great option for women. If [the birth] goes well, don't use it. We have the right to ask [for an epidural] without feeling like less of a woman or less of a mother."

Rachele responses show the ability of Italian women to simultaneously hold seemingly competing opinions about childbirth. While there are ideal courses of birth, such as natural, women do not necessarily believe that other options are bad. In the last chapter, I demonstrated how women often remained flexible to understanding how the course of birth would proceed. Having an epidural or a cesarean section was not seen as a poor outcome, under the right circumstances, even though medical interventions are not the ideal. Medical anthropologists have 
shown that in some cases, women who are not able to fit into ideal reproductive behavioral models often ignore their own difficult experiences in favor of support for the idealized reproductive behaviors. These women often understand that they've experienced difficult circumstances but have internalized the narrative that shames them for not partaking in ideal reproductive behaviors (Singer 2017; Gammeltoft 2007). My research shows something slightly different. Ideal birth is not opposed to non-ideal birth.

Women in Florence take into account the realities and difficulties of each woman's birth experience, allowing space for acceptance of variations in their own ideal birth choices. Early work on the anthropology of childbirth focused on resisting the medicalization of birth set up a dichotomy between biomedical birth and natural or "wholistic" modes of birth (Martin 1987; Davis-Floyd 1992; Kaufert and O’Neil 1993; Davis-Floyd and Sargent 1997). While a move in the literature toward understanding women's birth decisions moved away from hierarchies of power and toward and understanding of pragmatism and agency, (Lock and Kaufert 1998; Obermeyer 2000), recent research has begun to look again at power dynamics, but by a different name. The move towards understanding birth in the frame of structural violence, along with a more recent focus on activist movements related to obstetric violence and the push for humanistic birthing models (Scheper-Hughes Dixon 2014; El Kotni 2018; Davis-Floyd 2017) have again reified, to some extent, the ways in which idealized modes of birth often serve to further marginalize disadvantaged groups of women. What could be seen as a contradiction based on other anthropological research on ideology and modes of birth underlies both a preference for natural childbirth, but a flexibility based on the unpredictable nature of birth. Rachele's seemingly contradictory opinions, while not completely representative of my research population, were representative of a small minority of women who desired some type of medical intervention in birth. Similarly, Patricia tried to have a completely natural birth at La 
Margherita but was moved to Careggi. She had wanted a birth without medical intervention, but after giving birth, she decided she wanted a future birth, "with oxytocin. Mostly natural, if then nothing happens, [there's] help with oxytocin." There's also Serafina, who chose to give birth at Torregali because she was told it was easy to get an epidural there. She ended up having an epidural and said it helped her a lot, but still said she would prefer to have a natural childbirth in the future, even though it's painful. She described natural childbirth as the "the best thing." These examples show not only the existence of a flexible ideology about birth, but show, once again, the internalization of the importance of natural childbirth in the local belief system.

\section{Experience vs Medical Discourse}

Women in Florence can simultaneously hold multiple seemingly contradictory beliefs about birth. Unlike the findings in other anthropological studies, the women in my study did not necessarily internalize the shame of deciding to partake in non-idealized reproductive behaviors. They gave themselves, and, hypothetically, other women a certain level of flexibility in birth choices. This section extends that discussion of women's seemingly contradictory views of childbirth and the healthcare systems in Tuscany to the rest of Italy. This analysis demonstrates how women often devalue their own experiences in explanations of maternity care that mirror the medicalized discourse of the Ministry of Health guidelines.

In the past chapters I have detailed many of the aspects of pregnancy and childbirth that women deemed valuable. Chief among these were social support during pregnancy and quality healthcare from midwives during childbirth. These types of social support were a significant part of women's positive experiences in childbirth. As I previously stated, only 8 women out of 50 were unsatisfied with their care. Almost all of the women in my research considered the care in Tuscany to be the best or at among the best of all the regions in Italy. Only one woman did 
not express such praise saying that she thought the services for breastfeeding were lacking. Three women answered, "I don't know." The rest of the women, however, overwhelmingly said that they thought the services in Florence were "buona" or "good" $(n=22)$, followed by "ottima/migliori" or "the best" $(\mathrm{n}=11)^{11}$. Other less common responses, spoken by only one or two women, also described the care as good. Care was described as good for several reasons including that it was "gratuito" (free), it was "avanti" (advanced), there was "molto attenzione" (a lot of attention). Women's experience with social support and "attention" is the foundation upon which women place their positive experiences in pregnancy and childbirth, however, these experiences are sometimes unacknowledged as a means through which expectations of care are met.

So far, women's discussion of the healthcare system has primarily aligned with the positive aspects they discussed in their experiences during pregnancy and childbirth. Women's descriptions, however, shifts slightly to the medicalized discourse present in the Ministry of Health guidelines when women discuss healthcare in other regions. A common belief among women in Florence is that information is an important aspect in women's decisions and behaviors relating to childbirth. When asked if Tuscan women, in general, made good decisions relating to childbirth, 34 out of 50 women said yes. Five women said they did not think women made good decisions. Eleven women would not give a definitive answer or answered, "I don't know." Of the women who said yes, the overwhelming reason given for women's good maternity care decisions in Tuscany was that there was a good amount of information available. The next two most common responses, both mentioned only 7 times, were "consapevolezza" which can translate to either "awareness" or "consciousness" and that the women were "seguite

\footnotetext{
${ }^{11}$ Answers were not mutually exclusive and some women gave multiple answers
} 
bene" or "well followed." Table 7.1 shows the most common responses. Responses are not mutually exclusive and some women mentioned more than one item.

Table 7.1 Most common reasons Italian women consider the Tuscan healthcare system to be good* $^{*}$

\begin{tabular}{|l|l|}
\hline Presence of Information & 19 \\
\hline Made decisions with awareness/consciousness & 7 \\
\hline Well Followed & 7 \\
\hline Good Healthcare System & 5 \\
\hline Libretto di gravidanza & 4 \\
\hline Natural childbirth encouraged & 3 \\
\hline Cesarean sections not encouraged & 3 \\
\hline Attention on maternity care & 2 \\
\hline Allowed to make autonomous choices & 2 \\
\hline Well assisted & 2 \\
\hline
\end{tabular}

*To make the table clearer, I have decided to exclude the responses that were only mentioned once

Table 7.1 shows that women place a high value on information as an indicator of quality maternity care. In Chapter 5, I showed that women were motivated to go to informational classes because of wanting to make connections with other mothers more so than wanting information, but table 7.1 shows that women consider information to be a far more important influence on other women's decision making in Tuscany. Even among the participants who did not give a definitive answer or who said women in Tuscany made poor decisions, 6 out of 14 (43\%) said this was due to a lack of information, showing that information was a key aspect of participants evaluation of women's behaviors.

Women's responses suggest that their own experiences are not being internalized as an important source of maternity care. Katerina, a mother of one from Florence, summarizes why she considers women to make good decisions in Italy:

There were a lot of women at the pregnancy courses. There was a lot of information. In my opinion, before the baby is born you're very followed. There's a lot of information, a lot of services. All the medical exams are free, 
everything is free. There's the libretto di gravidanza. These are important things and this leads you to make conscious decisions.

Katerina's response shows that women own experiences and social relationships fostered outside of the healthcare system are completely forgotten when evaluating the quality of healthcare in Tuscany. The positive experiences facilitated by midwives are fade away to the praise of general "services." When evaluating the system as a whole, women seem to move away from their own experiences in favor of rhetoric that mirrors the medicalized discourse found in the Ministry of Health guidelines

\section{North vs. South: An Ideological Battleground}

Participant's general opinions about women's behaviors in Tuscany lean towards biomedical rationalist discourse relating to information and women's appropriate maternity care decisions. However, analysis of how women discuss places in other parts of the country unveils deep-seated beliefs about the differences between the North and the South of Italy. As anthropologists have shown (Schneider and Schneider 1971; Schneider 1998; Krause 2005) ideological divisions between the north and south of Italy have a long history and are often prevalent in discourse on reproduction and fertility. Through discussions of quality of care and cesarean sections, I show not just that these divisions manifest in discussions of childbirth, but that they do so based on a moral framework that integrates rationalist medicalized ideas about women's reproductive decisions.

Eliciting women's opinions about health services in other regions was difficult, as 21 women would not provide a definitive answer or answered I don't know. Of the women who did answer only 9 thought women in other parts of Italy made good decisions. Table 7.2 shows the main reason why participants thought women in the rest of Italy did not make good decisions. Answers are not mutually exclusive and some women provided multiple answers. 
7.2 Reasons participants gave for women not making good decisions in the rest of Italy

\begin{tabular}{|l|l|}
\hline $\begin{array}{l}\text { Services are worse (poor assistance, not } \\
\text { followed well, less attention) }\end{array}$ & 13 \\
\hline Less/worse information & 11 \\
\hline More cesarean sections (in the south) & 7 \\
\hline $\begin{array}{l}\text { Services in other regions are for a fee which } \\
\text { causes them to be underutilized }\end{array}$ & 4 \\
\hline $\begin{array}{l}\text { Doctors receive more money for cesarean } \\
\text { sections (in the south) }\end{array}$ & 2 \\
\hline No libretto di gravidanza & 2 \\
\hline
\end{tabular}

Table 7.2 shows similar trends to participants reasons why women in Tuscany make good decisions about childbirth, but with a few new explanations. The importance placed on information is still present, but now there is also more importance placed on the quality of services. As Maura, a mother of one from the northern region of Lombardia, summarizes:

In Sicily, I have a cousin that gave birth. It's not the same kind of accompaniment, both before and after. You don't have the same type of information and the quality of the services is worse...I know that in Milano the service is good. In Emilia Romagna, the service is good.

Maura's quote shows a clear belief in a significant division between the quality of the services in the southern region of Sicily and the northern regions of Lombardia and Emilia Romagna.

While women discussed good services in Tuscany without a reference to economics, economics becomes an issue here in relation to doctor's motivations and the availability of services for women. As Clara recounts, "One of my friends, she is in Tuscany but lived in Rome and had a baby in Rome...All the free exams I had, there [in Rome] she didn't have [the same exams]." While women connected the economics of worse services with constraints placed on women in other regions, only one woman suggested the difficulty these systemic issues put on women. Almost. Pauletta said, "I think they want to make good decisions, but in the South they are not qualified, like always." Pauletta recognized the difficulties women have in making good 
decisions, but also reverted to acceptance of what she considered to be a shared characteristic of the south: lack of qualifications. Two women even went as far as calling the systems in the south, "dietro" or "backwards."

The focus on stereotypes of the south becomes even more clear among women's discussion of the cesarean section trends throughout the country. When asked why they thought cesarean sections in the south were higher than the north, the most common answer given was economic. The most common statement was that doctors or the hospital would get a "rimborso" (reimbursement) from the government that was higher for a cesarean section than a vaginal birth. Whether it was a general statement about the hospital or specifically tied to the motivations of doctors, the main opinion concerning the higher rates of cesarean sections in the south are related to financial motivations. As Stefania suggested, "It must be only and exclusively an economic motivation." Women saw the high rates of cesarean sections as a failing of the southern healthcare system to care for patients rather than seek money. Some women even associated the high rates to corruption and abuse in the system. In talking about why doctors in Florence wouldn't try to get more money one woman said, "I think that the healthcare system in Italy is administrated worse in the South, but there's less mafia here [Tuscany]." Her comment links poor healthcare not just to poor practice but directly to criminal organizations.

The subtle implication in the arguments about the financial aspect of high cesarean section rate is that doctors are first and foremost trying to make money rather than take care of their patients. The lack of patient centered care by the doctors was echoed in the less common suggestions that doctors didn't want to have difficult work. Women also commented that they thought doctors would perform more cesarean sections because the operation made their job easier. One woman suggested that doctors in the south perform more cesarean sections because that's the "modus operandi of many doctors, to avoid problems, to reduce time. Instead of being 
ready, instead of being patient." Some women saw doctors as not prepared or educated too long ago. These evaluations suggest that women consider doctors to be trying to work for money instead of providing high-quality patient care.

It was rare for women to discuss southern women's behaviors and preferences as a part of the higher cesarean section rate, however, some women shared their opinions after being asked. Some participants thought southern women added to the high rates because they weren't informed, reifying rationalist medicalized ideas about information and women's maternity care decisions. Some participants went as far as to say that high cesarean section rates stem from southern women's "ignoranza" or "ignorance." Other participants mentioned there was not a cultural of natural childbirth and sometimes women were not even given a choice for birth options. Other participants thought women were too afraid of the pain and wanted an easy birth. One woman said, "I don't know, maybe [there is] less information on the part of the women. They don't know they can choose something else." The individual qualities and behaviors of southern women are suggested as the reason for their own high cesarean section rate. The differences in the way women interacted with the healthcare systems were barely mentioned. General differences between Tuscany or the North and the South were glossed over by suggesting that the South "non funziona" or doesn't work. Camilla, whose parents are from the southern region of Calabria, stated that, "The reality [in the south] is very different from Tuscany...there is an abyss of function between the North and the South...And in Calabria, nothing works" Only one woman mentioned the potential for midwives to ameliorate the high rates and nobody mentioned the possibility of social support in helping women through the difficulties of pregnancy and childbirth.

As women discuss the healthcare systems within Tuscany and throughout Italy, it's clear that their own experiences fade away to generalized medical explanations. Women afford their 
own decisions a bit of flexibility to make decisions based on difficult circumstances, but do not do so for women elsewhere. Women consider poor health outcomes, particularly in the South, as indicative of women's failures or the moral failures of the healthcare system. For women in Tuscany, information was less of a motivator than social support they sought during pregnancy, but in discussing other women's behaviors, my participants accepted the connection between information and poor maternal health outcomes. Women devalued their own social experiences in favor of medicalized rhetoric of the importance individual information seeking behaviors. This medicalized rhetoric served to reify the idea that the south was backwards. Working in a corrupt system, doctor's only wanted money instead of providing patient care and women's ignorance facilitated such behavior. Women's own positive experiences of social support were ignored as a possible factor through which women in the south might be able to combat high cesarean section rates. Instead, the South is seen as a failing geographical region where uninformed women cannot receive in a system being drained of money from unscrupulous doctors. Evaluations of maternity care become entwined with existing moral judgments about the South.

\section{Fractured Care and (Seemingly) Contradictory Beliefs}

In this chapter, I have attempted to discuss women's experiences with maternity care in Florence in a different way than in previous chapters. Women's experiences of maternal care and their own beliefs about childbirth are sometimes fractured and contradictory. When women's expectations of care go unmet, cracks in in the system show how expectations of care can be a mode through which to see the definitions and boundaries of local healthcare beliefs. In the first section, I showed how the positive experience of a majority of women does not mean that all women received the care they desired. The handful of women who asked for an epidural only to 
be thwarted by midwives attempts at dissuasion, show that women's departure from the beliefs of local healthcare systems can lead to unmet expectations concerning care.

In discussing higher cesarean section rates in the South, Florentine women suggested that there is a "culture of natural childbirth" in Tuscany that is lacking elsewhere. Natural childbirth was seen as a way to counter high cesarean section rates, but the natural childbirth beliefs in Tuscany were constraining to women whose choices in labor did not fit the belief system. Anthropologists have discussed midwife-based care as a type of woman-centered care in which the ideology of the medicalized body requiring intervention is cast off in favor of a more holistic approach (Davis-Floyd 1997; Cheyney 2012). The examples in the first part of this section demonstrate that quality midwife-based care and woman-centered care are not always synonymous. In discussing home birth in Minnesota, Hazen suggests that "the midwifery model frames birth as a family event, with labor and birth viewed as natural processes that usually require little interference, and which benefit from a holistic approach that values connection between mother and caretaker.” (2017: 556). While women in Florence often received highquality care through a "connection" made with midwives, barriers midwives created for women who requested epidurals suggest that these views of birth as a "natural process" and with a "valued connection" between woman and midwife are not always connected. In Florence, midwives seem to give preference to the natural processes of birth over woman-centered care. While it is hard to separate whether the barriers to epidurals were created as a function of the midwife being a part of the healthcare system, midwifery-based care in Florence departs from this woman-centered model in which the laboring woman is meant to be capable of making her own birth decisions with little interference. As MacDonald (2006) reminds us, midwife-based care is one of many birthing options that is not necessarily the paragon of care. 
The barriers women experienced in requesting an epidural demonstrate the way in which local healthcare systems shape women's agency. Women who desired a natural childbirth were easily able to assert their agency because their desires aligned with the beliefs of the healthcare system. Women whose beliefs did not align with the local healthcare system (i.e. those who wanted a cesarean section) had to assert their agency more forcefully. Through understanding midwife-based care as focused on natural childbirth rather than the patient's desires, the natural birth belief system can be seen as the foundation of care provided to women. An integral part of understanding women's agency in Florence is Giddens concept of "structuration," which he defines as the "rules and resources, recursively implicated in the reproduction of social systems" (64). A request for an epidural broke the "rules" of the natural childbirth system.

In discussing midwife-based care, a deeper discussion of care is needed. While I limited my use of the word "care" to women's expectations of the behaviors and services provided by healthcare professionals, care has taken on a multitude of meanings. Anthropologists have discussed care as something that was previously handled in private, such as by stay at home mothers or care for elderly parents (Mol et al. 2015). This often meant that care was synonymous with caretaking within the home (Kleinman and Hanna 2008). While Kleinman and Hanna (2008) argue for more integration of caretaking into biomedical practices, care or caretaking of the chronically ill is still seen by doctors in the highly biologically reductionist field of medicine as non-medical care. Italian narratives of maternity and post-natal care in hospitals serves to demonstrate that care in hospitals is not always a function of biomedical vs social practices. Care can be fragmented or fractured, such as when women received great midwifery-based care during labor, but need for aid in breastfeeding was left unmet.

Discussions of care also often move beyond the confines of the biomedical world to include discussions of unique political histories. Political changes or upheavals can cause care to 
be reconfigured, both within the private sphere (Epele 2018) and within the more public sphere of ideology (Ticktin 2011). As Ticktin (2011) demonstrates, humanitarian organizations often have the power to shape the rhetoric of care. In the French example, healthcare is seen as a right through the humanitarian lens of ending suffering. Ironically, while healthcare is supposed to be a right in France, immigrants are only able to access that right if they are considered a victim. As Fassin and D'Haulin (2007) have found, behaviors of care begin to merge with the political and ideological processes of a particular moment in time. While I do believe that local ideologies about birth in Florence have influenced women's interactions with doctors, I do not believe my research can be described in the same terms as the women in my research were not suffering or victims.

Because of the relative privilege of women in Florence, I suggest that Mol et al.'s (2015) discussion of care as practice is the best way in which to frame care in Florence. Mol et al. discuss care as practice in terms of the behaviors of those providing care. By framing care in terms of practice, care becomes individualized which is far more suited to the Florentine context and reflects my discussions of women's individual experiences. I, however, would like to add to their formulation of care as practice by suggesting that patients' expectations of care are vital in understanding how care is evaluated by patients. By understanding women's expectations of care, the behaviors of healthcare professionals can be discussed in conjunction with larger ideologies of birth. I have shown how women see care as a means through which to obtain socioemotional support as well as medical care. Through this lens care can be seen as both ideologically constructed and practically enacted.

Through attention to care as encompassing women's expectations, we can see how women's failure to receive proper care shows certain fragmentations and fractures within the local healthcare system. When anthropologists have studied fragmented care, it is often based on 
the failure of healthcare systems as a whole, primarily due to a poor transition to a new healthcare system (Janes 2004a; Molina et. Al 2014). As Jones demonstrated, maternal health of low-income rural communities was at risk when Mongolia transitioned to a private healthcare system because the quality and access had decreased partially due to changing economic circumstance. The healthcare system had changed, but other barriers still remained, such as the inability to find transportation or the inability to stop working to make long trips to the doctor. Fragmented care happens under these circumstances not just because care is poor, but because vulnerable populations are often subject to more economic difficulties. Among vulnerable populations, these fragmentations can often be life-threatening. In the Florentine context, I do not believe this definition of fragmented care fits entirely as women were not subjected to a healthcare or economic system that created significant barriers to life-saving care. Instead of fragmented care, I prefer to define women's unmet expectations of care as "fractured care." In Florence, women who received primarily self-evaluated good care often experienced points of fracture where care was not so good. While fragmentation evokes the image of large spaces unoccupied by care, fracture suggests points where a relatively cohesive field of care breaks. Fractures are not necessarily full breaks but represent a break in the cohesive field of care. Fractures do not happen randomly. Fractures happen in spots where the surface is weak and/or where heavy pressure is applied. Fractures can happen in many places and by attuning to the similar points of fracture that women experience in a single healthcare system provides the opportunity to understand where the healthcare system is weakest and how those weaknesses impact women's experiences with maternity care.

Privilege sets the stage for fractured care, but women in Florence are also able to use this privilege as a means to avoid certain acts of reproductive shame. Women in Florence are able to hold multiple seemingly contradictory ideas about childbirth because none of these ideologies 
are a basis of moral shame. As Elyse Singer (2017) demonstrates in her work on abortion in Mexico, behaviors that are shameful can cause women to ignore the importance of their own experience. While abortion is legal in Mexico City, it is still slightly stigmatized. At the local abortion clinic, one abortion is considered acceptable, but two is considered a moral failing and women are often berated by clinic nurses. Women internalize this this stigma by accepting the narrative of moral failure (2017). Tuscan women, however, have not accepted any rhetoric of moral failings if they deviate from the ideal. But why don't they extend such flexible thinking to southern women's experiences? I argue that the rhetoric surrounding childbirth aligns with old values relating to the moral inferiority of the south. Childbirth becomes another way to analyze Schneider's (1998) "southern question" of the "backwards" southerner. The privilege Tuscan women experience by living in a wealthy region with high investments in healthcare allows them the ability to eschew a narrative of shame in favor of a narrative of flexibility.

The connection between reproductive decisions and "backwards" behaviors allows women in Tuscany to make claims to a superior status as northern Italians. The ability of women to identify with a specific geographical area based on their reproductive decisions evokes Petryna's (2002) concept of biological citizenship. For Petryna, biological citizenship was embodied in the ways in which Ukrainians made claims to the state for welfare based on their biological precarity precipitated by work at the Chernobyl reactor after the meltdown. For citizens in a post-socialist country, making biological claims allowed them to assert their right to be recognized by the state through receiving benefits. Women in Florence are not making such overt claims to the state, but through their judgments of Tuscan healthcare compared to southern healthcare, we see that women use reproduction as a way to claim a quasi-citizenship status as both the region of Tuscany and the North as a sub-region of Italy. By ignoring their own sociality and behaviors (in favor of a rationalist medical rhetoric) in their evaluation of 
healthcare systems, women align themselves with ideal behaviors in order to claim a type of morally superior regional affiliation. Italian women's perception of healthcare between the North and South of Italy aligns with Parkhurst's (2008) suggestion that regions represent an often ignored, but relevant, geographical division with which anthropologists can use to analyze their research. The Italian example presents biological citizenship as a claim not to the state or national government, but to a larger regional identity.

The flexibility of women to judge their own circumstances but not women in the south must also be set within a context of the rationalistic medicalized ideas about birth. Though women were careful to detail the importance of social experiences during their maternity care (both with the mother groups in pregnancy and with the midwives during birth), women did not translate these to either reasons for high quality care or lack thereof in other regions. Instead, women favored the highly medicalized rhetoric found in the Ministry of Health documents. Fear and lack of information, both impediments to good birth decisions, are tools through which women in Florence are able to condemn southern women's maternal healthcare decision making. The flexibility women have in discussing the way childbirth may proceed to medical intervention gives way to a more rigid judgments of the southern women. The importance of social support in women's experiences gives away to medical rhetoric. For women, experience is simultaneously valued and ignored. I believe understanding how this rhetoric enters the mind of women in Florence to be a useful future endeavor, requiring a more thorough analysis of the many different childbirth classes, and possibly women's interactions with doctors.

The adherence to medicalized and rationalist discourse in discussing women's behaviors suggests alignment with larger global trends in healthcare recommendations. Janes (2004b) notes that as anthropologists we can track changes in healthcare to larger global processes. Janes analyzes his work in Mongolia through the frame of World Bank healthcare initiatives. As he 
shows, discussions of healthcare did little to focus on local problems, favoring discussions of cost-efficiency. The use of cost-efficiency models and other metrics have been the foundation upon which many healthcare programs have rested and, yet, anthropologists have started to show how these models fail to recognize the totality of human experience. Particularly for maternity care, numbers can hide what's actually happening in local communities. In discussing maternal mortality data, Wendland (2016) suggests that metrics "flatten messy events."

In a recent Valuing Health conference at the University of Edinburgh, Leslie Sharp made the claim that one of the key values of anthropologists is that we can give voice to the ambiguities of life and the points in which metrics fail to provide information. In this chapter, I have sought to do such a thing. As the region with one of the lowest cesarean section rates and the lowest maternal mortality rate in Italy, Tuscany is seen as having some of the best healthcare in the country. Women's unmet needs, both in childbirth and after, demonstrate how statistics cannot possibly describe the complexities of local environments. I use women's appraisals of healthcare both within Tuscany and in other parts of the country to show the ways in which healthcare ideologies impact how women conceive of healthcare behaviors and outcomes. Through attending to the many instances of unmet expectations and sometimes contradictory ideologies, I hope to provide the "messy" context of maternity care in Florence.

\section{Conclusion}

This chapter pushes the boundaries of how we conceptualize high-quality care. While in previous chapters natural childbirth was seen as a benefit to women, the focus on natural childbirth became a burden for those who did not believe in the same birth ideology. Positive experiences in pregnancy and childbirth gave way to difficulties and feelings of abandonment in new motherhood. By showing when women experience barriers in the healthcare system, we are 
able to demonstrate how local cultural healthcare values that can be positive for most still present problems for some women in achieving desired care.

Seemingly contradictory beliefs about natural childbirth and medical interventions are simultaneously held as women acknowledge the potential risks and multiple possibilities of what can happen during birth. Risk and binary appraisals of healthcare options are called into question as the complexities of women's beliefs are realized. These seemingly contradictory beliefs also show the ways in which local healthcare ideologies become ingrained in women's psyche.

The ability to hold seemingly disparate health beliefs is a part of the flexibility in beliefs women hold about birth. Flexibility and acceptance, however, does not seem to translate to the experience of women giving birth in the south, as their presumed behaviors are judged more harshly. Women's experiential narrative gives way to a rationalist medical narrative that places medical failures fully on the shoulders of the patients. Flexibility and acceptance are available only to the privileged. Differences in healthcare decisions become moral issues when placed in certain ideological frames of the south of Italy. Experience is ignored in favor or portraying women as moral failures. 


\section{CHAPTER 8 \\ CONCLUSION: WOMEN'S REPRODUCTIVE SOCIALITIES AND GLOBAL MATERNITY CARE NARRATIVES}

Throughout this dissertation I have tried to demonstrate the way in which maternity care and Florentine women's experiences are frequently at odds with Italian government recommendations. By prefacing my analysis with a study of Ministry of Health guidelines, I demonstrated the substantial distance that exists between medical discourse portraying a universal reproductive body and women's experiences. The foundation of the medical narrative is the idea of the universal body based on objective research. By moving through different levels at which women talk about their own experiences with pregnancy and childbirth, I demonstrate the many different points where medical rhetoric fails to accurately represent women's experiences with maternity care.

But I have also shown how the acceptance of medical rhetoric can cause women themselves to ignore their own experiences. By looking at Italian women's experiences with maternity care in Florence I have shown the magnitude with which sociality and personal relationships impact the decisions of expectant mothers. Women craved sociality with other mothers as a means to cope with their changing lives. Women, however, devalued these experiences with evaluating the Italian healthcare system as a whole. As anthropologists have noted, the move towards evidence-based medicine and clinical trials have rendered subjective bodies invisible in order to make individuals more manageable (Storeng and Béhague 2014; Wendland 2007). In my research, however, I have shown that rationalist medical discourse serves to render invisible the reproductive sociality and experiences women themselves deemed 
valuable. Rationalist medical rhetoric allowed women in Tuscany to reify the image of the "backwards" southerner. For women in Tuscany, however, relative privilege allowed them to simultaneously maintain the importance of sociality and maintain the importance of rationalist reproductive behaviors of others. As Gammeltoft (2007) and Singer (2017) have shown, women are not always able to avoid moral judgments about their reproductive behaviors, suggesting that privilege provides a level of protection from not partaking in idealized reproductive behaviors.

The effort through which women went to maintain these relationships are a testament to the significance of these relationships to women's experiences in pregnancy. By moving away from a focus on technology to a focus on women's sociality surrounding reproduction (Faria 2017; Allison 2011; Rapp 1999), I expand the understanding of sociality to encompass a much wider range of women's activities. This broader range of activities could be useful to Ministry of Health officials who tend to construct women's pregnancy related behaviors and decisions as a simple individualized process affected only by information provided through the doctor. My research demonstrates that women's motivations for information seeking behaviors (i.e. attending prenatal classes) were based on a desire for emotional support during a changing time.

While I outlined my theory of reproductive sociality in Chapter 5 in the context of women's experiences in pregnancy, looking at women's entire experience shows that sociality played an important part in all of women's reproductive experiences. Women's search for sociality did not lessen between pregnancy and labor. Desire for support from a group of expectant mothers shifted to a desire of support from a smaller group of people (i.e. the midwife and partner). Support also shifted from a group of peers to a smaller group of people who were more familiar with the situation: the husband, who was more familiar with the woman's needs, and the midwife, who was an expert in birth. While I outlined sociality in terms of women's positive experiences, women's desire for social relationships also emerged in times in which care 
was lacking. From the women who had to use friends to help with breastfeeding, to the women who called doctor or midwife friends from the hospital, sociality played a role in mediating difficult experiences. Women, however, do not simply turn to these people because they are experts, but because other experts had failed to attend to their needs. The utilization of this social care suggests that social relationships are also important when those with expertise (doctors, midwives etc.) fail to provide care. Understanding more completely the ways in which reproductive sociality provides women with the opportunity to ameliorate healthcare fractures is a potential avenue for future research.

\section{Midwifery-Based Care}

These relationships, however, are not created in a vacuum and are facilitated by local healthcare system. Local healthcare facilities offer services, including the prenatal classes, for free. Midwives are available to provide medical care during pregnancy and childbirth. And beyond the simple services offered, the local healthcare system also supports the role of midwife as primary healthcare professional. Thus, the sociality of women's lives during pregnancy and birth is supported by the Italian healthcare system. Midwives around the world are not always integrated into the healthcare system. Especially in the U.S., where midwifery-based care requires a fee for access, access to midwifery-based care could possibly mimic societal hierarchies, with access available only to those who can pay. This model of midwifery-based care integrated into the hospital is common throughout Europe. DeVries et al. (2009) consider the Dutch system to be the "vanguard" of maternity care models, however, their analysis is based little on analysis of women within the system. Future research, especially within anthropology, should provide significant attention to how maternity care is perceived by women receiving such care. 
Women's experiences with maternity care in Florence show that this privilege does not always lead to patient-centered care. Even though the local healthcare system provides a significant amount of maternity related services free to women in Tuscany, the services are not offered with complete objectivity. Services and care are provided by healthcare professionals with their own set of beliefs about how to provide care. In Florence, women who had positive birth experiences had positive interactions with midwives. Women who encountered barriers to care experienced similar types of barriers. The similar trajectories with which women in each group experienced care suggests that healthcare professionals subscribe to a shared ideology about the importance of natural childbirth. The local healthcare system facilitated the agency of those who subscribed to the same natural childbirth beliefs but put up barriers against those who did not. Most women in my research had positive birth experiences and encountered few barriers, but the stories of the women who encountered such barriers demonstrate how Florentine beliefs about natural childbirth can serve to limit the care desired by women.

The influence of beliefs about natural childbirth, however, can be hard to disentangle from practical limitations placed on care. The best example in this project is women's experiences with receiving aid in breastfeeding after birth. While women detailed that they learned about breast feeding and were encouraged to do so, the care after birth was lacking. Learning about breastfeeding during pregnancy made it seem easy, although in reality it was not. For many women, the high-quality maternity care ended abruptly after birth. While women learned about the importance of breastfeeding during prenatal classes, support was not available, suggesting that structural constraints were a barrier for women to receive support for even ideologically approved behaviors. Further research in Florence should focus on understanding why high-quality care is provided through labor, but not the postpartum period. This research could also focus on potential budget constraints and midwives' evaluations of their own care. 
Similarly, future research could focus on why midwives are so reluctant to provide epidurals, with a particular focus on whether hospital policy encourages midwives to delay the use of epidurals as a cost-saving measure. While I think these avenues of future research are important, in my experience trying to gain permission to conduct research in a hospital, I would caution anybody from designing a project that relies heavily on approval from hospital administration, especially related to the economics of healthcare.

My research on women's experiences with midwives in Florence also offers a critique of the way anthropologists have portrayed midwife-based care. As MacDonald (2006) and Wendland (2006) have suggested, midwife-based care and natural childbirth is not necessarily the ideal mode of birth, but one of many options available to women. Construing midwives as the paragon of maternity care essentially erases the contexts in which women themselves desire midwife-based care. A heavy focus by anthropologists on midwives' practices has left little understanding of women's preferences for midwives beyond home birth (Hazen 2017, Cheyney 2011). By focusing on women who desired midwife-based care, opinions about midwifery in the general population who will use hospitals is unknown. A discussion of woman-centered care in childbirth must contain, first and foremost, the opinions of women. In the Florentine context, the midwives' inability to provide requested care in several instances demonstrates that we must move beyond discussing midwifery-based care as the only example of woman-centered care. A more nuanced understanding of midwifery-based care must explore those instances in which woman-centered care succeeds and those in which it fails, drawing on evaluations of mothers-tobe themselves.

Perhaps the term woman-centered care is not necessarily even the best way to understand how women receive care. Mol et al.'s (2015) “practice of care”, in which the actual acts of care are the focus of inquiry, may be the best alternative. Mol et al. (2015) define "practice of care" as 
the specific behaviors that are a part of healthcare professionals' interactions with patients. But I have also demonstrated that even those who received great care during pregnancy and labor did not necessarily receive the same quality of care after. This aligns with research that has shown women considered the small, short term, incentives for having a child were insufficient actually raising a child (Krause 2005). My work shows that the contranst in the importance placed on fertility versus raising a childhood can start as early as immediately after birth. Further research of an in-depth longitudinal study researching how women evaluate care from pregnancy through one to two years of the child's life could demonstrate more fully how fractured care aligns with political motives.

While local beliefs about birth may influence women's expectations and the care they receive, systemic constraints in a hospital can lead to ideals like woman-centered care being impossible to enact. In large organizations like hospitals, factors such as funding, available personnel, and existing policies can impact the type of care healthcare professionals can provide. Even in a relatively high-resource setting, these demands of large institutions can lead to fractured care in which ideologies of care, such as the woman-centered model, fail. Focusing on when ideologies of care fail offers the opportunity to understand care in practice. Is womancentered care an appropriate model with which to label the type of maternity care midwives provide? Not completely. While healthcare providers can also experience constraints in their practice of care outside of a hospital, I believe that hospital constraints must be taken into account when discussing women's care from midwives. Future research within a hospital context and with midwives would further elaborate midwifery-based care outside of the U.S.

The Florence example also portrays a more nuanced role for midwives and birthing and expectant mothers in the context of demedicalization. Similar to my argument about womancentered care, understanding the process of demedicalization of birth should include how and 
under which circumstances women value medical intervention in childbirth. As I have shown in this dissertation, women's beliefs about safety and technology in birth are strongly tied to space. The hospital is a space of safety, particularly because of the presence of technology. While women may not want the use of these technologies during birth, their mere presence influences women's preferences to such a degree that home birth is seen as unsafe by most. Homebirth with a midwife, often praised by anthropologists (Cheyney 2011; Hazen 2017), is seen as unsafe even in an environment in which natural childbirth is idealized. Women's beliefs about birth in Florence demonstrate the importance of space in understanding how technology in birth is accepted or rejected. Through the addition of space as a mediating variable, processes of demedicalization can become more clearly defined.

The question of acceptance or rejection of technology also has a strange relationship within the Florentine context, as women do not outright reject or accept technology. Acceptance of technology is conditional. Using technological interventions and pain control techniques in childbirth, like epidurals and cesarean sections, are acceptable only when necessary. Thus, technology is not outright rejected or accepted but is based on a certain set of conditions that a woman must go through. Women's flexibility in acceptance and rejection of medical technologies in birth raises the question of how we define medicalization. In Chapter 6 I stated that medicalization must be seen as a spectrum, but how do we define that spectrum? Georges (2008) pointed out that demedicalization is not necessarily a linear trajectory from high to low use of technology, but should the process of demedicalization have an end point in mind in which technology is used only in the rarest of occasions? Or should demedicalization be context specific and a fluid process that changes as contexts do? I would argue that anthropological research could create more precise understandings through comparative projects that focus on specific circumstances under which reproductive technologies are accepted or rejected. 
Women's flexibility in how they perceive pain control techniques highlights an aspect of privilege that requires more elucidation: the ways in which privilege allows women to shape a positive world view. Research by Logsdon and Smith-Morris (2017) and my own demonstrate the flexibility with which women have created judgments surrounding the use of pharmaceuticals in birth. Women in Tuscany were simultaneously able to hold the belief that birth without pharmacological pain control or medical intervention (cesarean section) was better, but that wanting either option was valid under certain circumstances. This type of flexibility, however, was not extended by women in Florence to their assessment of women in the South, whose use of cesarean sections was seen as a negative aspect of both their decisions and the healthcare system they lived in. Similarly, Gammeltoft (2007) and Singer (2017) contested ways in which women partially accept criticism of their use of reproductive technologies. The difference between these research populations, however, is the relative privilege of each of the groups. Logsdon and Smith-Morris (2017) do research in the Netherlands and I do research in a region of Italy with high quality maternity care. Gammeltoft and Singer, however, have done research in Vietnam and Mexico, two countries still considered developing. More comparative research should be done to understand how differences in the relative privilege of different populations impacts how they view their use of reproductive technologies.

Finally, Italian women's ability to hold seemingly contradictory ideas about medical interventions and pain management in childbirth does not mean that women did not face barriers to care. For women in Florence, the hospital was both a site to facilitate agency and a cite in which agency had to be fought for. Hazen (2017) and Bruce (2015) suggest that literature on the medicalization of birth delineate hospitals as a space of biomedical intervention and home birth as a space of women's empowerment. This dichotomy is not quite true. The hospital space in Florence is imbued with different meanings under different circumstances. For most women 
who wanted to have a natural childbirth, the hospital was considered the appropriate place. The hospital was not considered a fully biomedical space. When women's desire for a natural childbirth aligned with the same hospital, midwife-based care facilitated women's agency. For women whose request for an epidural broke the natural childbirth "rules," midwifery-based care presented barriers and women had to more forcefully assert their agency. Women's request for epidural highlights an important aspect of the arguments about homebirth with a midwife vs. hospital birth: midwives at home can never reject the request for an epidural because the request can never be made. By highlighting midwives in the hospital, we see again that understanding biomedical models of birth vs. midwife-models of care requires an analysis of space and place. By attuning to the construction the hospital as a space of natural childbirth, I demonstrate the ways in which midwives in Italy do not necessarily provide women with a woman centered model of care.

\section{Maternity Care: State Discourse Meets Practical Application}

As I have shown, the narrative of maternity care documents, both at the national and regional levels, have several limitations and leave out key aspects of care in Italy and Tuscany that could provide the foundation for significant improvements in maternity care throughout the county. The Ministry of Health and Tuscan documents, however, all focus primarily on interventions designed through medical data rather than through the experiences of women with maternity care. Basic aspects of care, such as the presence of prenatal classes, the importance of midwives, and women's use of specific non-pharmacological pain control techniques, are left out of the governmental narrative of birth and interventions. When women are discussed in these documents, they are most likely to be construed without emotional complexity and as easily controlled. The desired patient who uses information and acts rationally is contrasted with the 
irrational (and emotional) woman who makes poor decisions because she is afraid. The simplicity with which women's behaviors are portrayed is not unexpected, given the reliance on clinical and medical data which focuses on population-level statistics as a true representation of women's experiences. Similarly, the lack of relevant contextual details about services offered to women in the maternity care narrative is unsurprising because the sources used were almost exclusively from other countries, primarily the UK, US, and Sweden. The authors' motivations for excluding Italian sources, not carrying out a study of their own, and not using expert knowledge from clinical practice is unknown. Their justification for their scientific sources suggests that the Ministry of Health is more interested in an objective, scientific analysis of human behavior than a context specific analysis that would actually reduce cesarean rates.

While the Ministry of Health is a federal organization, the decentralization of the healthcare system has caused significant differences in care between regions. Yet, the Ministry of Health did nothing to acknowledge those differences, or to address the difficulty in making recommendations throughout the entire country. In an attempt to make the recommendations general enough to speak to the entire country, the authors made the documents imprecise for any location. Further guidelines released from the Ministry of Health might use research from at least two regions (one in the North and one in the South) to better elucidate actual systemic issues facing the healthcare system.

Tuscany could be one of those models. At the very least, my research could point to the need to understand more fully the role of midwives and the prenatal classes in women's experiences with maternity care in Italy. As my research shows, social relationships played a key role in women's decisions during pregnancy and childbirth. Social relationships may not have a similar role, or may even be detrimental, in other areas, but understanding women's social needs in pregnancy could provide a new avenue with which to understand women's emotional needs as 
complex and multifaceted. A key part of this understanding is the emotion of fear. As I have shown, in Florence, fear does not play a significant role in women's decisions, at least not in the simplistic way that the guidelines suggest women experience their pregnancy and labor. The rationalist model of the individual must be cast aside in favor of understanding the complexities of women's emotions. While the rationalist individual may be easier to analyze, the expectant mothers experience their pregnancy and childbirth through the experience with their emotions. Women's search for different means of sociality is a signal that that they crave support in a difficult and changing period of their life. Emotions are not something to be overcome, but something to be understood. Only with this understanding can accurate recommendations be made.

The Ministry of Health must also recognize the crucial role of the midwife in facilitating women's positive experiences in childbirth. While the guidelines recommend information be provided to expectant mother from doctors, women in Florence consider the midwife as the key healthcare professional for information about childbirth. Even though women considered information to be a less important motivation for attending prenatal classes than social support, women still received both social support and information in these courses. While not all courses are facilitated completely by a midwife, the midwife as course instructor was still a significant part of women's positive experience in pregnancy. As the positive interactions with midwives extended into birth, women sought not just the medical competence of the midwife, but the relationship created. Unlike the Ministry of Health documents which construed the doctorpatient relationship as one of top-down disbursement of information, women's evaluation of care from midwives showed that medical information and qualifications were less important than how women interacted with their midwives. Women were concerned more with the quality of their relationships rather than medical competence. Where the Ministry of Health documents place 
more importance on individual behaviors, women placed more importance on relationships. In the Ministry of Health narrative, the doctor furnishes the information and references to relationships are minimal. Midwives, however, offer collaborative decision making. Because the document does not accurately construe women's relationships with midwives, at least not in Tuscany, women's motivations and reasoning for their birth-related decisions cannot accurately be portrayed.

But even documents from Tuscany do very little to portray women as active agents in their birth-related decisions. Women were considered less important as a site of healthcare intervention than the healthcare professionals. While the Tuscan documents do more to demonstrate the importance of midwives in healthcare, systemic issues are valued over individual relationships. Healthcare systems can indeed have a profound effect on the type of maternity care that women receive, but not without understanding individual behaviors and relationships made between expectant mothers and midwives. The Tuscan documents portray a more nuanced picture of the local healthcare system, but still fail to include the importance of women's behaviors or their evaluations of that care.

\section{Global Flows, National Ideologies and Maternity Care within Anthropology}

In anthropology, there has been a strong focus recently on understanding the connection between the local and the global. While many anthropologists have focused on how information and goods circulate globally and are reutilized or reshaped locally, medical anthropologists have shown how these global forces often serve to disenfranchise certain groups and communities. The groups and communities most impacted by global flows are often the most vulnerable to begin with, such as indigenous tribes in Venezuela (Briggs and Mantini-Briggs 2006) or HIV patients in poverty in Brazil (Biehl 2007). The effect of globalizing biomedical discourse (and 
population-level statistics) has been to erase local realities that are essential to receiving treatment. Individual experience is considered unimportant in light of larger medical discourse. But if my research shows anything, it is that this discourse is not necessarily a source of shame for women who do not fit specific models of reproductive behavior, like other anthropologists have found (Singer 2017; Gammeltoft 2007). For the women in my research, the local, wellfunded, healthcare system provided them with the resources they needed to have a positive pregnancy and birth.

As previously stated, the positive experiences afforded, especially through sociality, did not necessarily lead to a complete denial of rationalist views of birth. If even women in my research succumb to the strength of rationalist ideology in describing healthcare, how can healthcare guidelines, recommendations, and policy be changed to better reflect the reality of women's experiences with maternity care? Of course, I would argue that more anthropological research should be utilized in drafting these documents. We must recognize that there is no utility in having national or even regional guidelines and recommendations if they are not representative of any reality due to their use of global data from outside of Italy. The difficulty in making healthcare recommendations for a nation with significant diversity between regions and healthcare systems means that healthcare documents cannot simply be made from research on populations from other countries. The difficulty with designing maternity care recommendations must be met with the conviction to understand local healthcare systems and women's experiences. The reliance on the idea that there is an objective body that behaves the same across geo-political boundaries makes the design of healthcare documents easy, but not accurate. Future anthropological research could provide more insight into these knowledgemaking processes by conducting an ethnographic study of the Ministry of Health office (and 
officials) tasked with creating these guidelines and recommendations. In doing so, the Ministry of Health officials could become more aware of their biases and the flaws in their work.

As medical anthropologists we study topics that have a strong impact on lives of others and we should always seek to use our research to help those who have helped us. Helping those who have helped us can also mean making uncomfortable realities known more broadly. Anthropologists must, therefore, make a concerted effort to reach broad public audiences with information about the subtle ways in which ideologies about the country and medical discourse are almost subconsciously accepted. While it may sometimes be hard to show the contradictions with which people have discussed very intimate details, I think that demonstrating how our participants hold competing beliefs can help to empower them to use their own experiences to better understand their place within the world.

Nader's concept of "studying up" came with the recognition that anthropologists often studied groups and societies that did not have the same advantages as anthropologists themselves (Nader 1972). "Studying up,” or studying people that are more advantaged, would offer knowledge about groups that are rarely the focus of investigation. In complex societies, however, these groups often have strong influence and a lot of power. While I would not say I have "studied up," I certainly have departed from much anthropological research that has focused on disadvantaged and marginalized populations. ${ }^{12}$ In focusing on a population that has access to significant resources related to their maternity care, I hope to have provided a more complex picture of how privilege impacts women's beliefs relating to maternity care. The relative privilege of women in Florence means that women are met with a system that provides adequate care, although not for all and not at all times. By taking a holistic view of women's

\footnotetext{
${ }^{12}$ I realize an irony in the fact that many anthropologists of reproduction, particularly those working on new reproductive technologies, have studied non-marginalized populations who often had enough resources to spend thousands of dollars on certain procedures. Medical anthropology as a whole, however, has tended to focus on marginalized populations.
} 
experiences with maternity care in Florence, I was able to demonstrate how and when care failed women's expectations and the impact of those failed expectations. I was also able to show how privilege cannot be measured solely by the availability of certain resources but can also be measured by ideological alignments that allow women to assert their own moral superiority without an evaluation of their own circumstances. Privilege allows women to receive quality maternity care without a reflection upon or understanding of the deep historical, economic, and political differences that provide the foundation of their circumstances. In the end, however, women are a part of an ideological system that is hard to break free of. Our enduring legacy as anthropologists is understanding the subtle ways these ideologies influence people's decisions and, hopefully, finding a way to use that knowledge to improve lives. 


\section{Appendix}

Chapter 3: Methods

Recruitment Flyer:

Mi chiamo Michaela Wallerstedt, sono una studentessa in Antropologia allo Southern Methodist University, USA. Sto facendo ricerca per la mia tesi di dottorato sul parto e la gravidanza in Italia. Vorrei parlare con donne Italiane che hanno partorito a Firenze meno di un anno e mezzo per comprendere di più l'esperienza del parto e la gravidanza. La partecipazione a questa ricerca è completamente volontaria. Pagherò $€ 5-10$ per la tua partecipazione. Manterrò la riservatezza sulla tua partecipazione a questa ricerca. Questa intervista durerà almeno 30 minuti e sarà in Italiano. Se vuoi parlare della tua esperienza, puoi contattarmi a mwallerste@smu.edu o telefonino (344) 291-5454

My name is Michaela Wallerstedt, I am an anthropology student at Southern Methodist University, USA. I am doing research for my dissertation on childbirth and pregnancy in Italy. I would like to talk with Italian women who have given birth in Florence in the past year and a half to understand better the experience of pregnancy and birth. The participation in this research is completely voluntary. I will pay $€ 5-10$ Euros for your participation. I will maintain the privacy of your participation in this research. The interview will last at least 30 minutes and will be in Italian. If you want to talk about your experience, you can contact me at...

Research questions

Pregnancy

1. Did you attend an informational classes provided by the hospitals
a. Where?
b. Why did you decide to attend these classes
c. What did you learn from these classes?

2. Where you followed by a doctor or midwife

a. Private or Public?

b. Man or woman

3. What information did you receive from doctors or midwives regarding pregnancy and childbirth during your doctor's visits

4. Did you receive information on any of these pain management techniques during pregnancy, not labor (and from whom)
i. Epidural
ii. Remifentanil
iii. Nitrous oxide
iv. Water birth
v. Massage
vi. Acupuncture
vii. Homeopathy
viii. Aromatherapy 

ix. Hypnosis
x. Transcutaneous electrical nerve stimulation (TENS)

5. During pregnancy, did you feel that you were pressured into choosing any of these over another?

a. If yes, why?

6. Did you attend any community activities run by a midwife?

a. When did you start attending?

b. Why did you chose to attend these?

c. What information were you given about childbirth and pregnancy through these activities?

7. Were there any other methods through which you obtained information about childbirth and pregnancy?

a. Why did you use this/these?

b. Did you use the internet?

c. Family?

d. Friends?

8. Which source of information has been the most important for your decisions regarding pregnancy and birth?

a. Why?

9. Was there any information you received that seemed strange

a. If yes, why?

10. Did you feel that there were any decisions your gynecologist/midwife didn't approve of?

a. If yes, what happened?

i. Did you ever search for a second opinion?

ii. If yes, from who?

1. What did they say?

11. Was there anything about pregnancy or birth that you felt pressured to do?

a. If yes, why did you feel pressured?

12. During pregnancy, were you afraid of birth

a. Why?

13. What did you like about pregnancy

14. What didn't you like about pregnancy

15. Can you please list all the behaviors pregnant women must start because they are pregnant

16. Can you please list all the behaviors pregnant women must stop because they are pregnant

Birth

1. Where did you chose to give birth?

a. Why did you chose to give birth here?

b. Why not the other hospitals?

c. Where there any reasons that made you doubt that decision?

i. If yes, what happened?

d. Did your doctor support your decision?

2. What was the date of the birth

3. How old were you at the time of birth

4. What time did you arrive at the hospital 
5. When you got to the hospital in labor, what happened.

6. At what time did active labor start?

7. What time was the baby born

8. What position did you give birth in

9. During labor did you receive any information of pain control techniques?

a. From who

b. What was said

c. What techniques did you try?

10. Did you ask for anything?

a. What was it?

11. Did you feel that all of your requests were met?

a. How were they met?

12. Were you afraid to ask for anything?

a. Why?

b. Do you think it's normal for women in Tuscany to not be afraid to ask for things in the hospital?

i. In Italy

13. How did you feel about the behaviors of the doctors and midwives you interacted with during birth

14. Was there anything that happened that you wish would have been different?

15. Overall, were you satisfied with your experiences during birth?

a. Can you explain why

16. Who was there with you?

a. Did you feel they helped you to obtain the outcome you wanted?

i. In which ways?

17. Would you choose to give birth in the same place again

18. On a scale of one to 10 , how painful was birth

19. What did you like about your experiences during birth

20. What didn't you like about your experiences during birth

21. (for women with more than one child) what were the biggest differences between your first and second birth

\section{Childbirth Preferences}

1. What is the role of the gynecologist during childbirth

2. What is the role of the midwife during childbirth

3. What is the role of the pregnant woman during childbirth

4. What is your opinion of childbirth with only pain management through complementary medicine?

a. Do you think it is safe?

5. What is your opinion of cesarean sections

a. Do you think it is safe?

i. Why?

6. What is your opinion of epidurals?

a. Do you think it is safe?

i. Why?

7. What is your opinion of home birth

a. Do you think it is safe

i. Why? 
8. If you give birth again, what type of birth would you prefer

9. Do you think women in Tuscany make good decisions regarding pregnancy and birth a. Why

10. And in the rest of Italy

a. Why/

11. What do you think about the quality of services for childbirth in Florence compared to other places in Italy?

12. Did you know that the percent of cesareans is higher in the south a. Do you have an opinion of the causes?

13. Is there anything else you would like to say

CODEBOOK

\begin{tabular}{|l|l|l|l|l|}
\hline Social Support & Idealized Birth & $\begin{array}{l}\text { Interactions with } \\
\text { Doctors and } \\
\text { midwives }\end{array}$ & $\begin{array}{l}\text { Information } \\
\text { seeking behaviors }\end{array}$ & Fear and risk \\
\hline Condividere & Parto Naturale & $\begin{array}{l}\text { When are doctors } \\
\text { utilized and when } \\
\text { midwives }\end{array}$ & $\begin{array}{l}\text { Where found } \\
\text { information about } \\
\text { birth }\end{array}$ & Fear of pain \\
\hline Childbirth classes & Hospital birth & $\begin{array}{l}\text { Qualities of a } \\
\text { good midwife in } \\
\text { birth }\end{array}$ & $\begin{array}{l}\text { Most important } \\
\text { sources }\end{array}$ & $\begin{array}{l}\text { Risk of different } \\
\text { types of birth }\end{array}$ \\
\hline $\begin{array}{l}\text { Advocates during } \\
\text { childbirth }\end{array}$ & Role of midwife & $\begin{array}{l}\text { Midwives } \\
\text { behaviors in corsi } \\
\text { pre parto }\end{array}$ & $\begin{array}{l}\text { Information vs } \\
\text { social }\end{array}$ & Home vs hospital \\
\hline & $\begin{array}{l}\text { Other areas of } \\
\text { support }\end{array}$ & & & \\
\hline
\end{tabular}

\begin{tabular}{|l|l|l|l|l|}
\hline Quality Care & $\begin{array}{l}\text { Women's roles } \\
\text { in childbirth }\end{array}$ & $\begin{array}{l}\text { Women's } \\
\text { behaviors in } \\
\text { pregnancy }\end{array}$ & Narratives & (non) Choice \\
\hline Information & $\begin{array}{l}\text { What must } \\
\text { women do }\end{array}$ & $\begin{array}{l}\text { What should(n't) } \\
\text { a woman do? }\end{array}$ & $\begin{array}{l}\text { How are } \\
\text { narratives } \\
\text { constructed }\end{array}$ & $\begin{array}{l}\text { Women } \\
\text { cesareans }\end{array}$ \\
\hline $\begin{array}{l}\text { Tuscan } \\
\text { exceptionalism } \\
\text { (almost) }\end{array}$ & $\begin{array}{l}\text { Difficulties of } \\
\text { pregnancy }\end{array}$ & $\begin{array}{l}\text { Idealized } \\
\text { pregnancy }\end{array}$ & $\begin{array}{l}\text { important } \\
\text { elements }\end{array}$ & $\begin{array}{l}\text { Natural birth } \\
\text { wanted }\end{array}$ \\
\hline
\end{tabular}




\title{
Chapter 4
}

\author{
List 4.1 \\ PubMed, \\ Embase, \\ Pascal \\ EMCare \\ British Nursing Index \\ Psychological Sciences Library (PSYC) \\ Social Sciences Citation Index (SSCI) \\ Cochrane Library
}

Table 4.2 Final Recommendations of Each Section

\begin{tabular}{|c|c|c|}
\hline $\begin{array}{l}\text { Offering Information and } \\
\text { Support to Women }\end{array}$ & $\begin{array}{l}\text { Informed Consent for Birth } \\
\text { Through Cesarean Section }\end{array}$ & $\begin{array}{l}\text { Maternal Request for } \\
\text { Cesarean Sections }\end{array}$ \\
\hline $\begin{array}{l}\text { Healthcare professionals, in } \\
\text { particular medical specialists } \\
\text { in obstetrics and gynecology, } \\
\text { midwives, general medicine } \\
\text { doctors, must actively offer to } \\
\text { all pregnant women, at the } \\
\text { end of the second trimester, } \\
\text { information based on } \\
\text { scientific evidence regarding } \\
\text { gestation and of the different } \\
\text { modes of birth, and adequate } \\
\text { support that comprehends } \\
\text { also a comparison of the } \\
\text { opinions and the possible } \\
\text { preoccupations expressed by } \\
\text { the women }\end{array}$ & $\begin{array}{l}\text { In case of caesarean section, } \\
\text { whether scheduled or } \\
\text { emergency, the doctor must } \\
\text { always ask the woman for } \\
\text { informed consent for the } \\
\text { intervention. In view of the } \\
\text { clinical picture, it is required } \\
\text { to provide information based } \\
\text { on scientific evidence, } \\
\text { through the mode of } \\
\text { respectful communication } \\
\text { with the woman, her opinion, } \\
\text { her dignity, her privacy and } \\
\text { her culture. The language } \\
\text { used in both verbal and } \\
\text { written communication must } \\
\text { always be appropriate and } \\
\text { understandable to the } \\
\text { interlocutor. }\end{array}$ & $\begin{array}{l}\text { The maternal request, in the } \\
\text { absence of clinical reasons, } \\
\text { does not represent an } \\
\text { indication for the caesarean } \\
\text { section. Healthcare } \\
\text { professionals must explain } \\
\text { the potential benefits and } \\
\text { damages of caesarean section } \\
\text { to vaginal delivery, discuss } \\
\text { the motivations of this } \\
\text { request with the woman and } \\
\text { document the entire decision- } \\
\text { making process in the } \\
\text { medical record. }\end{array}$ \\
\hline $\begin{array}{l}\text { Actively offer to the pregnant } \\
\text { women informed } \\
\text { interventions and support, } \\
\text { standardized and validated }\end{array}$ & $\begin{array}{l}\text { The minimum contents of the } \\
\text { caesarean section consent } \\
\text { form must include: } \\
\text { - clinical indication for } \\
\text { surgery; } \\
\text { - the balance of the potential } \\
\text { benefits and damages, in the } \\
\text { short and long term, for the } \\
\text { health of the mother and the } \\
\text { unborn child in the event of a } \\
\text { caesarean section with respect } \\
\text { to the vaginal birth, with }\end{array}$ & $\begin{array}{l}\text { If the reason for the caesarean } \\
\text { request by the woman is } \\
\text { primarily due to the fear of } \\
\text { childbirth, it is recommended } \\
\text { to offer, during pregnancy, } \\
\text { standardized and validated } \\
\text { information and support } \\
\text { interventions (such as one-to- } \\
\text { one assistance). and the } \\
\text { provision of childbirth and } \\
\text { non-pharmacological } \\
\text { analgesia), able to reassure }\end{array}$ \\
\hline
\end{tabular}




\begin{tabular}{|c|c|c|}
\hline & $\begin{array}{l}\text { particular regard to the } \\
\text { specificity of the woman and } \\
\text { her pregnancy; } \\
\text { - the procedures for } \\
\text { performing surgery; } \\
\text { - the various anesthetic } \\
\text { techniques; } \\
\text { - the implications for future } \\
\text { pregnancies and births after } \\
\text { caesarean section or vaginal } \\
\text { delivery. }\end{array}$ & $\begin{array}{l}\text { the pregnant woman and } \\
\text { support her in the decision- } \\
\text { making process. }\end{array}$ \\
\hline $\begin{array}{l}\text { All pregnant women must } \\
\text { receive information, on } \\
\text { scientific evidence, about the } \\
\text { caesarean section, which } \\
\text { include: } \\
\text { - absolute and relative } \\
\text { instructions of caesarean } \\
\text { section; } \\
\text { - The benefits and damages } \\
\text { associated of the [cesarean } \\
\text { section] for a woman's health; } \\
\text { - the procedures for } \\
\text { performing surgery; } \\
\text { - the various anesthetic } \\
\text { techniques; } \\
\text { - the implications for future } \\
\text { pregnancies and births after } \\
\text { caesarean section. }\end{array}$ & $\begin{array}{l}\text { In the planned caesarean } \\
\text { section, consent must be } \\
\text { discussed before admission, } \\
\text { to allow the woman to } \\
\text { express any doubts and have } \\
\text { enough time to reflect on the } \\
\text { information received, and to } \\
\text { the doctor to evaluate any } \\
\text { problems that would be } \\
\text { difficult resolution in the } \\
\text { imminence of the } \\
\text { intervention. }\end{array}$ & $\begin{array}{l}\text { In the absence of an } \\
\text { appropriate clinical } \\
\text { indication, the doctor has the } \\
\text { right to refuse a planned } \\
\text { caesarean section. In any } \\
\text { case, women must be given } \\
\text { the opportunity to access a } \\
\text { second opinion. }\end{array}$ \\
\hline $\begin{array}{l}\text { Information and support must } \\
\text { be offered to all pregnant } \\
\text { women, using every possible } \\
\text { opportunity to meet with } \\
\text { dedicated professionals (for } \\
\text { example visits to obstetric } \\
\text { surgery or birth support } \\
\text { courses). The contents and } \\
\text { methods of communication } \\
\text { must take into consideration } \\
\text { cultural aspects (for example } \\
\text { in the case of women for } \\
\text { whom Italian is not the } \\
\text { mother tongue), the level of } \\
\text { education and the specific } \\
\text { needs of women with } \\
\text { disabilities. or learning } \\
\text { difficulties. }\end{array}$ & $\begin{array}{l}\text { In case of emergency } \\
\text { caesarean section, it is } \\
\text { recommended that the doctor } \\
\text { always acquires the consent, } \\
\text { making sure that the woman } \\
\text { has understood the indication } \\
\text { of the intervention. }\end{array}$ & \\
\hline
\end{tabular}




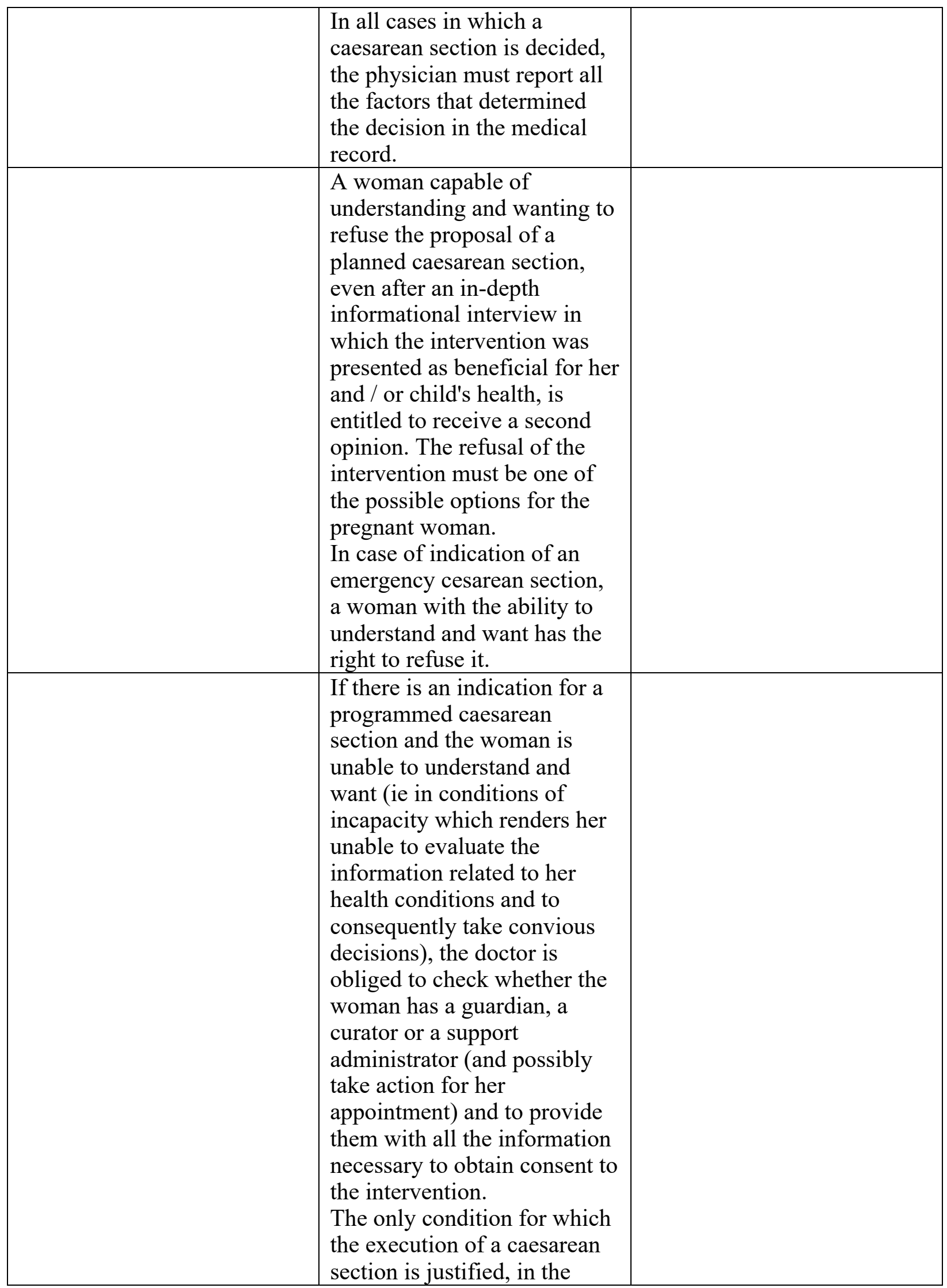




\begin{tabular}{|l|l|}
\hline & $\begin{array}{l}\text { impossibility of acquiring the } \\
\text { consent due to the inability of } \\
\text { the woman, is represented by } \\
\text { the state of urgency, defined } \\
\text { as a need unable to be } \\
\text { deferred to intervene to avoid } \\
\text { death or serious harm. }\end{array}$ \\
\hline
\end{tabular}

Table 4.3 Health outcomes measured in Cochrane study

\begin{tabular}{|c|c|c|c|c|}
\hline Labor & Delivery Mode & The Newborn & $\begin{array}{l}\text { Immediate } \\
\text { maternal } \\
\text { psychological } \\
\text { outcomes }\end{array}$ & $\begin{array}{l}\text { Long term } \\
\text { maternal } \\
\text { psychological } \\
\text { outcomes }\end{array}$ \\
\hline Amniotomy & $\begin{array}{l}\text { Caesarean } \\
\text { Section }\end{array}$ & $\begin{array}{l}\text { Low Apgar at } 5 \\
\text { minutes }\end{array}$ & $\begin{array}{lr}\text { Tension } & \text { and } \\
\text { anxiety } & \text { during } \\
\text { labor } & \end{array}$ & $\begin{array}{l}\text { Postpartum } \\
\text { depression }\end{array}$ \\
\hline Oxytocin & $\begin{array}{l}\text { Operative } \\
\text { Vaginal } \\
\text { Delivery }\end{array}$ & Low cord $\mathrm{pH}$ & $\begin{array}{l}\text { Judgement and } \\
\text { negative } \\
\text { emotions related } \\
\text { to the experience } \\
\text { of childbirth }\end{array}$ & $\begin{array}{l}\text { Low self-esteem } \\
\text { in the } \\
\text { postpartum } \\
\text { period }\end{array}$ \\
\hline Cardiotocography & $\begin{array}{l}\text { Spontaneous } \\
\text { Vaginal } \\
\text { Delivery }\end{array}$ & $\begin{array}{l}\text { admission in } \\
\text { specialized care } \\
\text { departments }\end{array}$ & $\begin{array}{l}\text { Perceiving } \\
\text { difficulty in } \\
\text { coping with } \\
\text { labor perception } \\
\text { of reduced } \\
\text { ability to control } \\
\text { during labor }\end{array}$ & $\begin{array}{l}\text { Anxiety in the } \\
\text { postpartum } \\
\text { period }\end{array}$ \\
\hline Epidural & Episiotomy & $\begin{array}{l}\text { prolonged } \\
\text { hospitalization }\end{array}$ & & $\begin{array}{l}\text { Difficulty in the } \\
\text { maternal role }\end{array}$ \\
\hline $\begin{array}{l}\text { Any form of } \\
\text { analgesia }\end{array}$ & Perineal Trauma & & & $\begin{array}{l}\text { Non-exclusive } \\
\text { breastfeeding }\end{array}$ \\
\hline Anesthesia & & & & $\begin{array}{l}\text { Prolonged } \\
\text { Perineal pain }\end{array}$ \\
\hline Severe Pain & & & & Dyspareunia \\
\hline \multirow[t]{2}{*}{ Duration of labor } & & & & $\begin{array}{l}\text { Urinary } \\
\text { incontinence }\end{array}$ \\
\hline & & & & $\begin{array}{l}\text { Fecal } \\
\text { incontinence }\end{array}$ \\
\hline
\end{tabular}




\section{Bibliography}

Abel, Emily and Carole Browner, 1998 "Selective Compliance with Biomedical Authority and the Uses of Experiential Knowledge" In Pragmatic Women and Body Politics Cambridge University Press. Margaret Lock and Patricia A. Kaufert, eds. Pp. 310-326 Cambridge: Cambridge University Press

Abu-Lughod, Lila, 2008 [1993], Writing Women's Worlds. Berkeley: University of California Press

Adams, Vincanne, 2016 "Metrics of the Global Sovereign: Numbers and Stories in Global Health” In Metrics: What Counts in Global Health. Vincanne Adams, eds. Pp. 1-54

Aginam, Obijiofor, 2005 Global Health Governance: International Law and Public Health in a Divided World. Toronto: University of Toronto Press

Allison, Jill, 2011 Conceiving silence: infertility as discursive contradiction in Ireland. Medical Anthropology Quarterly, 25(1), 1-21.

Arcury, T. and Quandt, S., 1999 Participant recruitment for qualitative research: A site-based approach to community research in complex societies. Human Organization, 58(2): 128-133.

Basili, Fulvio et al., 2018 Certificato di Assistenza al Parto (CeDAP). Analisi dell'evento Nascita-Anno 2015. Direzione Generale della Digitalizzazione del Sistema Informativo Sanitario e della Statistica-Ufficio di Statistica.

Banfield, Edward, 1958 The Moral Basis of Backward Society. New York: Free Press

Bernard, Russell, 2011 Research Methods in Anthropology: Qualitative and Quantitative Approaches ( $5^{\text {th }}$ Edition) United Kingdom: Altimira Press

Béhague, Dominique, 2002 Beyond the simple economics of cesarean section birthing: women's resistance to social inequality. Culture, Medicine and Psychiatry 26(4): 473-507.

Behar, Ruth, 1993 Translated Woman: Crossing the Border with Esperanza's Story. Boston: Beacon Press

Biehl, João, 2007 Will to Live. Princeton: Princeton University Press

Biehl, João, and Amy Moran-Thomas, 2009 Symptom: Subjectivities, Social Ills, Technologies. Annual Review of Anthropology 38: 267-288 
Blackwood, Evelyn, 2000 Webs of Power: Women, Kin, and Community in a Sumatran Village. Oxford: Rowman and Littlefield

Bohannan, Laura, 1966 Shakespeare in the Bush. Language: Readings in Language and Culture, 27-36.

Bourdieu, Pierre, 1977 Outline of a Theory of Practice. Cambridge: Cambridge University Press. -2010 Structures, Habitus, Practices. In Social Theory: The Multicultural \& Classic Readings Pp.444-449

Braff, Lara, 2013 "Somos Muchos (We Are So Many): Population Politics and "Reproducing Othering" in Mexican Fertility Clinics. Medical Anthropology Quarterly 27(1): 121-138

Brettell, Caroline, 2006 “Anthropology, Gender and Narrative” pp. 68-86 In Exploring Women's Studies: Looking Forward, Looking Back. Carol Berkin, Judith Pinch and Carole Appel, eds. Pearson.

— 1995 We Have Already Cried Many Tears: The Stories of Three Portuguese Migrant Women. Waveland Press.

Briggs, Charles and Clara Mantini-Briggs, 2003 Stories in the Time of Cholera: Racial Profiling During a Medical Nightmare. Berkeley: University of California Press.

Browner, Carole and Nancy Press, 1997 The Production of Authoritative Knowledge in American Prenatal Care In Childbirth and Authoritative Knowledge: Cross-Cultural Perspectives. Robbie Davis-Floyd and Carolyn Sargent, eds. Pp. 113-131

Browner, Carole and Carolyn Sargent, 2011 Reproduction, Globalization, and the State: New Theoretical and Ethnographic Perspectives. Durham: Duke University Press

Bucholtz, Mary, 2003 Theories of Discourse as Theories of Gender: Discourse Analysis in Language and Gender Studies. The Handbook of Language and Gender: 43-68

Burns, Emily, 2015. More than Four Walls: The Meaning of Home in Home Birth Experiences. Social Inclusion 3: 6-16.

Callister, Lynn Clark, Inaam Khalaf, Sonia Semenic, Robin Kartchner, and Katri VehvilainenJulkunen, 2003 The Pain of Childbirth: Perceptions of Culturally Diverse Women." Pain Management Nursing 4(4): 145-154.

Cavalieri, Marina et al., 2013 Effects of Tariff Differentials on Cesarean Sections in Italy. La Finanza Pubblica Nei Sistemi Multilivello. Società Italiana di Economia Pubblia. Aule Storiche delll'Università, Pavia. 26 Sept. 2013. Lecture.

Centri regionali di riferimento, Rete Toscana Medicina Integrata, Azienda USL 2 di Lucca, 2014 "Partoanalgesia: Il Contributo delle Medicine Complementare" in Dolce Parto in Toscana -2011 "Nascere Seconod Natura." In Medicine Complementare a Sostegno del Parto Fisiologico 
Cicchetti, Americo, Silvia Coretti, and Valentina Iacopino, 2015 Healthcare Reform, Quality and Safety. Perspectives, Participants and Prospects in 30 countries.

Central Intelligence Agency, 2018 "Maternal Mortality" Available at: https://www.cia.gov/library/publications/the-world-factbook/rankorder/2223rank.html

Cheyney, Michelle, 2011 Reinscribing the Birthing Body: Homebirth as Ritual Performance. Medical Anthropology Quarterly, 25(4): pp.519-542.

Chiavola Birnbaum, Lucia, 1986 Liberazione della Donna. Middletown, CT: Wesleyan.

Cohen, Jeffrey, 2000 Problems in the Field: Participant Observation and the Assumption of Neutrality. Field Methods, 12(4): 316-333.

Conrad, Peter, 1992 Medicalization and Social Control. Annual Review of Sociology 18: 29-32

Cosminsky, Sheila, 2001 Midwifery Across the Generations: A Modernizing Midwife in Guatemala. Medical Anthropology: Cross-Cultural Studies in Health and Illness. 20(2-3): $345-378$

Counihan, Carole, 2004 Around the Tuscan Table: Food, Family, and Gender in Twentieth Century Florence. New York: Routledge

Crawford, Robert, 1980 Healthism and the Medicalization of Everyday Life. International Journal of Health Services, 10(3): 365-388

Davis-Floyd, Robbie, 1992 Birth as an American Rite of Passage: With a New Preface. Berkeley: University of California Press.

Davis-Floyd, Robbie and Elizabeth Davis, 1997 Intuition as Authoritative Knowledge in Midwifery and Home Birth. In Childbirth and authoritative knowledge: Cross-cultural perspectives. Robbie Davis-Floyd and Carolyn Sargent, eds. Berkeley: University of California Press

Davis-Floyd, Robbie, and Carolyn Sargent, 1997 Childbirth and Authoritative Knowledge: Cross-Cultural Perspectives. Berkeley: University of California Press.

Davis-Floyd, Robbie, Stacy Leigh Pigg, and Sheila Cosminsky, 2001 Introduction. Daughters of Time: The Shifting Identities of Contemporary Midwives. Pp. 105-139.

Davis-Floyd, Robbie E., Lesley Barclay, Jan Tritten, and Betty-Anne Daviss, eds., 2009 Birth models that work. Berkeley: University of California Press

Desjarlais, Robert, 1997. Shelter Blues: Sanity and Selfhood among the Homeless. Philadelphia: University of Pennsylvania. 
De Vries, Raymond, Therese A. Wiegers, Beatrijs Smulders, and Edwin Van Teijlinge, 2009 The Dutch Obstetrical System" In Birth Models That Work, Robbie Davis-Floyd, Lesley Barclay, Betty-Anne Daviss, Jan Tritten, eds.

De Zordo, Silvia, 2012 Programming the Body, Planning Reproduction, Governing Life: The '(Ir-) Rationality' of Family Planning and the Embodiment of Social Inequalities in Salvador da Bahia (Brazil)." Anthropology \& medicine, 19(2): 207-223.

Donati, Serena, Michele Grandolfo, and Silvia Andreozzi, 2003 Do Italian Mothers Prefer Cesarean Delivery?. Birth, 30(2): 89-93.

El Kotni, Mounia, 2018 Regulating Traditional Mexican Midwifery: Practices of Control, Strategies of Resistance. Medical anthropology, pp.1-15.

Epele, Maria Esther, 2018 Neoliberal Care: Intimacy, Romance, and Drug Use in Argentine Dispossessed Populations. The Journal of Latin American and Caribbean Anthropology, 23(1): 152-168.

Fabrega, Horatio, 1980 The Idea of Medicalization: An Anthropological Perspective. Perspectives in Biology and Medicine 24(1): 129-142

Faria, Inês, 2018 Therapeutic Navigations and Social Networking: Mozambican Women's Quests for Fertility. Medical anthropology: Pp: 1-15.

Fassin, Didier, and Estelle d'Halluin, 2005 The Truth From the Body: Medical Certificates as Ultimate Evidence For Asylum Seekers. American anthropologist, 107(4): 597-608.

-2007 Critical Evidence: The Politics of Trauma in French Asylum Policies. Ethos 35(3): 300329

Federfarma, 2016 "Lea, Via Libera del Mef, a Settembre in Parlamento.” Accessed 12/15/2018 Available at https:/www.federfarma.it/Edicola/FiloDiretto/Filodiretto/luglio2016/02-082016-00-01-23.aspx

Foucault, Michel, 1972 Birth of a Clinic. New York: Pantheon Books

-1980 Power and Knowledge: Selected Interviews and Other Writings, 1972-1977. Vintage Books

—1991 History of Sexuality, Volume One: An Introduction. Vintage Books

- 1991 Governmentality. In The Foucault Effect: Studies in Governmentality. Michel Foucault, Graham Burchell, Colin Gordon, and Peter Miller, eds. University of Chicago Press

-2007 Security, Territory, Population: Lectures at the Collège de France, 1977-78. Springer.

Franklin, Sarah, 2012 Anthropology of Biomedicine. The SAGE Handbook of Social Anthropology, 42.

-2014 Analogic Return: The Reproductive Life of Conceptuality. Theory, Culture \& Society, 31(2-3): 243-261.

Gammeltoft, Tine, 2007 Sonography and Sociality: Obstetrical Ultrasound Imaging in Urban Vietnam. Medical Anthropology Quarterly, 21(2): 133-153 
Geertz, Clifford, 1973 Deep Play: Notes on the Balinese Cockfight. In Geertz, The Interpretation of Cultures

-1988 "Chapter 1: Being There: Anthropology and the Science of Writing". In Works and Lives: The Anthropologist as Author. Stanford University Press: Stanford, CA.

Georges, Eugenia, 2008 Bodies of Knowledge: The Medicalization of Reproduction in Greece. Vanderbilt University Press

Giddens, Anthony, 1973 Capitalism and Modern Social Theory. Cambridge: Cambridge University Press.

-1984 The Constitution of Society: Outline of the Theory of Structuration. Berkeley: University of California Press.

Gibbon, Sahra and Carlos Novas, eds., 2008 Biosocialities, Genetics and the Social Sciences: Making Biologies and Identities. Routledge.

Goddard, Victoria, 1996 Gender, Family, and Work in Naples. Berg Pub Limited

Good, Byron, 1994 Medicine, Rationality, and Experience: An Anthropological Perspective. Cambridge: Cambridge University Press

Gruppo di Lavoro dal Consiglio Sanitario Regionale Toscano, 2014 "Raccomandazioni su Modalità di Controllo del Dolore Durante il Travaglio ed il Parto in Regione Toscana." http://www.regione.toscana.it/documents/10180/12157370/Allegato+Parere+n.+542014.pdf/4ed42b0b-d7a2-4f86-af00-

7f8cf9b87bea;jsessionid=D8B101C3DDFE9EB7E32455A4E01A2C51.web-rt-as01p2? version $=1.0$

Hazen, Helen, 2017 'The First Intervention Is Leaving Home': Reasons for Electing an Out-ofHospital Birth among Minnesotan Mothers." Medical anthropology quarterly, 31(4): 555571.

Herzfeld, Michael, 2016 The Hypocrisy of European Moralism: Greece and the Politics of Cultural Aggression. Anthropology Today 32(1): 11-13 \& 32(2): 10-13.

Hirsch, Eric, 1995 Landscape: Between Place and Space. In The Anthropology of Landscape: Perspectives on Place and Space. Hirsch, Eric, and Michael O'Hanlon, eds. Oxford: Clarendon Press

Hofberg, Kristina and Ian Brockington, 2000 Tokophobia: An Unreasoning Dread of Childbirth: A Series of 26 Cases. British Journal of Psychiatry, 1(176): 83-85

Horn, David, 1994 Social Bodies: Science, Reproduction, and Italian Modernity. Princeton: Princeton University Press

Inhorn, Marcia, 2006 Defining Women's Health: A Dozen Messages From More Than 150 Ethnographies. Medical Anthropology Quarterly, 20(3): 345-378. 
Irwin, Susan, and Brigitte Jordan, 1987 Knowledge, Practice, and Power: Court-Ordered Cesarean Sections. Medical Anthropology Quarterly 1(3): 319-334.

Ivry, Tsipy, 2010 Embodying Pregnancy: in Japan and Israel. Piscataway: Rutgers University Press

Janes, Craig, 2004a Going Global in Century XXI: Medical Anthropology and the New Primary Health Care." Human Organization 457-471.

-2004b Free Markets and Dead Mothers: The Social Ecology of Maternal Mortality in PostSocialist Mongolia. Medical Anthropology Quarterly, 18(2), 230-257

Jordan, Brigitte, 1993 [1978] Birth in Four Cultures .Prospect Heights: Waveland Press

-1997 Authoriative Knowledge and its Construction in Childbirth and Authoritative

Knowledge: A Cross-Cultural Perspective. Carolyn Sargent and Robbie-Davis Floyd, eds. Berkeley: University of California Press

Kanaaneh, Rhoda, 2002 Birthing theNnation: Strategies of Palestinian Women in Israel. Berkeley: University of California Press.

Ketler, Suzanne, 1997 Preparing for Motherhood: Authoritative Knowledge and the Undercurrents of Shared Experience in Two Childbirth Education Courses in Cagliari, Italy. Medical Anthropology Quarterly, 14(2), 138-158.

Kaufert, Patricia and John O'Neil, 1990 Cooption and Control: The Reconstruction of Inuit Birth. Medical Anthropology Quarterly, 4(4): 427-442

- 1993 Analysis of a Dialogue of Risks in Childbirth: Clinicians, Epidemiologists, and Inuit Women. In Knowledge, Power, and Practice: The Anthropology of Medicine and Everyday Life. Shirley Lindenbaum and Margaret Lock, eds. Pp. 32-54 Berkeley: University of California Press.

Kenny, Michael and David Kertzer, 1983 Urban Life in Mediterranean Europe: Anthropological Perspectives.

Kertzer, David, 1989 Family, Political Economy, and Demographic Change: The Transformation of Life in Casalecchio, Italy 1861-1921. University of Wisconsin Press

-1993. Sacrificed for Honor: Italian Infant Abandonment and the Politics of Reproductive Control. Boston: Beacon Press.

Kirmayer, Laurence, 1992 The Body's Insistence on Meaning: Metaphor as Presentation and Representation in Illness Experience. Medical Anthropology Quarterly, 6(4): 323-346.

Kleinman, Arthur, 1997 Writing at the Margin: Discourse Between Anthropology and Medicine. Berkeley: University of California Press

-1988 The Illness Narrative: Suffering, Healing, and the Human Condition. New York: Basic Book 
Kleinman, Arthur, and Bridget Hanna, 2008 "Catastrophe, Caregiving and Today's Biomedicine." Biosocieties 3(3): 287-301.

Kligman, Gail, 1998 The Politics of Duplicity: Controlling Reproduction in Ceausescu's Romania. Berkeley/Los Angeles: University of California Press

Krause, Elizabeth L., 2001. "Empty Cradles" and the Quiet Revolution: Demographic Discourse and Cultural Struggles of Gender, Race, and Class in Italy. Cultural Anthropology 16(4):576611.

-2005 A Crisis of Births: Population Politics and Family Making in Italy. Belmont, CA: Thomson/Wadsworth

-2012 "They Just Happened": The Curious Case of the Unplanned Baby, Italian Low Fertility, and the "End" of Rationality. Medical Anthropology Quarterly 26(3): 361-382.

Krause, Elizabeth L., and Silvia De Zordo., 2012 "Introduction. Ethnography and biopolitics: tracing 'rationalities' of reproduction across the north-south divide." Anthropology \& Medicine 19(2): 137-151.

Krause, Elizabeth L. and Milena Marchesi, 2007 "Fertility Politics as "Social Viagra": Reproducing Boundaries, Social Cohesion, and Modernity in Italy." American Anthropologist 109 (2): 350-362.

Kuan, Chen, 2010 "A Reinterpretation of Maternal Requests for Cesarean Sections in Taiwan" The Journal of Archaeology and Anthropology 72: 97-136.

Lee, Richard, 1969 Eating Christmas in the Kalahari. American Museum of Natural History.

Li, Tania Murray, 2007 "Governmentality." Anthropologica: 275-281.

Lo Scalzo, Alessandra et al., 2009. Healthcare Systems in Transition: Italy. Copenhagen: WHO regional office for Europe on behalf of the European Observatory on Health Systems and Policies.

Lock, Margaret, 1998 "Cultivating the Body: Anthropology and Epistemologies of Bodily Practice and Knowledge," Annual Review of Anthropology 22:133-155.

Lock, Margaret and Patricia Kaufert, 1998 Pragmatic Women and Body Politics. New York: Cambridge University Press

Lock, Margaret and Scheper-Hughes, 1990 Lock, M., \& Scheper-Hughes, N. (1990). A criticalinterpretive approach in medical anthropology: Rituals and routines of discipline and dissent. Medical anthropology: Contemporary theory and method, 3, 47-73.

Logsdon, Katie and Carolyn Smith-Morris, 2017 "An ethnography on perceptions of pain in Dutch "Natural” childbirth." Midwifery, 55, 67-74. 
Lopez, Iris, 1993 Agency and Constraint: Sterilization and Reproductive Freedom Among Puerto Rican Women in New York City. Urban Anthropology and Studies of Cultural Systems and World Economic Development, 299-323.

Low, Setha, 2016 Spatializing Culture: The Ethnography of Space and Place. Routledge.

Low, Setha and Denise Lawrence-Zúñiga, 2003 "Locating Culture." The Anthropology of Space and Place: Locating culture: 1-47.

MacDonald, Margaret, 2006 “Gender Expectations: Natural Bodies and Natural Births in the New Midwifery in Canada” In Medical Anthropology Quarterly 20(2): 235-256

Marchesi, Milena, 2012 "Reproducing Italians: Contested Biopolitics in the Age of 'Replacement Anxiety'." Anthropology and Medicine, 19(2): 171-188

Martin, Emily, 1987 The Woman in the Body: A Cultural Analysis of Reproduction. Beacon Press

-2009 Bipolar Expeditions: Mania and Depression in American Culture. Princeton University Press.

—2012 "Grafting Together Medical Anthropology, Feminism, and Technoscience." Medical Anthropology at the Intersections: Histories, Activisms and Futures pp. 23-40.

Mattingly, Cheryl, 1998a Healing Dramas and Clinical Plots: The Narrative Structure of Experience. Cambridge University Press

—1998b "In Search of the Good: Narrative Reasoning in Clinical Practice." Medical Anthropology Quarterly, 12(3), 273-297.

Mattingly, Cheryl and Garro, Linda eds., 2000. Narrative and the Cultural Construction of Illness and Healing. Univ of California Press.

Maynes, May Jo, Jennifer Pierce, Barbara and Laslett, 2012 Telling Stories: The Use of Personal Narratives in the Social Sciences and History. Cornell University Press.

Mead, Margaret, 1973 [1928] Coming of Age in Samoa: The Psychological Study of Primitive Youth in Western Civilizations. William Morrow \& Company.

Ministero della Salute, 2010 Taglio Cesareo: Una Scelta Appropriata e Consapevole. Linea Guida, 19.

-2012 Taglio Cesareo: Una Scelta Appropriata e Consapevole. Seconda Parte. Linea Guida, 22.

Mishtal, Joanna, 2012 "Irrational Non-Reproduction? The 'Dying Nation' and the Postsocialist Logics of Declining Motherhood in Poland" Anthropology and Medicine. 19(2): 153-169

Moe, Nelson, 2002 The View Vrom Vesuvius: Italian Culture and the Southern Question (Vol. 46). Univ of California Press. 
Mol, Annemarie, Ingunn Moser, and Jeannette Pols, eds., 2015 Care in Practice: On Tinkering in Clinics, Homes and Farms. Verlag, 2015.

Molina, Rose Leonard, and Daniel Palazuelos, 2014 "Navigating and Circumventing a Fragmented Health System: The Patient's Pathway in the Sierra Madre Region of Chiapas, Mexico." Medical anthropology quarterly 2891): 23-43.

Molé, N.J., 2012. Labor Disorders in Neoliberal Italy: Mobbing, Well-being, and the Workplace. Indiana University Press.

Monella, Lillo, 2018 "Women Feel Italy's North-South Divide with Lack of Access to Epidurals." Euro News https://www.euronews.com/2018/03/22/less-than-half-of-southernitaly-offers-childbirth-with-an-epidural Accessed 12/15/18

Morgan, Lynn and Elizabeth Roberts, 2012 "Reproductive Governance in Latin America." Anthropology \& medicine 19(2): 241-254.

Nader, Laura, 1972 "Up the Anthropologist: Perspectives Gained From Studying Up."

National Collaborating Centre for Women's and Children's Health, (NICE), 2004 "Caesarean Section". RCOG Press, London, http://www.nice.org.uk/CG013

New Oxford English Dictionary, 2017 Oxford University Press

Nuti, Sabina, Chiara Seghieri, Milena Vainieri, and Silvia Zett, 2012. "Assessment and Improvement of the Italian Healthcare System: First Evidence From a Pilot National Performance Evaluation System. Journal of Healthcare Management, 57(3), pp.182-199.

O'Dougherty, Maureen, 2008 Lia Won't: Agency in the Retrospective Pregnancy Narratives of Low-Income Brazilian Women. The Journal of Latin American and Caribbean Anthropology, 13(2), 414-446.

Obermeyer, Carla Makhlouf, 2000 "Pluralism and Pragmatism: Knowledge and Practice of Birth in Morocco.” Medical Anthropology Quarterly. 180-20

OECD, 2017 "Caesarean Sections", in Health at a Glance 2015: OECD Indicators , OECD Publishing. http://dx.doi.org/10.1787/health_glance-2011-37-en

Ortner, Sherry, 1984 "Theory in Anthropology Since the Sixties." In Readings for a History of Anthropological Theory (pp.453-485)

- 1996 "Is Female to Male as Nature is to Culture?" and "So, Is Female to Male as Nature is to Culture?" In Making Gender: The Politics and Erotics of Culture. Boston: Beacon Press.

-2006 Anthropology and Social Theory: Culture, power, and the acting subject. Duke University Press.

Pardo, Italo and Giuliana Prato, eds., 2016 Anthropology in the City: Methodology and Theory. Routledge. 
Parkhurst, Shawn, 2008 "Local Correspondence: A Village Writer's Contribution to the Cultural Production of REgionality in the Alto Duoro of Northern Portugal" In Recasting Culture and Space in Iberian Contexts Sharon Roseman and Shawn Parkhurst (eds) Pp. 225-249

Patriarca, Silvana, 1998 'How Many Italies? Representing the South in Official Statistics. Italy's "Southern Question", Oxford: Berg, 77-98.

Pavolini, Emannuelle and Giovanna Vicarelli, 2012 "Is Decentralization Good for Your Health? Transformations in the Italian NHS.” Current Sociology, 60(4), pp.472-488.

Petryna, Adriana, 2004 "Biological Citizenship: The Science and Politics of Chernobyl-Exposed Populations." Osiris: 250-265.

Plesset, Sonja, 2006 Sheltering Women: Negotiating Gender and Violence in Northern Italy. Stanford, California: Stanford University.

Puglia, Monia, Eleonora Fanti, Valeira Dubin, and Fabio Voller, 2017 Gravidanza e Parto in Toscana: Serie in Cifre n. 13, Electronic Document. https://www.ars.toscana.it/files/pubblicazioni/in_cifre/InCifre_N_13_2017_Gravidanza_part o.pdf

Rabinow, Paul, 1996 Essays on the Anthropology of Reason. Princeton: Princeton University Press.

Rabinow, Paul and Rose, Nikolas, 2006. Biopower Today. BioSocieties, 1(2), pp.195-217. -2008 "Concept Work” In Biosocialities, Genetics and the Social Sciences: Making Biologies and Identities. Routledge.

Rapp, Rayna, 2000 Testing Women, Testing the Fetus: The Social Impact of Amniocentesis in America: New York: Routledge

-2001 "Gender, Body, Biomedicine: How Some Feminist Concerns Dragged Reproduction to the Center of Social Theory" Medical Anthropology Quarterly. 15(4): 466-477

Roberts, Elizabeth, 2007 "Biology, Sociality and Reproductive Modernity in Ecuadorian in-vitro Fertilization: The Particulars of Place" In Biosocialities, genetics and the social sciences: making biologies and identities. eds Gibbon, S. and Novas, C. Routledge.

Rosaldo, Michelle and Louise Lamphere, 1974 Woman, Culture, and Society: Stanford: Stanford University Press

Rose, Nikolas. And Carlos Novas, 2005. Biological citizenship. Global assemblages: Technology, Politics, and Ethics as Anthropological Problems, pp.439-463.

Sargent, Carolyn and Grace Bascope, 1996 Ways of Knowing About Birth in Three Cultures. Medical Anthropology Quarterly, 10(2), pp.213-236.

Scheper-Hughes, Nancy and Lock Margaret, 1987 “The Mindful Body: A Prolegomenon to Future Work in Medical Anthropology” Medical Anthropology Quarterly, 1(1), 6-41. 
Schneider, Jane, ed., 1998 Italy's" Southern question": Orientalism in One Country. New York: Berg Publishers

Schneider, Jane and Peter Schneider, 1996 Festival of the Poor: Fertility Decline and the Ideology of Class in Sicily, 1860-1980. Tucson: University of Arizona Press

Scottish Intercollegiate Guidelines Network- SIGN "Critical Appraisal: Notes and Checklists." Available at: http://www.sign.ac.uk/methodology/checklists.html Accessed 3/5/2018

Sesia, Paola, 1997 "Women Come Here on Their Own When They Need To": Prenatal Care, Authoritative Knowledge, and Maternal Health in Oaxaca" In Childbirth and Authoritative Knowledge Carolyn Sargent and Robbie-Davis Floyd, eds. 397-420 Berkeley: University of California Press

Singer, Elyse, 2017 "From Reproductive Rights to Responsibilization: Fashioning Liberal Subjects in Mexico City's New Public Sector Abortion Program." Medical anthropology quarterly, 31(4): 445-463

Shostak, Marjorie, 2018. Nisa: The Life and Words of a! Kung Woman. Routledge.

Smith-Morris, Carolyn, Gilberto Lopez, Lisa Ottomanelli, Lance Goetz, and Kimberly DixonLawson, 2014 "Ethnography, Fidelity, and the Evidence that Anthropology Adds: Supplementing the Fidelity Process in a Clinical Trial of Supported Employment." Medical Anthropology Quarterly 28:(2) 141-161

Spinelli, Angela, I Parti Cesarei in Italia: Andamenti e Variabilità Regionale, Electronic Document. http://www.epicentro.iss.it/percorso-nascita/spinelli

Storeng, Katerini and Dominique Béhague, 2014 "Playing the Numbers Game": Evidence-based Advocacy and the Technocratic Narrowing of the Safe Motherhood Initiative. Medical Anthropology Quarterly, 28(2): 260-279

Szurek, Jane, 1997 Resistance to Technology-Enhanced Childbirth in Tuscany. In Childbirth and Authoritative Knowledge: Cross-Cultural Perspectives, Berkeley: University of California Press Robbie Davis-Floyd and Carolyn Sargent (eds.) 287-314

Terrasi, Marinella, 1999 Convergence and Divergence Across Italian Regions. The Annals of Regional Science, 33(4): 491-510.

Ticktin, Miriam, 2011 Casualties of Care: Immigration and the Politics of Humanitarianism in France. Berkeley: University of California Press.

Tokophobia. (n.d.) Miller-Keane Encyclopedia and Dictionary of Medicine, Nursing, and Allied Health, Seventh Edition. (2003). Retrieved December 222018 from https://medicaldictionary.thefreedictionary.com/Tokophobia 
Triolo, Nancy, 1994 The Fascist Unionization and the Professionalization of Midwives in Italy: A Sicilian Case Study" Medical Anthropology Quarterly: 8(3): 259-281

Tully, Kristin and Hellen Ball, 2013 "Misrecognition of Need: Women's Experiences of and Explanations for Undergoing Cesarean Delivery." Social Science \& Medicine. 85:103-111

Van Hollen, Cecilia, 2003 "Invoking Vali: Painful Technologies of Modern Birth in South India." Medical Anthropology Quarterly, 17(1), 49-77.

Weber, Max, [1930] 2002 The Protestant Ethic and the Spirit of Capitalism. New York

Wendland, Claire L., 2006 "The Vanishing Mother: Cesarean Section and "Evidence-Based Obstetrics"." Medical Anthropology Quarterly 21(2): 218-233.

-2016 "Estimating Death: A Close Reading of Maternal Mortality Metrics in Malawi” In Metrics: What Counts in Global Health. Vincanne Adams, eds.

Whitaker, Elizabeth, 2000 Measuring Mamma's Milk: Fascism and the Medicalization of Maternity in Italy. Ann Arbor: The University of Michigan Press

- 2003. The Idea of Health: History, Medical Pluralism, and the Management of the Body in Emilia-Romagna, Italy. Medical Anthropology Quarterly, 17(3), pp.348-375.

World Health Organization, 2015 "WHO Statement on Cesarean Sections Rights." Accessed $9 / 20 / 2018$. Available at http://apps.who.int/iris/bitstream/handle/10665/161442/WHO_RHR_15.02_eng.pdf;jsessioni $\mathrm{d}=49 \mathrm{~A} 108 \mathrm{~F} 1 \mathrm{C} 8 \mathrm{E} 50 \mathrm{DBF}$ A47CBA285FB6570? sequence $=1$

World Bank, 2018 "Gross Domestic Product 2017” https://databank.worldbank.org/data/download/GDP.pdf

Wynn, Lisa and James Trussell, 2006 "The Social Life of Emergency Contraception in the United States: Disciplining Pharmaceutical Use, Disciplining Sexuality, and Constructing Zygotic Bodies." Medical Anthropology Quarterly 20, (3): 297-320.

Zacher Dixon, Lydia, 2015 "Obstetrics in a Time of Violence: Mexican Midwives Critique Routine Hospital Practices." Medical Anthropology Quarterly, 29(4): 437-454. 